\title{
ANOMALIAS DE FLÚOR NAS ÁGUAS SUBTERRÂNEAS DO ESTADO DE SÃO PAULO
}

\section{Sibele EZAKI}

Annabel PÉREZ-AGUILAR

Raphael HYPOLITO

Mirian Chieko SHINZATO

\begin{abstract}
RESUMO
O presente trabalho apresenta uma compilação de dados da literatura sobre as principais ocorrências de íon fluoreto $\left(\mathrm{F}^{-}\right)$nas águas subterrâneas do estado de São Paulo. Os resultados desse estudo revelaram que, pelo menos, 208 poços tubulares apresentam concentrações elevadas de $\mathrm{F}^{-}\left(>1,0 \mathrm{mg} \mathrm{dm}^{-3}\right)$, das quais 122 são consideradas anômalas $\left(>1,5 \mathrm{mg} \mathrm{dm}^{-3}\right)$ e prejudiciais à saúde, quando ingeridas em excesso. $\mathrm{O}$ aquífero mais estudado tem sido o Guarani, devido a sua elevada produtividade e explotação, mas também se destacam os aquíferos Cristalino (Pré-Cambriano), Serra Geral e Tubarão, além do Aquitarde Passa Dois. O enriquecimento pretérito dos aquíferos em $\mathrm{F}^{-}$está relacionado a processos hidrotermais e eventos tectônicos com controles estruturais, como a quebra do supercontinente Gondwana, que teriam propiciado a circulação de soluções residuais do magma, provocando mineralizações, e a remobilização do $\mathrm{F}^{-}$contido nas rochas percoladas. Os processos atuais de liberação de $\mathrm{F}^{-}$para as águas são atribuídos à interação rocha-água sob condições hidroquímicas com $\mathrm{pH}$ alcalino, em águas tipicamente $\mathrm{Na}-\mathrm{HCO} 3$, pobres em $\mathrm{Ca}^{2+}$ e sob influência da força iônica das soluções, do tempo de contato, profundidade, temperatura, capacidade de troca iônica, entre outros fatores. Nos aquíferos fissurais de composição granítica e de rochas vulcânicas, os minerais que podem fornecer flúor para as águas são biotita e anfibólio (onde o $\mathrm{F}^{-}$encontra-se substituindo o $\mathrm{OH}^{-}$, dada à similaridade de seus raios iônicos) e, ocasionalmente, fluorita secundária preenchendo fraturas, além de apatita. Em aquíferos sedimentares, o $\mathrm{F}^{-}$se encontra principalmente na estrutura de argilominerais (illita, muscovita, esmectita, vermiculita, caulinita, entre outros) também substituindo os íons $\mathrm{OH}^{-}$. Portanto, a presença de elevados teores de $\mathrm{F}^{-}$nas águas subterrâneas está intrinsicamente associada às características e aos tipos de minerais de cada aquífero.
\end{abstract}

Palavras-chave: Flúor; anomalia de fluoreto; águas subterrâneas; estado de São Paulo.

\section{ABSTRACT}

FLUORINE ANOMALIES IN THE GROUNDWATER OF THE STATE OF SÃO PAULO. This work examines the data compiled from the literature about the main occurrences of fluoride ( $\left.\mathrm{F}^{-}\right)$in the groundwater of the State of São Paulo. The results of this study showed that at least 208 wells had high concentrations of $\mathrm{F}^{-}\left(>1.0 \mathrm{mg} \mathrm{dm}^{-3}\right)$, 122 of which were considered anomalous $\left(>1.5 \mathrm{mg} \mathrm{dm}^{-3}\right)$ and harmful when ingested in large quantities. Because of its high productivity and large-scale exploitation, the Guarani aquifer is the most studied one, but other aquifers, such as the Crystalline (Precambrian), Serra Geral and Tubarão aquifers, and the Passa Dois aquitard should also be considered important. In the past, the increase in the concentration of $\mathrm{F}^{-}$in the aquifers was related to hydrothermal processes and tectonic events with structural controls, such as the Gondwana supercontinent breakup, which would have enable the circulation of residual magma solutions, mineralization, and remobilization of the fluorine contained in the percolated rocks. Currently, the release of $\mathrm{F}^{-}$is caused due to the rock-water interaction under alkaline $\mathrm{pH}$ hydrochemical conditions, in typical 
sodium-bicarbonated (Na-HCO3) waters, poor in $\mathrm{Ca}^{2+}$, and under the influence of ionic strength, contact time, depth, temperature, ion exchange capacity, among others. In fissured aquifers of granitic composition and volcanic rocks, the minerals that can release $\mathrm{F}^{-}$into water are biotite and amphibole (where $\mathrm{F}^{-}$is replacing $\mathrm{OH}^{-}$, due to the similarity of its ionic radii) and, occasionally, secondary fluorite filling fractures and apatite. In sedimentary aquifers, $\mathrm{F}^{-}$is mainly found in clay minerals structures (illite, muscovite, smectite, vermiculite, kaolinite, among others) replacing $\mathrm{OH}^{-}$. Therefore, the high levels of $\mathrm{F}^{-}$in the groundwater are intrinsically associated with the characteristics and types of minerals of the aquifers.

Keywords: Fluorine; fluoride anomaly; groundwater; State of São Paulo.

\section{INTRODUÇÃO}

Ocorrências de elevadas concentrações de flúor nas águas subterrâneas têm sido registradas em poços de abastecimento público e de uso privado dos principais aquíferos do estado de São Paulo. Apesar de serem consideradas anomalias naturais, por estarem associadas à dissolução e alteração de minerais, essas águas requerem vigilância dos órgãos gestores relacionados ao uso de recursos hídricos e à saúde pública.

A importância do estudo do flúor em águas se deve aos efeitos causados na saúde humana, sendo benéfico à saúde dental quando em concentrações entre 0,6 e 0,8 $\mathrm{mg} \mathrm{dm}^{-3}$ (SÃO PAULO 1995, NARVAI 2000) como um fator para o declínio da cárie dentária (RAMIRES \& BUZALAF 2007), especialmente em crianças. Para a Organização Mundial da Saúde a concentração máxima de fluoreto aceita em água potável é de $1,5 \mathrm{mg} \mathrm{dm}^{-3}$ (WHO 2006), valor também adotado pela Portaria No 2914, de 12/12/2011, do Ministério da Saúde do Brasil.

Devido à importância do $\mathrm{F}^{-}$na manutenção das características da estrutura dentária, cuja propriedade é reconhecida mundialmente desde a década de 1930, o seu conteúdo nas águas naturais e de consumo vem sendo controlado desde então (HEM 1968, EDMUNDS \& SMEDLEY 2013, GUPTA \& AYOOB 2016).

Por outro lado, o flúor em excesso na água pode produzir alterações na mineralização do esmalte dentário acarretando aparecimento de manchas nos dentes (NARVAI 2001) e provocar doenças como fluorose dentária ou esqueletal, principalmente em crianças até oito anos de idade (FRAZÃO et al. 2011). A fluorose esqueletal pode causar sérios danos aos ossos, levando à sua malformação, deformidade, fratura, osteoesclerose e outros, quando associada a águas contendo de 3 a 6 $\mathrm{mg} \mathrm{dm}^{-3} \mathrm{de} \mathrm{F}^{-}$(WHO 2006).
Casos de fluorose relacionados ao uso de águas naturais captadas em poços profundos, têm sido relatados em diversas localidades do estado de São Paulo. No município de Lorena, DINIZ et al. (2006) verificaram que, entre os 487 estudantes avaliados de escolas municipais com idades variando de 6 a 12 anos, havia o predomínio de casos considerados muito leves (74) e leves (25), conforme índice de Dean, seguidos de casos moderados (14) e severo (1). Em Pereira Barreto também foi relatada a presença de fluorose dentária em escolares de 6 a 15 anos, expostos à água de abastecimento público proveniente de três poços profundos com $\mathrm{F}^{-}$variando de 2,5 a $17,5 \mathrm{mg} \mathrm{dm}^{-3}$ (UCHÔA \& SALIBA 1970). Uma avaliação realizada por CANGUSSU et al. (2002), a partir de dados de outros trabalhos, indicaram a elevada prevalência (em \% da população avaliada) de formas moderadas a severas de fluorose dentária em crianças e jovens com idades entre 6 e 15 anos em Cosmópolis, Icém e Piracicaba. RIBEIRO (1992) também relatou a ocorrência de altos índices de fluorose dentária na Bacia do Médio Tietê (região de Piracicaba), observada por pesquisadores vinculados à faculdade de Odontologia.

Diante de vários relatos de ocorrência de fluorose, inúmeros estudos hidrogeológicos vêm constatando anomalias de flúor nos aquíferos da Bacia do Paraná, do Embasamento Cristalino e bacias terciárias, tanto no estado de São Paulo como no Paraná, Santa Catarina e Rio Grande do Sul. Seguem alguns exemplos:

- Aquifero Guarani (SILVA 1983; PERRONI et al. 1985; KIMMELMANN E SILVA et al. 1986; SRACEK \& HIRATA 2002; SILVÉRIO DA SILVA et al. 2002; MARIMON 2006; BONOTTO 2006, 2012; SANTIAGO 2010; MARIMON et al. 2009, 2013); 
- Aquífero Guarani relacionado ao Aquífero Bauru e/ou Aquífero Serra Geral (SZIKSZAY et al. 1981, PERRONI et al. 1986, FRAGA 1992);

- Aquifero Guarani relacionado às formações Ponta Grossa e Irati (KERN et al. 2007);

- Aquifero Tubarão (PINHEIRO et al. 1965, PERRONI et al. 1985, RIBEIRO 1992, HYPOLITO et al. 2010);

- Aquifero Taubaté (DINIZ et al. 2006);

- Aquífero Serra Geral (GIAMPÁ et al. 1981, GIAMPÁ \& FRANCO FILHO 1982, PERRONI et al. 1985, NANNI et al. 2008);

- Aquífero Cristalino Pré-Cambriano (RIBEIRO 1992, ROISENBERG et al. 2003, VIERO et al. 2009, EZAKI 2011, GOFFERMANN et al. 2015).

Dessa forma, o presente trabalho tem como objetivo realizar uma revisão sobre a ocorrência do flúor nas águas subterrâneas do estado de São Paulo, e avaliar sua origem e comportamento nos principais aquíferos. Cabe ressaltar a importância desse levantamento de dados, que poderá auxiliar os órgãos gestores na tomada de decisões relacio- nadas ao abastecimento público e ao controle endêmico de fluorose dentária.

\section{AQUÍFEROS DO ESTADO DE SÃO PAULO}

Os principais aquíferos do estado de São Paulo estão representados no Mapa de Águas Subterrâneas, elaborado em escala 1:1.000.000 por DAEE/ IG/IPT/CPRM (2005), e correspondem às unidades geológicas maiores extraídas do Mapa Geológico do Estado elaborado pela CPRM em escala 1:750.000 (PERROTA et al. 2005). Os aquíferos são classificados em fissurais ou fraturados (PréCambriano, Pré-Cambriano Cárstico, Serra Geral, Serra Geral Diabásio) e granulares ou sedimentares (Furnas, Tubarão, Guarani, Bauru, São Paulo, Taubaté, Litorâneo). A disposição e distribuição destes aquíferos podem ser observadas na figura 1 .

O aquífero fraturado Pré-Cambriano, normalmente denominado de Cristalino, aflora na porção leste do estado e é composto de rochas ígneas e metamórficas. Apresenta baixa produtividade, com vazões prováveis entre 1 e $23 \mathrm{~m}^{3} / \mathrm{h}$, mas de grande importância para o abastecimento privado. As capacidades específicas medianas em poços nos granitos e gnaisses são, respectivamente, de
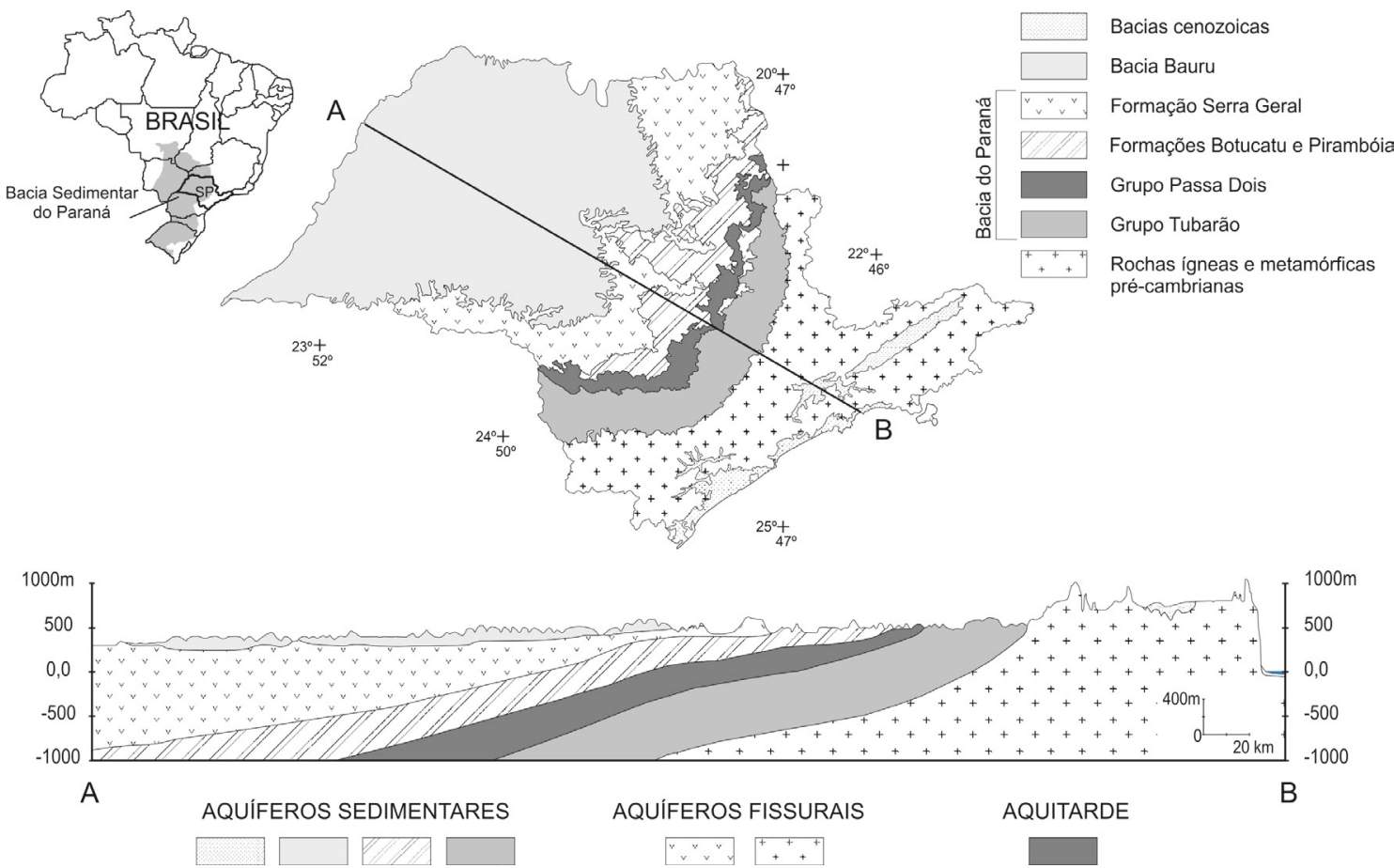

FIGURA 1 - Mapa de Águas Subterrâneas do Estado de São Paulo simplificado e seção hidrogeológica esquemática (adaptado de DAEE/IG/IPT/CPRM 2005). 
0,06 e $0,09 \mathrm{~m}^{3} / \mathrm{h} / \mathrm{m}$ (DAEE/IG/IPT/CPRM 2005, ROCHA et al. 2006).

O Aquífero Tubarão é livre a semi-confinado, granular, de porosidade primária, podendo apresentar descontinuidades estruturais (juntas, fraturas ou falhas). Sua principal unidade é o Subgrupo Itararé, com cerca de $800 \mathrm{~m}$ de espessura (DAEE 1982), depositado em ambientes marinho, deltaico, fluvial, lacustrino e glacial, representado por intercalações e associações de arenitos, siltitos, folhelhos, argilitos, diamictitos e ritmitos (ZALÁN et al. 1991, PETRI \& PIRES 1992, SANTOS 1996, SALVETTI 2005). O isolamento de corpos arenosos, a baixa permeabilidade, devido à presença de lentes de argila, e baixa porosidade dificultam o fluxo vertical da água, conferindo-lhe características anisotrópicas (DAEE 1981). Apresenta baixa disponibilidade hídrica com capacidade específica média de 0,3 m³/h/m (DAEE/IG/IPT/CPRM 2005).

O Aquitarde Passa Dois é composto de duas unidades, as formações Irati e Corumbataí, que contêm e armazenam água, mas a permeabilidade é extremamente baixa e desfavorece a extração de água (DAEE/IG/IPT/CPRM 2005).

Assentado sobre o aquitarde está o Aquífero Guarani, granular, homogêneo, composto por arenitos das formações Pirambóia e Botucatu. Sua porção livre aflora em faixa de $16.000 \mathrm{~km}^{2}$ na porção oeste da Depressão Periférica Paulista e apresenta espessura de cerca de $100 \mathrm{~m}$, e a porção confinada, no oeste do estado, apresenta espessuras maiores que $400 \mathrm{~m}$. A produtividade é muito elevada, com vazões recomendadas de $80 \mathrm{~m}^{3} / \mathrm{h}$ no sistema livre e de $360 \mathrm{~m}^{3} / \mathrm{h}$ no confinado (DAEE/ IG/IPT/CPRM 2005).

O Aquífero Serra Geral corresponde a basaltos da Formação Serra Geral, sobrepõe e confina parte do Aquífero Guarani e é recoberto pelo Aquífero Bauru. Ocorre como faixa irregular na porção central do estado, com espessuras variáveis de 300 a 2000 m (BISTRICHI et al. 1981). A circulação de água ocorre nas zonas de contato entre os derrames e nas descontinuidades verticais e horizontais. Seu potencial de produção é maior que o Pré-Cambriano, com vazões estimadas entre 7 e $100 \mathrm{~m}^{3} / \mathrm{h}$ (DAEE/IG/IPT/CPRM 2005).

O Aquífero Diabásio foi gerado no mesmo evento da Formação Serra Geral. Ocorre de forma restrita como diques e soleiras que intrudem as rochas dos aquíferos Tubarão, Guarani e o Aquitarde Passa Dois, em profundidades variáveis, chegando a penetrar as rochas pré-cambrianas (DAEE/IG/ IPT/CPRM 2005).
O Aquífero Bauru apresenta extensão regional, ocorre de forma livre, e localmente semiconfinada a confinada, contínua, e é constituído de rochas sedimentares dos Grupos Bauru e Caiuá. Apresenta espessuras saturadas que podem atingir $300 \mathrm{~m}$ e seu potencial produtivo é variável com vazões entre 10 e $120 \mathrm{~m}^{3} / \mathrm{h}$ (DAEE/IG/IPT/CPRM 2005).

O Aquífero Taubaté é composto por rochas sedimentares do Grupo Taubaté e da Formação Pindamonhangaba. Ocupa uma área alongada segundo a direção ENE e deprimida de $2.340 \mathrm{~km}^{2}$ no vale do rio Paraíba do Sul, encaixada em um semigraben sobre o Aquífero Pré-Cambriano, entre as serras da Mantiqueira e do Mar. Ocorre de forma livre ou pouco confinada, apresenta espessura saturada de 200 a $300 \mathrm{~m}$ na área e sua potencialidade é variável de $<10$ a $120 \mathrm{~m}^{3} / \mathrm{h}(\mathrm{DAEE} / \mathrm{IG} / \mathrm{IPT} / \mathrm{CPRM}$ 2005).

Os demais aquíferos não foram descritos, uma vez que neles não foram levantados registros de ocorrências de fluor em condições anômalas.

\section{FONTES E GEOQUÍMICA DO FLÚOR}

As principais fontes de flúor para as águas subterrâneas são os minerais que apresentam esse elemento em sua composição, como fluorita, topázio, villiaumita e criolita. Outros minerais como anfibólios (hornblenda), micas (biotita, muscovita) e argilominerais (illita, esmectita, clorita, caulinita) também podem apresentar $\mathrm{F}^{-}$no lugar de $\mathrm{OH}^{-}$de suas estruturas, devido à similaridade de seus raios iônicos $\left(\mathrm{OH}^{-}=1,32 \AA\right.$ e $\mathrm{F}^{-}=1,36 \AA$ ) (ALLMANN \& KORITNIG 1969, BOYLE 1992, AMPABIRE et al. 1997, BANKS et al. 1998, KIM \& JEONG 2005, CHAE et al. 2007).

Assim sendo, os teores de $\mathrm{F}^{-}$nas águas subterrâneas podem variar conforme a ocorrência de minerais com flúor, natureza das rochas, grau de interação rocha-água (CHAE et al. 2007). Geralmente as províncias hidrogeológicas enriquecidas em flúor de várias partes do mundo estão associadas a: aquíferos do embasamento cristalino, especialmente de composição granítica (Índia, Sri Lanka); aquíferos de zonas vulcânicas ativas e fontes geotermais (oeste dos Estados Unidos; Rift Valley Etiópia, Quênia, Tanzânia, Uganda, Ruanda; norte da África - Tunísia; Nova Zelândia); e a alguns aquíferos sedimentares, particularmente em zonas áridas (Argentina central, norte da China, Sudão, Líbia, Senegal) (EDMUNDS \& SMEDLEY 2005).

Os principais mecanismos responsáveis pelo enriquecimento dos aquíferos em $\mathrm{F}^{-}$envolvem os 
processos de percolação de fluidos hidrotermais ricos em flúor durante ou após a formação das rochas (ALLMANN \& KORITNIG 1969, AMPABIRE et al. 1997, BANKS et al. 1998, FRAGA 1992, RIBEIRO 1992, NANNI 2008), e os processos intempéricos (hidrólise, dissociação e dissolução) que atuam sobre os minerais ricos nesse elemento.

$\mathrm{O}$ mecanismo de enriquecimento de $\mathrm{F}^{-}$das águas subterrâneas provocado pela percolação de fluidos hidrotermais, no estado de São Paulo, está associado principalmente à intrusão de corpos granitoides durante o Brasiliano (Neoproterozoico), e a eventos magmáticos basálticos e alcalinos do Mesozoico, relacionados ao processo de separação da América do Sul e África (FRAGA 1992).

Os fluidos estariam enriquecidos em flúor extraído do manto que constitui um reservatório deste íon (EDGAR \& ARIMA 1985) e, ainda mais enriquecidos, através de troca iônica com rochas encaixantes (KUNDU et al. 2001).

Grandes lineamentos tectônicos com controle estrutural preferencial também podem condicionar os fluidos hidrotermais, levando ao enriquecimento de flúor em determinados locais. SZIKSZAY et al. (1981) observaram anomalias químicas no estado de São Paulo, incluindo elevados teores de flúor e boro nas águas dos poços perfurados no aquífero Bauru e em basaltos ao longo de lineamentos nas direções NS e EW. Devido à semelhança da composição química dessas águas com as do aquífero Guarani, os autores apontam a possível existência de uma grande fratura vertical (de 400 a $500 \mathrm{~m}$ de extensão) ligando esses aquíferos. Essas águas teriam, ainda, se enriquecido com os constituintes do basalto, devido à mineralização secundária.

No estado do Paraná foram constatadas anomalias de fluoreto em águas subterrâneas em áreas com intersecções de lineamentos NW e NE (LICHT 2001). No Rio Grande do Sul, NANNI (2008) e NANNI et al. (2008) associam estas anomalias a estruturas tectônicas de direção NW na Formação Serra Geral. Em Santa Catarina as fraturas mineralizadas em fluorita estão dispostas segundo as direções NW e NS (SAVI 1980, ZALÁN 1991).

FRANK et al. (2008) associam a origem do flúor à desgaseificação e colocação de corpos intrusivos da Formação Serra Geral na Bacia do Paraná durante este grande evento hidrotermal. Nesse caso, os gases $\left(\mathrm{CO}_{2}, \mathrm{SO}_{2}, \mathrm{HF}, \mathrm{HCl}\right.$ e outros $)$ desprendidos em subsuperfície, teriam sido incorporados aos aquíferos profundos e, consequentemente, fixados na estrutura dos minerais (hornblenda, mica e apatita) durante a sua formação, ou retidos localmente em armadilhas estruturais ou estrati- gráficas como fluidos com HF exsolvido. Estes fluidos teriam sido lentamente liberados ao longo de diques da Formação Serra Geral ou por falhas verticais na Bacia, que conectam os aquíferos profundos confinados aos aquíferos superiores.

Quanto ao mecanismo de liberação do $\mathrm{F}^{-}$pelos processos intempéricos, observa-se a influência de alguns fatores como, solubilidade e capacidade de troca iônica dos minerais, $\mathrm{pH}$, temperatura, profundidade e salinidade do meio, tempo e grau de contato água-mineral entre outros (HEM 1985, GARICI \& DAVIES 1993, APAMBIRE et al. 1997, BANKS et al. 1998, SAXENA \& AHMED 2003, KIM \& JEONG 2005, CHAE et al. 2007, ABDELRAHMAN et al. 2009).

Outro fator que também controla as concentrações de $\mathrm{F}^{-}$nas águas é a solubilidade da fluorita $\left(\mathrm{Ks}_{\text {fluorita }}=10^{-10,6}\right)$. Se a concentração de $\mathrm{Ca}^{2+}$ estiver acima deste limite de solubilidade, ou seja, do produto de suas atividades, a dissolução cessa, ocorrendo precipitação (AMPABIRE 1997, CHAE et al. 2006). Todavia, pelo fato da calcita apresentar maior solubilidade $\left(\mathrm{Ks}=10^{-8,48}\right)$ que a fluorita, ela não se precipita antes. É difícil, portanto, definir os processos que controlam a dissolução da fluorita, podendo as concentrações de $\mathrm{Ca}^{2+}$ e F- serem também controladas por dissolução simultânea de fluorita e calcita, e afetadas pela dissolução de outros minerais contendo flúor (como biotita), precipitação de calcita e troca de $\mathrm{Ca}^{2+}$ por $\mathrm{Na}^{+}$(CHAE et al. 2007).

Em relação ao $\mathrm{pH}$, observa-se que, em meio alcalino, a formação da fluorita é inibida, apesar de sua baixa solubilidade, favorecendo a dissolução do $\mathrm{F}^{-}$e a precipitação do cálcio como carbonato. Portanto, águas do tipo $\mathrm{Na}-\mathrm{HCO} 3$ aceleram a dissolução de $\mathrm{CaF}_{2}$, conforme a reação: $\mathrm{CaF}_{2}(\mathrm{~s})$ $+2 \mathrm{NaHCO}_{3}(\mathrm{aq})<=>\mathrm{CaCO}_{3}(\mathrm{~s})+2 \mathrm{Na}^{+}+2 \mathrm{~F}^{-}(\mathrm{aq})$ $+\mathrm{H}_{2} \mathrm{O}(\mathrm{l})+\mathrm{CO}_{2}(\mathrm{~g})$ (FRAGA 1992; SAXENA \& AHMED 2001, 2003; GUO et al. 2007). Outro processo que pode regular os teores de $\mathrm{F}^{-}$na água é o de evaporação, que resulta na diminuição da concentração de $\mathrm{Ca}^{2+}$ na água devido à precipitação de $\mathrm{CaCO}_{3}$ (GUO et al. 2007).

A salinidade das águas pode favorecer o processo de dissolução do $\mathrm{F}^{-}$conforme verificado por SAXENA \& AHMED $(2001,2003)$ ao estudarem este comportamento sob condutividades elétricas entre 1000 e $2000 \mu \mathrm{S} / \mathrm{cm}$. KUHN (1968) e STRUBEL (1965 apud ALLMAN \& KORITNIG 1969) estudando as relações de solubilidade da fluorita em água destilada e água do mar, também observaram que ela aumenta com a elevação das concentrações salinas, utilizando, no caso, $\mathrm{MgSO}_{4}$ e NaCl. 
$\mathrm{O}$ aumento da concentração de $\mathrm{F}^{-}$também pode ocorrer pelo mecanismo de substituição do radical $\mathrm{OH}^{-}$encontrado nas águas alcalinas, com o $\mathrm{F}^{-}$da estrutura de certos minerais, como muscovita e biotita, cujas reações estão representadas a seguir, respectivamente (GUO et al. 2007):

$$
\begin{aligned}
& \mathrm{KAl}_{2}\left[\mathrm{AlSiO}_{3} \mathrm{O}_{10}\right] \mathrm{F}_{2}+2 \mathrm{OH}^{-}<>\mathrm{KAl}_{2}\left[\mathrm{AlSi}_{3} \mathrm{O}_{10}\right][\mathrm{OH}]_{2}+2 \mathrm{~F}^{-} \\
& \mathrm{KMg}_{3}\left[\mathrm{AlSiO}_{3} \mathrm{O}_{10}\right] \mathrm{F}_{2}+2 \mathrm{OH}^{-} \Leftrightarrow \mathrm{KMg}\left[\mathrm{AlSi}_{3} \mathrm{O}_{10}\right][\mathrm{OH}]_{2}+2 \mathrm{~F}^{-}
\end{aligned}
$$

O tempo de residência da água no aquífero também pode influenciar a dissolução de fluorita, o que explicaria sua correlação com a profundidade (KIM \& JEONG 2005, GASCOYNE 2004, OZSVATH 2005). O aumento da profundidade pode levar à perda progressiva de $\mathrm{HCO}_{3}^{-} \mathrm{e} \mathrm{Ca}^{2+}$ por precipitação de carbonatos ou troca iônica e aumento da salinidade da água devido à elevação dos teores de $\mathrm{Na}^{+}, \mathrm{Cl}^{-}$e $\mathrm{SO}_{4}{ }_{4}^{2-}$. CHAE et al. (2007) observaram que a concentração de fluoretos decresce na sequência de grupo de classificação de águas: $\mathrm{Na}-\mathrm{HCO} 3>\mathrm{Na}-\mathrm{SO} 4-\mathrm{Cl} \gg \mathrm{Ca}-\mathrm{SO} 4-\mathrm{Cl} \geq$ $\mathrm{Ca}-\mathrm{HCO} 3$.

De modo geral, pode-se concluir que as concentrações de $\mathrm{F}^{-}$nas águas subterrâneas apresentam relação com o aumento das concentrações de $\mathrm{Na}^{+}, \mathrm{OH}^{-} \mathrm{HCO}_{3}^{-}$e pH e com a diminuição de $\mathrm{Ca}^{2+}$ (BOYLE 1992, APAMBIRE et al. 1997, GENXU \& GUODON 2001, KUNDU et al. 2001, OZVATH 2006, GUO et al. 2007, CHAE et al. 2007).

\section{MATERIAIS E MÉTODOS}

Este trabalho foi desenvolvido a partir de uma revisão bibliográfica sobre o tema, procurando-se realizar, também, um levantamento e seleção de poços de interesse, a fim de elaborar um banco de dados sobre as ocorrências de flúor no estado de São Paulo. Os dados hidroquímicos levantados nessa pesquisa foram compilados e tratados para analisar a correlação geoquímica do flúor em cada aquífero.

O levantamento de dados de poços públicos e privados foi realizado em fontes oficiais de órgãos gestores de recursos hídricos do estado de São Paulo, como o Departamento de Águas e Energia Elétrica - DAEE e a Companhia Ambiental do Estado de São Paulo - CETESB. Além disso, também foram consultados projetos de pesquisas científicas.

Os estudos de caráter regional consistem em importantes registros de dados, como, por exemplo, os desenvolvidos pelo DAEE na década de 1980 nas regiões administrativas do estado, e pelo DAEE-UNESP (2013) nas bacias hidrográficas, bem como teses de doutoramento e outros estudos (SILVA 1983, PERRONI et al. 1986, FRAGA 1992, CAMPOS 1993 e VIDAL 2002). Estes últimos também utilizaram dados do cadastro de poços do Sistema de Informações de Águas Subterrâneas - SIDAS do DAEE.

$\mathrm{Na}$ etapa de seleção de poços definiram-se os seguintes dados e informações para compilação e elaboração do banco de dados: identificação do poço, coordenadas, profundidade, ano de perfuração, data da amostragem, perfil geológico, aquífero explorado, dados físico-químicos e químicos $(\mathrm{pH}$, condutividade elétrica, alcalinidade, concentração de íons maiores e menores disponíveis). Embora a concentração máxima permitida de $\mathrm{F}^{-}$para consumo humano seja $1,5 \mathrm{mg} \mathrm{dm}^{-3}$, foram também acrescidos poços com concentração de $\mathrm{F}^{-}$maior que $1,0 \mathrm{mg} \mathrm{dm}^{-3}$.

Durante a elaboração do banco de dados de poços realizou-se a consistência de dados, a fim de eliminar os registros repetidos ou duvidosos quanto à qualidade das informações.

A representação espacial da distribuição de poços foi gerada em mapa com auxílio das ferramentas do programa ArcGis (ESRI, versão 10.1.2), com base no Mapa de Águas Subterrâneas do Estado de São Paulo.

Os dados analíticos compilados foram (re)avaliados quanto ao balanço iônico por meio do programa AquaChem (Waterloo), eliminando-se os poços com erro $>10 \%$. O mesmo programa foi utilizado para classificar os tipos hidroquímicos. Os cálculos dos índices de saturação em calcita e fluorita foram efetuados utilizando-se o programa PHREEQC (PARKHURST \& APPELO 1999). Correlações iônicas foram realizadas para análise geoquímica do flúor nos aquíferos estudados.

\section{RESULTADOS}

\subsection{Distribuição de $\mathrm{F}^{-}$no estado de São Paulo}

Os estudos que detectaram anomalias de $\mathrm{F}^{-}$em águas subterrâneas no estado de São Paulo já indicavam, na década de 1980, que elas ocorriam com maior frequência nos aquíferos Tubarão, Guarani e Serra Geral, e no aquitarde Passa Dois (PERRONI et al. 1985). Contudo, o aquífero mais estudado é o Guarani, em função de sua elevada produtividade e explotação.

Para este estudo foram selecionados 208 registros de poços com dados de concentração de $\mathrm{F}^{-}$ maior que $1,0 \mathrm{mg} \mathrm{dm}^{-3} \mathrm{em} 24$ fontes bibliográficas. 
Desse total, 122 poços (58\%) apresentam teores iguais ou superiores a $1,5 \mathrm{mg} \mathrm{dm}^{-3}$ (Apêndice 1).

A maior parte dos poços explota os aquíferos Cristalino-CR (57) e Tubarão-TU (35 poços), seguidos dos aquíferos Bauru-BA (25), Serra GeralSG (17), Guarani-G (12) e Taubaté-TA (6); menos expressivos estão os aquíferos Diabásio-DB (1), além do aquitarde Passa Dois-PD (4) e sua associação com Diabásio $(\mathrm{PD} / \mathrm{DB}=6)$ e Tubarão $(\mathrm{PD} / \mathrm{TU}=5)$. Os poços mistos que explotam mais de um aquífero (TU/CR, PD/DB, PD/TU, BA/SG, SG/G, CR/São Paulo, BA/G, Cenozóico/TU, TU/ DB) totalizam 36 registros. Considerando o total de poços, há 7 casos em que o aquífero explotado foi inferido com base no Mapa de Águas Subterrâneas do DAEE/IG/IPT/CPRM (2005). Há ainda, 9 poços sem informações sobre o aquífero explotado ou descrição litológica que não puderam ser classificados e nem inferidos com base neste mapa.

Os doze registros de poços do Aquífero Guarani encontram-se na sua porção confinada e explotam o Aquífero Botucatu, e apenas um deles é misto (Botucatu/Pirambóia). Dois poços muito profundos $(3.459 \mathrm{~m}$ em Lins e $3.663 \mathrm{~m}$ em Paraguaçu Paulista) foram perfurados pela Petrobrás na década de 1960 para pesquisa de petróleo na Bacia do Paraná e não são utilizados para explotação de água. Contudo, eles fornecem informações importantes, uma vez que suas águas apresentam características distintas e com concentrações iônicas bastante acentuadas.

Parte considerável dos dados analíticos são das décadas de 1970 (26\% dos poços) e 1980 (21\%), sendo provenientes dos Estudos do DAEE e de teses que utilizaram estes estudos. Os dados analíticos das décadas de 1990 (3\% dos poços), 2000 (43\%) e 2010 (9\%) provêm do banco de dados do DAEE, dos poços de monitoramento da CETESB e de estudos acadêmicos em escala regional a local.

As profundidades medianas dos poços, considerando o aquífero explotado e as respectivas quantidades de dados existentes (n), são: Cristalino - $175 \mathrm{~m}(\mathrm{n}=39$ poços), Tubarão $-200 \mathrm{~m}(\mathrm{n}=23)$, Bauru - $169 \mathrm{~m}(\mathrm{n}=17)$, Serra Geral $-180 \mathrm{~m}(\mathrm{n}=13)$, Guarani - $821 \mathrm{~m}(\mathrm{n}=12)$, Taubaté $-201 \mathrm{~m}(\mathrm{n}=10)$.

$\mathrm{Na}$ figura 2 é apresentada a distribuição das ocorrências anômalas de $\mathrm{F}^{-}\left(>1 \mathrm{mg} \mathrm{dm}^{-3}\right)$ no estado de São Paulo.

É importante destacar que os poços estão plotados sobre áreas de domínio dos principais aquíferos do estado, porém, em alguns casos, eles podem explotar tanto a unidade aquífera correspondente à superfície como também outras unidades subja- centes ou somente a(s) unidade(s) subjacente(s). O mapa da figura 2, portanto, auxilia a correlação visual com o aquífero, mas o Apêndice 1 deve ser consultado para se confirmar qual(is) o(s) aquífero(s) explotado(s).

\subsection{Ocorrência anômala de F- nos aquíferos}

\section{Aquífero Cristalino / Pré-Cambriano (CR)}

As águas deste aquífero são classificadas, predominantemente, como bicarbonatadas cálcicas (Ca-HCO3), seguidas das bicarbonatadas sódicas (Na-HCO3), podendo também ocorrer tipos clorosulfatados sódicos e cálcicos (Na-SO4-Cl, $\mathrm{Na}-\mathrm{Ca}-\mathrm{SO} 4-\mathrm{Cl})$. Estas características são semelhantes às descritas nas publicações de DAEE (1981, 1982) e CAMPOS (1993). São águas pouco salinizadas, com condutividade elétrica mediana de $179 \mu \mathrm{S} \mathrm{cm}{ }^{-1}$ e pH variando de 5,0 a 9,4, com mediana de 6,9, considerando 65 amostras de poços de monitoramento do estado (CETESB 2016). CAMPOS (1993) mencionou a tendência do aumento do teor salino e dos íons sódio e cloreto no sentido do Planalto Atlântico para a Planície Costeira onde poços profundos do Cristalino sobre a faixa litorânea podem receber influência da cunha salina. As concentrações de $\mathrm{F}^{-}$nesses poços de monitoramento variaram de 0,06 a $10,0 \mathrm{mg} \mathrm{dm}^{-3}$ no período de 2013-2015 (CETESB 2016), tendo sido destacadas anomalias em Santo Antônio de Posse, Amparo, Embu, São Paulo, Cotia, Mogi das Cruzes, Biritiba Mirin, Itapira e Miracatu (CETESB 2004, 2007, 2013, 2016) (Apêndice 1).

RIBEIRO (1992) identificou elevado teor de $\mathrm{F}^{-}$em poço de Vinhedo $\left(1,7 \mathrm{mg} \mathrm{dm}^{-3}\right)$, cuja água é do tipo bicarbonatada sódica, com pH 7,0 e condutividade elétrica de $184 \mu \mathrm{S} \mathrm{cm}^{-1}$.

$\mathrm{Na}$ Região Administrativa de Campinas o DAEE (1981) identificou anomalias de $\mathrm{F}^{-}$em um poço no Cristalino, no município de Indaiatuba $\left(\mathrm{N}^{\circ}\right.$ DAEE 301/81), com 1,30 $\mathrm{mg} \mathrm{dm}^{-3}$, e outro misto, associado ao Aquífero Tubarão, em Campinas (277/60), com 3,9 mg dm${ }^{-3}$. Na Região Administrativa de Sorocaba o DAEE (1982) também identificou um poço em Salto (300/35) com 1,23 mg dm ${ }^{-3} \mathrm{de} \mathrm{F}^{-}$, e outro em Araçoiaba da Serra (339/08) com 1,34 mg dm${ }^{-3}$, este associado ao Aquífero Tubarão (Apêndice 1).

No litoral paulista foram encontrados 4 poços que explotam o Cristalino a uma distância até $10 \mathrm{~km}$ do mar, com teores de $\mathrm{F}^{-}$acima de $1,0 \mathrm{mg}$ $\mathrm{dm}^{-3}$ até $2,2 \mathrm{mg} \mathrm{dm}^{-3}$. Dois estão em Santos: um com 1,48 $\mathrm{mg} \mathrm{dm}^{-3}$ (poço DAEE 363/46) e outro 


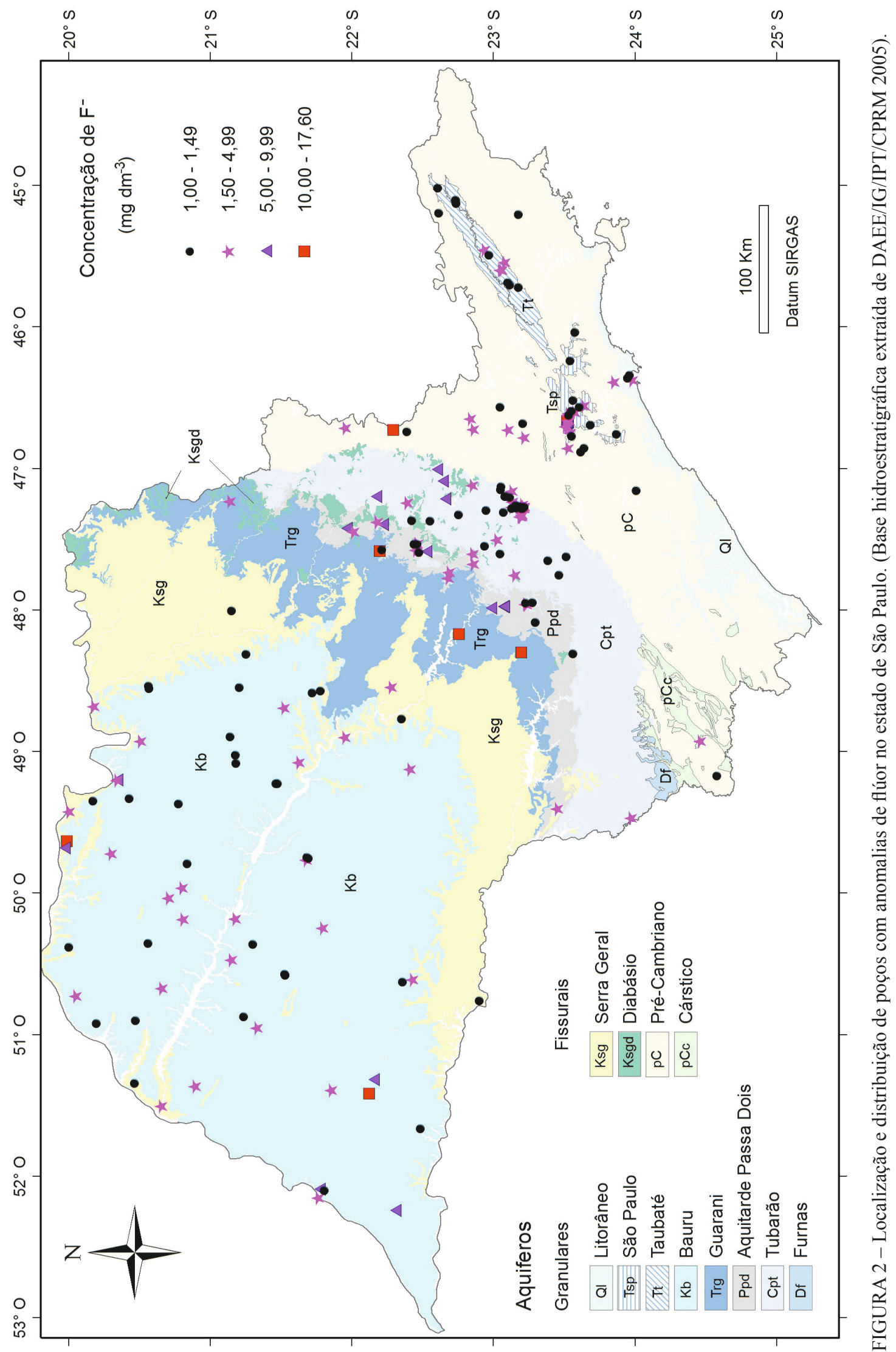


com 1,28 mg dm-3 (363/47) (Apêndice 1). Essas águas são classificadas como cloretadas sódicas e, secundariamente, cloretadas cálcicas, com possível influência de intrusão marinha através de fraturas profundas (DAEE 1979a).

HYPOLITO et al. (2010) levantaram 10 poços com elevado teor de $\mathrm{F}^{-}\left(>1,5 \mathrm{mg} \mathrm{dm}^{-3}\right)$ que explotam o Aquífero Cristalino nos municípios de Salto e Indaiatuba (SP). As águas subterrâneas são predominantemente bicarbonatadas sódicas e cálcicas, podendo ocorrer tipos sulfatados e cloretados. Os autores constataram que apesar da fluorita e apatita ocorrerem como minerais acessórios nos granitos da região, a fonte de flúor para as águas seria a biotita. Segundo GALLEMBECK (1997) os teores de $\mathrm{F}^{-}$dessas águas variam entre $0,21 \mathrm{e}$ 1,33 em porcentagem em peso, com média de 0,82 . $\mathrm{O}$ enriquecimento do aquífero se deve à interação de águas alcalinas com cristais de biotitas dos granitos e à percolação pretérita de fluidos hidrotermais enriquecidos em flúor. Esses fluídos percolaram por fraturas e estão associados ao evento de colocação de extensos volumes de lava gerados a partir da quebra do Supercontinente Gondwana e abertura do Atlântico Sul. Fluidos hidrotermais provenientes desse evento magmático mesozoico estariam associados, na porção sudeste de Salto, a um controle estrutural preferencial de direção NW e, secundariamente, em NS e NE.

EZAKI et al. (2016) simularam em laboratório, por meio de testes em batelada, a alteração de granitos da região de Salto (SP) e, separadamente, de suas biotitas. As soluções lixiviadas apresentaram elevadas correlações entre $\mathrm{F} / \mathrm{Na}(\mathrm{r}=0,92), \mathrm{F} /$ $\mathrm{Ca}(\mathrm{r}=0,85)$ e $\mathrm{F} / \mathrm{K}(\mathrm{r}=0,87)$ indicando dissolução progressiva de plagioclásio, feldspato e biotitas. A constância das concentrações de $\mathrm{Ca}^{2+}$ nos lixiviados, ao longo do tempo, das soluções saturadas em fluorita $\left(\mathrm{CaF}_{2}\right)$ e o aumento progressivo da liberação de F- para as soluções, indicaram um processo contínuo de dissolução de biotita, ao qual está relacionada sua origem. A concentração de $\mathrm{F}^{-}$em solução depende, portanto, tanto da saturação em fluorita como da dissolução de biotita, em condições alcalinas $(\mathrm{pH}>7,7)$. Altas temperaturas $\left(70^{\circ} \mathrm{C}\right) \mathrm{e}$ elevada força iônica da solução $\left(\mathrm{CE}>800 \mu \mathrm{S} \mathrm{cm}^{-1}\right)$ favorecerem a liberação de $\mathrm{F}^{-}$para as águas. Nesta região a cobertura sedimentar contribui para elevar a força iônica das águas subterrâneas ( $\mathrm{I}=0,011$ M), como observado por EZAKI (2011) em alguns poços da região. A influência das coberturas sedimentares também foi constatada por VIERO et al. (2009) no aquífero granítico de Porto Alegre (RS), cujas águas misturaram-se àquelas da cobertura cenozoica com características mais salinas. Neste caso, a dissolução de fluorita, mineral secundário presente em fraturas de rochas granítico-gnáissicas, foi favorecida pelo acréscimo de bicarbonato e pela elevação de $\mathrm{pH}(7,3-8,5)$.

PACHECO (2009) estudou as anomalias de $\mathrm{F}^{-}$(até $10,04 \mathrm{mg} \mathrm{dm}^{-3}$ ) em 10 poços que explotam o Aquífero Cristalino no Bairro da Barra Funda em São Paulo - SP (326,5 kmE/7396kmN; $333 \mathrm{kmE} / 7400 \mathrm{kmN}$ - zona $23 \mathrm{~S}$ ), as quais foram previamente detectadas pela Coordenação de Vigilância em Saúde - COVISA do município. As águas destes poços são do tipo $\mathrm{Na}-\mathrm{HCO} 3$. $\mathrm{O} \mathrm{F}^{-}$ apresenta correlação com $\mathrm{pH}(>7,3)$, condutividade elétrica $\left(>200 \mu \mathrm{S} \mathrm{cm}^{-1}\right)$ e grandes profundidades. A região corresponde a uma área de depressão alongada de direção E-W, formada por blocos abatidos delimitados por falhas e fraturas WNW-ESE geradas por zonas de cisalhamento (Taxaquara). A origem do flúor foi atribuída a zonas de falhas e dissolução de minerais secundários, como fluorita, que preenchem fraturas. Concluiu que se trata de uma contaminação natural, uma vez que a análise dos solos e efluentes industriais de uma potencial fonte antrópica, bem como as águas rasas (do aquífero sedimentar sobrejacente) apresentaram baixos teores de flúor nas respectivas composições químicas.

PINO (2009) aplicou técnicas de análises isotópicas $\left(\delta \mathrm{D}, \delta^{18} \mathrm{O},{ }^{87} \mathrm{Sr} r{ }^{86} \mathrm{Sr}\right)$ nas mesmas amostras de PACHECO (2009), cujos resultados permitiram identificar águas de origens distintas. As anomalias de $\mathrm{F}^{-}$apresentaram maior correlação com águas empobrecidas em isótopos de ${ }^{2} \mathrm{H}(-50 \%$ a $-35 \%$ ) e ${ }^{18} \mathrm{O}(-7,85 \%$ a $-6,8 \%$ ) do Aquífero Cristalino, em relação às águas do Aquífero São Paulo (sobrejacente), cujas concentrações de $\mathrm{F}^{-}$são inferiores. Os valores isotópicos tornam-se mais negativos com a profundidade do nível dinâmico dos poços denotando maior tempo de trânsito pelo aquífero. As razões isotópicas do estrôncio também são maiores $(0,722-0,726)$ em locais onde o Aquífero Cristalino é mais profundo (100-250 m) e se distinguem das águas do aquífero sedimentar.

\section{Aquifero Tubarão (TU)}

As águas do Aquífero Tubarão são predominantemente bicarbonatadas sódicas, seguidas de tipos bicarbonatados mistos e cálcicos, considerando 25 poços de monitoramento do estado de São Paulo. Possuem pH mediano alcalino $(7,9)$ variando de 4,5 a 10,0 e concentrações de $\mathrm{F}^{-}$entre $<0,04$ a $2,03 \mathrm{mg} \mathrm{dm}^{-3}$ (CETESB 2016). 
Estas fácies hidroquímicas foram previamente identificadas por DIOGO et al. (1981), DAEE (1981, 1982) e CAMPOS (1993), com predomínio das bicarbonatadas sódicas. Na Região Administrativa de Sorocaba (DAEE 1982) estabeleceu-se, a partir de 30 poços, a seguinte distribuição: bicarbonatadas sódicas $(66,7 \%)$, bicarbonatadas cálcicas ou magnesianas (30\%) e cloretadas sódicas $(3,3 \%)$. Foram consideradas fracamente salinas (DIOGO et al. 1981), com condutividades elétricas inferiores a $350 \mu \mathrm{S} \mathrm{cm}^{-1}$ e $790 \mu \mathrm{S} \mathrm{cm}^{-1}$, respectivamente, nas regiões de Campinas (DAEE 1981) e Sorocaba (DAEE 1982), e inferiores a $560 \mu \mathrm{S} \mathrm{cm}^{-1}$ na região do médio Tietê (DINIZ 1990).

PINHEIRO et al. (1965) relataram a ocorrência de teores elevados de $\mathrm{F}^{-}$em 2 poços no município de Pereiras (SP), sendo um do Serviço de Abastecimento Público $\left(6,2 \mathrm{mg} \mathrm{dm}^{-3}\right)$ e outro particular na área rural $\left(1,47 \mathrm{mg} \mathrm{dm}^{-3}\right)$. No entanto, não se observou casos de fluorose dentária em 13 crianças examinadas com idades de 2 a 13 anos.

Também foi registrada pelo DAEE (1981) a ocorrência de elevados teores de $\mathrm{F}^{-}$(de 2,7 a 6,4 mg $\mathrm{dm}^{-3}$ ) em quatro poços da Região Administrativa de Campinas: poço misto Tubarão/Cenozoico (DAEE 220/22) em Araras; poço misto Tubarão/Diabásio (247/07) em Holambra; poço misto Tubarão/Cristalino (277/60) em Campinas; e poço que explota o Tubarão em Cosmópolis (249/011) (Apêndice 1).

$\mathrm{Na}$ Região Administrativa de Sorocaba foram registrados três poços que explotam o Aquífero Tubarão com as seguintes concentrações em F: $5,14 \mathrm{mg} \mathrm{dm}^{-3}$ em Pereiras (DAEE 298/12), 1,42 mg $\mathrm{dm}^{-3}$ em Cesário Lange (298/17) e $1,24 \mathrm{mg} \mathrm{dm}^{-3} \mathrm{em}$ Quadra (317/07) (DAEE 1982) (Apêndice 1).

RIBEIRO (1992) identificou elevados teores de $\mathrm{F}^{-}\left(1,5\right.$ até $\left.9,0 \mathrm{mg} \mathrm{dm}^{-3}\right)$ em poços de Pereiras, Piracicaba (Bairros Santana, Santa Olímpia, Saltinho), Rio Claro (Bairros Batovi, Ajapi e Assistência), Conchas e Charqueada (SP). Estas anomalias ocorrem em águas bicarbonatadas sódicas dos grupos Tubarão e Passa Dois e, segundo a autora, elas estão geralmente associadas à ocorrência de sills de diabásio. Destaca-se a correlação iônica entre $\mathrm{Na}^{+}$e F-, e o pH das águas que varia de 8,0 a 9,0.

VIDAL (2002) associou as concentrações de $\mathrm{F}^{-}$às águas de maior salinidade do Aquífero Tubarão da porção central do estado de São Paulo. A condutividade elétrica dessas águas subterrâneas variou de $344 \mathrm{a} 1199 \mu \mathrm{S} \mathrm{cm}^{-1}$ nos poços de Saltinho $\left(2,10 \mathrm{mg} \mathrm{dm}^{-3} \mathrm{~F}^{-}\right)$, Iperó $\left(1,45 \mathrm{mg} \mathrm{dm}^{-3} \mathrm{~F}^{-}\right)$, Cesário Lange (2,34 $\left.\mathrm{mg} \mathrm{dm}^{-3} \mathrm{~F}^{-}\right)$e Rio das Pedras (4,78 mg $\left.\mathrm{dm}^{-3} \mathrm{~F}^{-}\right)$. Considerando as 56 amostras analisadas pelo autor e mais as 34 estudadas por CAMPOS
(1993), constatou-se a melhor correlação do $\mathrm{Cl}^{-}$ com o $\mathrm{F}^{-}$, enquanto as maiores concentrações de $\mathrm{F}^{-}$ocorrem em amostras com teores de cálcio inferiores a $10 \mathrm{mg} \mathrm{dm}^{-3}$.

As ocorrências de teores de $\mathrm{F}^{-}>1,0 \mathrm{mg} \mathrm{dm}^{-3}$ foram observadas em poços de monitoramento de Elias Fausto, Cesário Lange, Capela do Alto e Itararé (CETESB 2004, 2007, 2010, 2013).

EZAKI (2011) constatou anomalias de $\mathrm{F}^{-} \mathrm{em}$ 12 poços da região de Salto-Indaiatuba (SP), por apresentarem concentração média de $2,01 \mathrm{mg} \mathrm{dm}^{-3}$, superior ao valor de referência de $0,97 \mathrm{mg} \mathrm{dm}^{-3}$ para o Aquífero Tubarão no estado (CETESB 2007). As águas desses poços são tipicamente bicarbonatadas sódico-cálcicas ou bicarbonatadas-sulfatadas sódicas, apesar de ocorrer também o tipo cloretado-sulfatado sódico com pH médio de 7,80 e condutividade elétrica média desde $311 \mu \mathrm{S} \mathrm{cm} \mathrm{cm}^{-1}$ até $822 \mu \mathrm{S} \mathrm{cm}^{-1}$. Nesse caso, a autora associa a presença de flúor nas águas com a alteração de minerais das frações mais finas das rochas sedimentares do Subgrupo Itararé - em Salto (SP) - constituídas de mica, esmectita, vermiculita e caulinita, uma vez que não se detectou apatita e fluorita entre os minerais fontes nas amostras. FLORÊNCIO (2000), em sua caracterização mineralógica e química de amostras de argilito e ritmito de Indaiatuba (SP), já havia associado o flúor das rochas ao argilomineral esmectita.

PERRONI et al. (1986) e EZAKI (2011) constataram a relação do aumento das concentrações de $\mathrm{Na}^{+}, \mathrm{F}^{-}, \mathrm{Cl}^{-}, \mathrm{SO}_{4}^{2-}$ e do $\mathrm{pH}$ das águas com a profundidade e a influência da salinidade, devido a elevada força iônica, assim como ao aumento da temperatura, para a liberação de F-

A heterogeneidade litológica do Grupo Tubarão influencia na circulação das águas subterrâneas, ocasionando seu escoamento lento e maior tempo de contato com os minerais (PERRONI et al. 1986). Além disso, nas porções confinadas ou de circulação restrita do aquífero, EZAKI (2011) sugeriu haver uma relação entre a elevação das concentrações de $\mathrm{HCO}_{3}^{-}, \mathrm{SO}_{4}{ }^{2-}$ e $\mathrm{Cl}^{-}$e o F- .

PERRONI et al. (1986) correlacionaram os teores de $\mathrm{F}^{-}$à $\mathrm{CE}, \mathrm{Na}^{+}, \mathrm{Cl}^{-}$, borato, $\mathrm{pH}$ e $\mathrm{CO}_{3}{ }^{2-}$ das águas subterrâneas do Aquífero Tubarão indicando sua associação ao aquitarde Passa Dois.

\section{Aquitarde Passa Dois (PD)}

Os estudos hidroquímicos desta unidade normalmente indicam que suas águas apresentam teores salinos mais altos em relação às demais unidades hidrogeológicas, o que explicaria a me- 
nor explotação e uso e, consequentemente, menor quantidade de dados.

Na Região Administrativa de Campinas (SP) suas águas apresentam condutividade elétrica superior a $200 \mu \mathrm{S} \mathrm{cm}^{-1}$, podendo atingir $2000 \mu \mathrm{S} \mathrm{cm}^{-1}$; o pH é geralmente alcalino $(>8,0)$ e as concentrações de $\mathrm{HCO}_{3}^{-}, \mathrm{SO}_{4}^{2-}$ e $\mathrm{Cl}^{-}$são altas (DAEE 1981). Seis poços que atravessam o Grupo Passa Dois apresentaram concentrações de $\mathrm{F}^{-}$acima dos padrões de potabilidade. Quatro desses poços estão associados a diabásio: dois deles em Leme (poços DAEE 193/02 e 193/16) com respectivamente 7,10 e $3,50 \mathrm{mg} \mathrm{dm}^{-3} \mathrm{e}$, os outros dois em Rio Claro (218/04 e 247/07) com respectivamente 2,2 e 6,6 $\mathrm{mg} \mathrm{dm}{ }^{-3}$. Há ainda um poço perfurado no Aquífero Tubarão (247/21) com 4,9 $\mathrm{mg} \mathrm{dm}^{-3}$ em Piracicaba e outro somente na Formação Irati (246/10) com 3,6 $\mathrm{mg} \mathrm{dm}^{-3}$, também em Piracicaba (Apêndice 1).

$\mathrm{Na}$ Região Administrativa de Sorocaba (DAEE 1982) há 4 poços que explotam o Aquitarde Passa Dois com anomalias de F-: em Anhembi com 10,4 $\mathrm{mg} \mathrm{dm}^{-3}$ (poço 273/03); em Bofete com $17,6 \mathrm{mg} \mathrm{dm}^{-3}$ (poço 297/06); em Quadra com 1,24 $\mathrm{mg} \mathrm{dm} \mathrm{d}^{-3}$ (poço 317/07); e em poço misto $(274 / 05$ ) com o Aquífero Tubarão em Conchas com 8,6 mg $\mathrm{dm}^{-3}$ (Apêndice 1).

RIBEIRO (1992) identificou elevados teores de $\mathrm{F}^{-}$em poços dos municípios de Corumbataí $\left(10,8 \mathrm{mg} \mathrm{dm}^{-3}\right)$ e Santa Gertrudes $\left(1,70 \mathrm{mg} \mathrm{dm}^{-3}\right)$ e os correlacionou às altas concentrações de $\mathrm{Na}^{+}$ e de $\mathrm{pH}$ condicionados pelo tempo de residência das águas subterrâneas e às zonas de estagnação de fluxo. A origem do F- também deve estar associada às áreas do marcante tectonismo, bem como às manifestações vulcânicas.

Assim como no Aquífero Tubarão, os teores de $\mathrm{F}^{-}$das águas dos poços do Aquitarde Passa Dois são correlacionáveis à $\mathrm{CE}, \mathrm{Na}^{+}, \mathrm{Cl}^{-}$e $\mathrm{BO}_{3}^{3-}$, temperatura, $\mathrm{pH}, \mathrm{CO}_{3}^{2-}$ e $\mathrm{HCO}_{3}^{-}$(PERRONI et al. 1986).

A origem do $\mathrm{F}^{-}$no Grupo Passa Dois pode ser atribuída à presença de sedimentos ricos em flúor, conforme constatado por alguns estudos petrológicos e geoquímicos. GARCEZ et al. (2003), por exemplo, analisaram as matérias primas cerâmicas (siltitos da Formação Corumbataí) na região de Santa Gertrudes (SP) e detectaram teores médios de flúor de 100 a $720 \mathrm{mg} \mathrm{kg}^{-1}$. O F-, nesse caso, está associado a minerais como illita, e pode ser liberado do corpo cerâmico durante o processo produtivo de revestimento a partir dos $900{ }^{\circ} \mathrm{C}$.

KERN et al. (2007) registraram a presença de fluorita microcristalina nos folhelhos negros das Formações Ponta Grossa e Irati da Bacia do Para- ná e verificaram que a sua dissolução enriquece as águas dessas unidades com flúor. Testes de lixiviação e de solubilização indicaram concentrações de flúor de 8,6 a $21,8 \mathrm{mg} \mathrm{kg}^{-1}$, que apresentaram boa correlação com o conteúdo de matéria orgânica. Os autores ainda discutem a interação das águas do Aquitarde Passa Dois com o Aquífero Guarani, por ascensão, através de conexões hidráulicas representadas por estruturas rúpteis regionais (falhas e fraturas).

GOFFERMANN et al. (2015) também constataram altos teores de $\mathrm{F}$ - em poços nas unidades Subgrupo Estrada Nova e Formação Irati, no Município de São Gabriel (RS). Os autores associaram sua origem à dissolução de fluorita disseminada nos sedimentos e circulação de água subterrânea através de fraturas, níveis de concreções carbonáticas, planos interlaminares e camadas e lentes arenosas.

PERRONI et al. (1986) mencionam que o Aquitarde Passa Dois, assim como o Aquífero Tubarão, são rochas intensamente cortadas por intrusões magmáticas (basálticas e alcalinas), que podem ter propiciado perturbações térmicas e circulação de fluidos responsáveis pela mobilização do $\mathrm{F}^{-}$nos sedimentos paleozoicos.

\section{Aquifero Guarani (G)}

As águas do Aquífero Guarani no estado de São Paulo apresentam características hidroquímicas e isotópicas variáveis da porção aflorante, a leste, em direção à parte confinada, a oeste, acompanhando o fluxo subterrâneo. Na porção livre predominam águas bicarbonatadas magnesianas a cálcio-magnesianas, com baixos teores salinos (100 $\mathrm{mg} \mathrm{dm}^{-3}$ de resíduo seco), pH ácido e temperaturas entre 22 e $25^{\circ} \mathrm{C}$. A partir do contato com os basaltos da Formação Serra Geral que capeiam as Formações Botucatu/Pirambóia, as águas adquirem características bicarbonatadas cálcicas, enriquecimento salino (200 $\mathrm{mg} \mathrm{dm}^{-3}$ de resíduo seco), aumento gradativo do $\mathrm{pH}$ e da temperatura $\left(30^{\circ} \mathrm{C}\right)$, idades de até 7.000 anos. Na porção confinada as águas são bicarbonatadas sódicas e, subordinadamente, cloro-sulfatadas sódicas (extremo sudoeste do estado), mais salinizadas (650 $\mathrm{mg} \mathrm{dm}^{-3} \mathrm{de}$ resíduo seco), e apresentam $\mathrm{pH}$ alcalino $(>9,0)$ e temperaturas de até $63{ }^{\circ} \mathrm{C}$ (SILVA 1983, SRACEK \& HIRATA 2002), além de maiores idades (até > 40.000 anos) (KIMMELMANN E SILVA et al. 1989 a,b). Nas condições de confinamento mencionadas é que se registraram as ocorrências de $\mathrm{F}^{-} \mathrm{em}$ concentrações superiores a $1 \mathrm{mg} \mathrm{dm}^{-3}$. 
No estudo sobre ocorrências de $\mathrm{F}^{-}$no estado de São Paulo, PERRONI et al. (1986) correlacionaram os teores de $\mathrm{F}^{-}$à condutividade elétrica (CE), $\mathrm{Na}^{+}, \mathrm{Cl}^{-}$e $\mathrm{BO}_{3}{ }_{3-}^{3-}$, temperatura e $\mathrm{HCO}_{3}^{-}$. Os autores verificaram que o enriquecimento progressivo de $\mathrm{F}^{-}$ocorre no sentido do interior da bacia, acompanhando a evolução química da água.

SILVA (1983) observou que a elevação dos teores de sódio e da salinidade é acompanhada do aumento da concentração de $\mathrm{F}^{-}$em toda a região confinada do aquífero. Os teores de $\mathrm{F}^{-}>1 \mathrm{mg} \mathrm{dm}^{-3}$ coincidem com valores de força iônica nunca inferiores a 5,22 × $10^{-3}$, indicando o potencial das águas em dissolver minerais traços disseminados no aquífero, como por exemplo, a apatita. A autora sugere que a concentração excepcional de $\mathrm{F}^{-}(13,3 \mathrm{mg}$ $\mathrm{dm}^{-3}$ ) no poço de Presidente Prudente possa estar associada à presença de rochas intrusivas básicas no pacote Botucatu-Pirambóia, que atuam como um fator de aceleração do enriquecimento de $\mathrm{F}^{-}$. Para SRACEK \& HIRATA (2002) a origem do $\mathrm{F}^{-}$neste poço de Presidente Prudente se deve à dissolução da fluorita, impulsionada pela troca catiônica $\mathrm{Ca}^{2+}-\mathrm{Na}^{+}$. No entanto, os autores não definem se esses processos ocorrem diretamente no Aquífero Guarani ou na Formação Serra Geral, uma vez que a fluorita não ocorre nas formações Botucatu e Pirambóia.

No estado do Rio Grande do Sul, na borda da Bacia do Paraná, SILVÉRIO DA SILVA et al. (2002) levantaram hipótese similar a de SILVA (1983), ou seja, que a origem do $\mathrm{F}^{-}\left(>0,9 \mathrm{mg} \mathrm{dm}^{-3}\right)$ nas águas do Aquífero Guarani estaria associada à sua mineralogia (micas e illitas das formações Rosário do Sul e Santa Maria) e, ocasionalmente, a níveis de calcretes e ossos de répteis fósseis. Além disso, diques básicos relacionados a eventos magmáticos tardios da Formação Serra Geral, podem ter contribuído com o enriquecimento das rochas sedimentares em $\mathrm{F}^{-}$e para o semi-confinamento local do Aquífero Guarani formando águas mais mineralizadas de elevada força iônica que contribuiriam para a liberação do F-

KIMMELMAN et al. (1989b) constataram uma correlação entre altas concentrações de $\mathrm{F}^{-}$com águas de idade ${ }^{14} \mathrm{C}$ mais antigas $(>25.000$ anos) de poços bem profundos, indicando que a origem estaria associada às partes profundas do Aquífero Guarani (Formação Pirambóia subjacente).

FRAGA (1992) associa as concentrações anômalas de $\mathrm{F}^{-}\left(3,6\right.$ a $\left.12,0 \mathrm{mg} \mathrm{dm}^{-3}\right)$ a águas alcalinas do Aquífero Botucatu confinado, do tipo $\mathrm{Na}-\mathrm{SO} 4-\mathrm{Cl}$ com totais de sólidos dissolvidos (TSD) superior a $1.000 \mathrm{mg} \mathrm{dm}^{-3}$, característicos de estag- nação de fluxo e longo tempo de residência. A presença destas anomalias é atribuída a um processo geoquímico pós-deposicional que solubilizou precipitados químicos portadores de flúor. As condições que favoreceram a presença de $\mathrm{F}^{-}$em solução foram influenciadas por clima árido a semi-árido, que assegurou a alcalinidade das águas, favorecendo a precipitação de $\mathrm{CO}_{3}^{2-}, \mathrm{Ca}^{2+}$ e $\mathrm{Mg}^{2+}$ e enriquecendo as águas em $\mathrm{SO}_{4}^{2-}, \mathrm{Cl}^{-}$e $\mathrm{Na}^{+}$. Segundo SRACEK \& HIRATA (2002) o enriquecimento de $\mathrm{F}^{-}$não pode ser explicado pela evaporação conforme sugerido por FRAGA (1992), porque deveria haver enriquecimento de $\delta^{2} \mathrm{H}$ e de $\delta^{18} \mathrm{O}$, mas os altos teores de $\mathrm{F}^{-}$estão associados aos valores mais empobrecidos de $\delta^{2} \mathrm{H}$ e de $\delta^{18} \mathrm{O}$ determinados por SILVA (1983).

MANZANO \& GUIMARÃES (2012) e GASTMANS et al. (2012) constataram que a concentração anômala de $\mathrm{F}^{-}\left(>>1 \mathrm{mg} \mathrm{dm}^{-3}\right)$ está associada à fácie hidroquímica com águas de composição variável (Na-HCO3-SO4-Cl, $\mathrm{NaCl}$, Na-SO4) no SAG (Sistema Aquífero Guarani). confinado, que apresentam mineralização média a alta $\left(\mathrm{CE}=500 \mathrm{a} 6000 \mu \mathrm{S} \mathrm{cm}^{-1}\right)$, e valores de $\mathrm{pH}$ entre 7 e 9. Em concordância ao exposto por MENG \& MAINARD (2001), os autores assumem que estas águas seriam resultado da mistura de águas da fácie $\mathrm{Na}-\mathrm{HCO} 3$ com águas mais salinas e de procedência mais profunda, uma vez que elas apresentam a relação $\mathrm{Cl} / \mathrm{SO} 4 \sim 1$, atribuídas ao pré-SAG. A fonte de $\mathrm{F}^{-}$, portanto, seria proveniente das águas do pré$\mathrm{SAG}$, rochas sedimentares subjacentes ao SAG, que correspondem às formações Corumbataí/ Teresina (na sua porção aflorante até a metade do estado) e da Formação Rio do Rasto na porção oeste, entre Tupã e Presidente Prudente.

BONOTTO (2006) também constatou relações significativas e aumento das concentrações de $\mathrm{HCO}_{3}^{-}, \mathrm{CO}_{3}^{2-}, \mathrm{Na}^{+}, \mathrm{SO}_{4}^{2-}, \mathrm{Cl}^{-}$e $\mathrm{F}^{-}$com a pressão geostática do aquífero, além do aumento de alcalinidade, índice de saturação de calcita, $\mathrm{pH}$, resíduo seco e temperatura. Teores altos foram encontrados em poços mais profundos, sugerindo que as águas do Guarani estão se misturando com aquelas provenientes de sedimentos paleozoicos

MENG \& MAINARD (2001) e MANZANO \& GUIMARÃES (2012) concluem que são necessários mais dados químicos de águas subterrâneas das formações acima e abaixo deste aquífero para comprovar que a origem do F- é unicamente do pré-SAG. Indicam também a necessidade de quantificar os fluxos ascendentes das águas do pré-SAG e sua influência nos processos naturais de mistura e de aporte de salinidade e de $\mathrm{F}^{-}$em escala local e regional. 


\section{Aquifero Serra Geral (SG)}

As águas do Aquífero Serra Geral são predominantemente bicarbonatadas cálcicas ou magnesianas, seguidas de bicarbonatadas sódicas nos 42 poços de monitoramento do estado de São Paulo. No período de 2013-2015 apresentaram pH mediano 7,2, variando de 4,7 a 10,1 e a condutividade elétrica (CE) mediana de $180 \mu \mathrm{S} \mathrm{cm}^{-1}$ com variações de 7 a $1060 \mu \mathrm{S} \mathrm{cm}{ }^{-1}$ (CETESB 2016). PERRONI et al. (1986) constataram um terceiro grupo hidroquímico de águas sulfatadas-cloretadas sódicas às quais estão associados os mais elevados teores de $\mathrm{F}^{-}$. As anomalias de $\mathrm{F}^{-}$neste aquífero são correlacionáveis a altas concentrações de $\mathrm{Na}^{+}, \mathrm{Cl}$, $\mathrm{BO}_{3}^{3-}, \mathrm{CO}_{3}{ }^{2-}, \mathrm{SO}_{4}^{2-}$, altos valores de $\mathrm{CE}$ e $\mathrm{pH}$ (PERRONI et al. 1986), resíduos secos e alta temperatura (FRAGA 1992).

Os poços que apresentam altas concentrações de sais dissolvidos nas águas estão normalmente associados a estruturas geológicas profundas como os alinhamentos estruturais das drenagens do Tietê, Paranapanema e Guapiara (FRAGA 1992, PERRONI et al. 1986). PERRONI et al. (1986) mencionam que a relação destas grandes estruturas com o magmatismo alcalino mesozoico e terciário seria responsável por manifestações hidrotermais ricas em soluções de flúor bem como por remobilização do flúor contido nas rochas encaixantes.

SZIKSZAY et al. (1981) analisaram águas de fontes termais do estado de São Paulo e constataram zonas anômalas de $\mathrm{HCO}_{3}^{-}, \mathrm{SO}_{4}^{2-}, \mathrm{Cl}^{-}, \mathrm{Na}^{+}, \mathrm{F}^{-} \mathrm{e}$ B nos aquíferos Bauru e Serra Geral, situadas ao longo de dois principais alinhamentos estruturais: um deles coincidente com o rio Grande (direção E-W) e, o outro, um eixo N-S que se inicia ao norte do estado no rio Grande e se estende por $300 \mathrm{~km}$ até encontrar uma inflexão do rio Tietê. Estas águas anômalas também possuem temperaturas elevadas e $\mathrm{pH}$ variando de neutro a alcalino, que indicam uma composição semelhante às aguas profundas e confinadas do Aquífero Botucatu. Isto poderia indicar a ascensão de águas quentes do Aquífero Botucatu, através de fraturas verticais nos basaltos da Formação Serra Geral para o Aquífero Bauru, e o enriquecimento das águas em sais decorrentes da dissolução de constituintes das rochas vulcânicas e mineralização secundária.

Resultados de análises químicas das águas de poços tubulares perfurados pela SABESP no Aquífero Serra Geral indicaram anomalias de Fnos poços dos municípios de: Gastão Vidigal com 4,4 $\mathrm{mg} \mathrm{dm}^{-3}$ (P4) e 3,3 $\mathrm{mg} \mathrm{dm}^{-3}$ (P5); Colômbia com 2,0 $\mathrm{mg} \mathrm{dm}^{-3}$; Mira Estrela com 2,0 $\mathrm{mg} \mathrm{dm}^{-3}$
(P2) e em 2 poços perfurados em Santa Albertina (SP) próximos a calhas de grandes rios como Tietê, e Grande Paraná com 4,4 mg dm³ (Poço P3 Ribeirão Jacú) e $1,3 \mathrm{mg} \mathrm{dm}^{-3}$ (Poço P4 - Córrego Borba Gato) (GIAMPÁ et al. 1981 e GIAMPÁ \& FRANCO FILHO 1982). Os autores associaram a presença de altas concentrações de $\mathrm{F}^{-}$aos níveis de derrames basálticos (zonas de alteração amigdaloidal/vesicular; fraturas, falhas, etc.) com entrada de água nos poços acima de $200 \mathrm{~m}$ de profundidade.

SPILLER (2005) analisou dados de 80 poços que explotam o Aquífero Serra Geral no oeste do estado de São Paulo e constatou que, em profundidade, as fraturas horizontais favorecem maior armazenamento de água do que as fraturas subverticais, e as águas encontradas são mais mineralizadas, bicarbonatadas sódicas, com $\mathrm{pH}$ alcalino e condutividade elétrica $>200 \mu \mathrm{S} \mathrm{cm}^{-1}$. O autor também associa a origem das anomalias hidrogeoquímicas (alcalinidade, dureza, $\mathrm{F}^{-}, \mathrm{Na}^{+}, \mathrm{Cl}^{-}, \mathrm{SO}_{4}^{2-}$, sílica) dessas águas à presença de zeólita, fluorita, calcita, quartzo, calcedônia e malaquita em zonas vesículo-amigdaloidais de derrames basálticos.

FRAGA (1992) estudou teores anômalos de $\mathrm{F}^{-}$de poços que penetraram o aquífero Serra Geral no estado do Paraná, e também os associou a águas alcalinas do tipo $\mathrm{Na}-\mathrm{SO} 4-\mathrm{Cl}$, típicas do aquífero Botucatu confinado, subjacente; concluiu que há influência de ampla transferência de fluxo do aquífero Botucatu para o Serra Geral.

Na Região Administrativa de Campinas (SP) o DAEE (1981) identificou um poço que explota água do Diabásio em Rio Claro (DAEE 218/12) com $1,40 \mathrm{mg} \mathrm{dm}^{-3} \mathrm{de} \mathrm{F}^{-}$e outro associado ao Aquífero Tubarão em Holambra (249/36) com 6,4 mg $\mathrm{dm}^{-3}$ de $\mathrm{F}^{-}$(Apêndice 1).

BITTENCOURT et al. (1996) também constataram a mistura de águas provenientes do Aquífero Guarani, sotoposto, para o Aquífero Serra Geral na bacia do Piqueri, estado do Paraná, baseada na mudança de composição típica de águas bicarbonatadas cálcicas (Ca-HCO3, Ca-Na-HCO3 e $\mathrm{Ca}-\mathrm{Mg}-\mathrm{HCO} 3$ ) para mais sulfatadas.

\section{Aquífero Bauru (BA)}

Em geral, as águas do Aquífero Bauru não apresentam problemas de anomalias em F-; ao contrário, elas possuem carência de flúor e necessitam de adição prévia à sua distribuição para abastecimento público (DAEE 1974, 1976, 1979b).

São águas predominantemente bicabornatadas cálcicas a cálcio-magnesianas $(70 \%)$ e, se- 
cundariamente, bicabornatadas sódicas (CAMPOS 1993, BARISON 2003, CETESB 2016, KIANG et al. 2016). Na região ao sul do Rio Tietê até o norte do Rio Paranapanema, BARISON (2003) constatou os seguintes tipos hidroquímicos na análise de 166 amostras: bicarbonatados cálcicos a cálciomagnesianos $(66,80 \%)$, bicarbonatados sódicos $(15,66 \%)$ e, em menor proporção, cloro-sulfatados sódicos e sódico-potássicos $(9,64 \%)$ e cálcicos $(7,83 \%)$.

As águas desse aquífero apresentam características pouco mineralizadas, condutividade elétrica média de $201 \mu \mathrm{S} \mathrm{cm}^{-1}$ com variação de 27 a 628 $\mu \mathrm{S} \mathrm{cm}^{-1}$, e o $\mathrm{pH}$ mediano 7,00, variando de 5,00 a 9,40 (CETESB 2013). No período de 2010-2012 as concentrações de $\mathrm{F}^{-}$foram relativamente baixas, mediana de $0,13 \mathrm{mg} \mathrm{dm}^{-3}$ com variações de $<0,02$ a $1,57 \mathrm{mg} \mathrm{dm}^{-3}$ (CETESB 2013). Esses valores são muito próximos à média de $0,14 \mathrm{mg} \mathrm{dm}^{-3} \mathrm{e}$ variação de 0,01 a $1,11 \mathrm{mg} \mathrm{dm}^{-3}$ encontradas por BARISON (2003) e BARISON \& CHANG (2004).

Uma vez que concentrações acima de $1,0 \mathrm{mg}$ $\mathrm{dm}^{-3}$ são pontuais no Aquífero Bauru, não há muitos estudos hidrogeoquímicos específicos sobre o assunto.

CAMPOS $(1987,1993,2004)$ indicou que o enriquecimento iônico em $\mathrm{HCO}_{3}^{-}, \mathrm{Ca}^{2+}$ e $\mathrm{Mg}^{2+}$ do Aquífero Bauru é atribuído à composição mineralógica das rochas, ou seja, ao carbonato de cálcio (calcrete) e argilominerais que constituem o cimento das litofácies. $\mathrm{O}$ aumento da salinidade dessas águas é acompanhado pelo aumento dos teores desses íons. Já os altos teores de $\mathrm{Cl}^{-}$e de $\mathrm{Na}^{+}$ que ocorrem localmente podem estar associados a alinhamentos estruturais ou a rochas basálticas.

SZIKSZAY et al. (1981) também relacionaram anomalias geoquímicas de $\mathrm{HCO}_{3}^{-}, \mathrm{SO}_{4}^{2-}, \mathrm{Cl}^{-}$, $\mathrm{Na}^{+}, \mathrm{F}^{-}, \mathrm{B}$, à regiões com elevada salinidade dos aquífero Bauru e Serra Geral, alinhadas a eixos de direção NS (Rio Grande até inflexão do Rio Tietê ao Sul) e EW (Rio Grande).

Uma ocorrência com altíssima concentração de F- $\left(9,20 \mathrm{mg} \mathrm{dm}^{-3}\right)$ em Teodoro Sampaio (Apêndice 1) pode estar associada à influência ou mistura com águas de outro(s) aquífero(s). Esse e outros casos semelhantes de teores em torno de $2-5 \mathrm{mg}$ $\mathrm{dm}^{-3}$ foram levantados em Andradina, Queiroz, Santo Expedito e Paulo de Faria (SP), e deveriam ser estudados para se investigar a origem do $\mathrm{F}^{-}$.

Sugere-se, portanto, que anomalias de $\mathrm{F}^{-}$podem estar associadas a águas de maior salinidade do aquífero e, assim, a condicionantes estruturais (fraturas verticais) da Bacia do Paraná que permitem a circulação ascendente.

\section{Aquífero Taubaté (TA)}

Os seis poços de monitoramento do estado no Aquífero Taubaté sugerem tipos hidroquímicos predominantemente bicarbonatados sódicos e, secundariamente, bicarbonatados cálcicos. Apresentam $\mathrm{pH}$ neutro e máximo de 7,70 , e condutividade elétrica mediana de $159 \mu \mathrm{S} \mathrm{cm}^{-1}$, variando de 58 a $274 \mu \mathrm{S} \mathrm{cm}^{-1}$. As concentrações de $\mathrm{F}^{-}$são baixas, com mediana de $0,2 \mathrm{mg} \mathrm{dm}^{-3}$ e variação de $0,04 \mathrm{a}$ $0,9 \mathrm{mg} \mathrm{dm}^{-3}$ (CETESB 2013). DAEE (1977) já havia constatado que as águas subterrâneas da região eram deficientes em F-, e que o teor médio de 0,24 $\mathrm{mg} \mathrm{dm}{ }^{-3}$, indica a necessidade de adicioná-lo nas águas para prevenção à problemas dentários.

Um teor anômalo de $2,5 \mathrm{mg} \mathrm{dm}^{-3}$ foi detectado pelo DAEE (1977) em um poço de $500 \mathrm{~m}$ de profundidade em Taubaté (23-YD-II-2-1).

CAMPOS (1993) observou na Bacia de Taubaté anomalias hidroquímicas pontuais de $\mathrm{F}^{-}, \mathrm{SO}_{4}^{2-}$, $\mathrm{Cl}^{-}$e teor salino.

VIDAL (1997) e VIDAL \& KIANG (2002) identificaram alguns poços na Bacia de Taubaté com teores de $\mathrm{F}^{-}$acima de $1,0 \mathrm{mg} \mathrm{dm}^{-3}$ nos municípios de Taubaté ( 2 poços com $3 \mathrm{mg} \mathrm{dm}^{-3}$ ), Pindamonhangaba ( 2 poços com 1,5 e $2,0 \mathrm{mg} \mathrm{dm}^{-3}$ ), Lorena ( 2 poços com 1,5 e $1,0 \mathrm{mg} \mathrm{dm}^{-3}$ ) e Cachoeira Paulista (1 poço com 1,03 $\mathrm{mg} \mathrm{dm}^{-3}$ ) (Apêndice 1).

DINIZ et al. (2006) identificaram 2 poços tubulares de abastecimento público no município de Lorena com altas concentrações de F-. Esses poços atravessavam arenitos das formações Caçapava e Tremembé, mas foram desativados, uma vez que ocasionaram problemas endêmicos de fluorose na população infantil da parte central da cidade. As águas dos poços da região de Lorena apresentavam, em geral, $\mathrm{pH}>7,0$ e se mostravam predominantemente bicarbonatadas sódicas.

No município de Taubaté (SP) SALLUN \& DINIZ (2016) descreveram amostras de sedimentos da Formação Tremembé coletadas em um poço de $80 \mathrm{~m}$ de profundidade, constituídas de pacotes métricos de argilitos, arenitos finos a grossos, ritmitos em alternância com lâminas e camadas centimétricas de folhelhos e margas. Os teores de flúor variaram de 576 a $2.318 \mathrm{mg} \mathrm{kg}^{-1}$ em 37 amostras coletadas ao longo do furo de sondagem, ultrapassando a Referência de Qualidade de $470 \mathrm{mg} \mathrm{kg}^{-1}$ estabelecido pela USEPA (2016) para solo residencial.

Os autores não discutem a origem do $\mathrm{F}^{-}$nas águas subterrâneas do Aquífero Taubaté ou do flúor nas rochas sedimentares, o que indica a necessidade de estudos geoquímicos e mineralógicos nas áreas anômalas. 


\subsection{Comportamento do fluoreto}

Do total de 208 poços catalogados, 157 apresentaram dados físico-químicos e químicos referentes às águas subterrâneas, mas somente 128 possuem resultados analíticos sobre os íons maiores para classificação hidroquímica. Desses poços, 115 (Apêndice 2) apresentaram erro inferior a 10\% no balanço iônico e foram utilizados para as correlações iônicas.

No diagrama da figura 3 observa-se que as altas concentrações de $\mathrm{F}^{-}$nas águas ocorrem em condições de $\mathrm{pH}$ alcalino. $\mathrm{O} \mathrm{pH}$ médio de 35 poços com $\mathrm{F}^{-}$entre 1,0 e $1,50 \mathrm{mg} \mathrm{dm}^{-3}$ é de 7,90 e esse valor cresce para 8,35 quando são considerados 70 poços com $\mathrm{F}^{-}>1,50 \mathrm{mg} \mathrm{dm}^{-3}$. As correlações entre $\mathrm{F}^{-}$e $\mathrm{pH}$ foram melhor observadas nos aquíferos Taubaté $(\mathrm{r}=0,59)$ e Serra Geral $(\mathrm{r}=0,58)$. As baixas correlações podem estar relacionadas à dispersão de dados devido a fontes variadas de informações, nas quais nem sempre são descritas as técnicas e equipamentos utilizados nas medições, além de outros fatores que poderiam interferir na obtenção do dado.
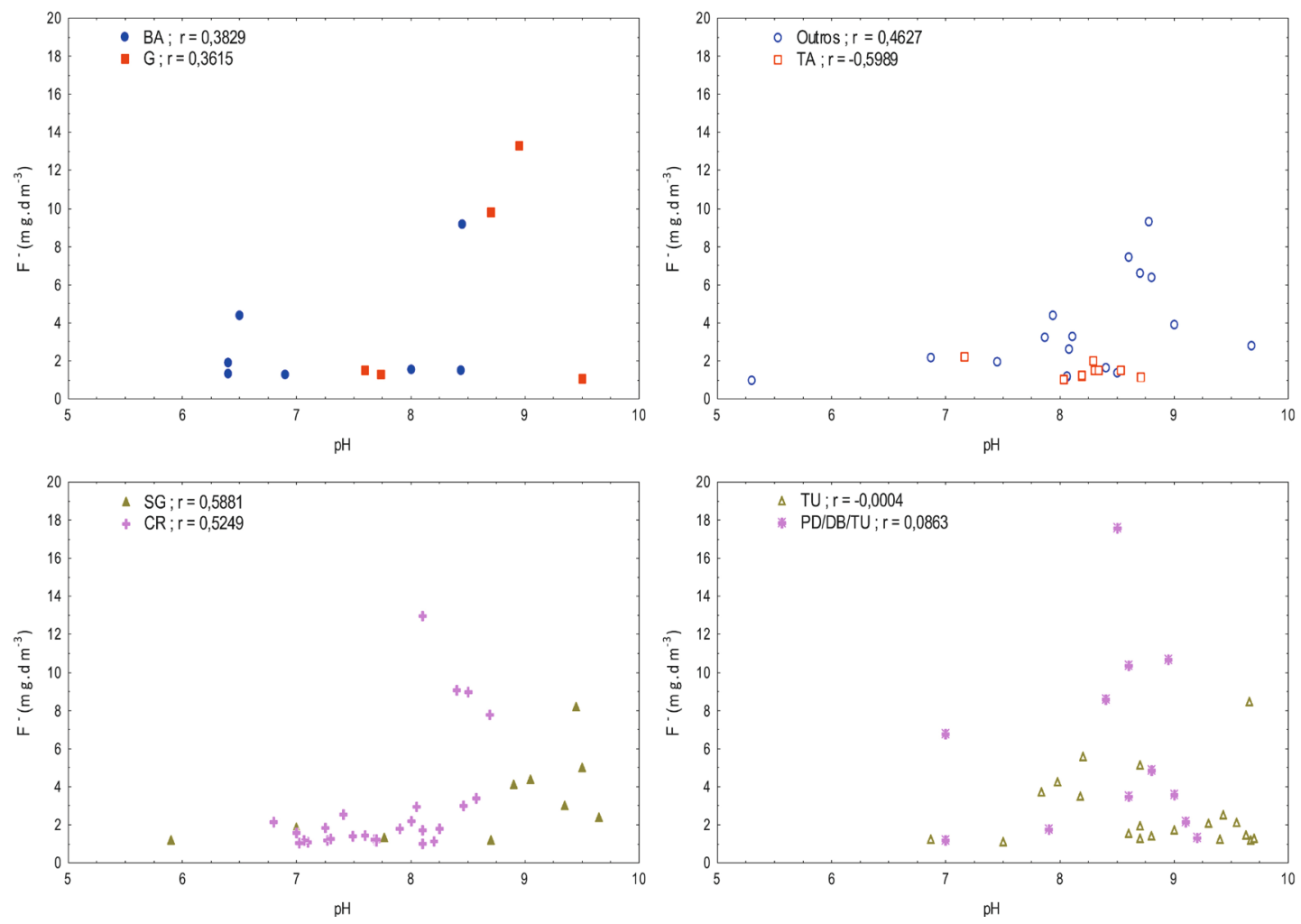

FIGURA 3 - Diagrama de [F-] em função de $\mathrm{pH}$ por aquífero explorado (BA=Bauru; $\mathrm{G}=\mathrm{Guarani}$; $\mathrm{SG}=\mathrm{Serra}$ Geral; $\mathrm{CR}=$ Cristalino; TA=Taubaté; Outros= Diabásio, poços mistos; $\mathrm{PD}=$ Aquitarde Passa Dois; TU=Tubarão). tudados são predominantemente bicarbonatadas e, secundariamente, bicarbonatadas-sulfatadas-cloretadas. As concentrações de $\mathrm{HCO}_{3}^{-}$variam de 4,0 a $712,0 \mathrm{mg} \mathrm{dm}^{-3}$. A projeção das concentrações de $\mathrm{HCO}_{3}^{-}$em função de $\mathrm{F}^{-}$mostrou que, em geral, há baixa correlação entre eles $(r=0,35)$. Porém, os poços associados ao Aquitarde Passa Dois e ao Aquífero Serra Geral apresentaram correlações maiores, de $r=0,76$ e $r=0,62$, respectivamente (Figura 4).

O comportamento do $\mathrm{F}^{-}$nestas águas está associado à liberação de $\mathrm{Na}^{+}$como constatado pela correlação positiva entre os teores de $\mathrm{F}^{-}$e $\mathrm{Na}^{+}$(Figura 5), embora o coeficiente de correlação geral obtido seja de $r=0,41$ considerando todos os aquíferos analisados. Por outro lado, baixas concentrações de $\mathrm{Ca}^{2+}$ (Figura 6) nas águas devem-se a sua remoção devido à precipitação como carbonato, conforme constatado em diversos estudos (OZSVATH 2006, GUO et al. 2007, CHAE et al. 2007, GENXU \& GUODON 2001, entre outros). Esta baixa correlação iônica de $\mathrm{F}^{-}$com $\mathrm{Ca}^{2+}$ também se constata com relação ao $\mathrm{K}^{+} \mathrm{e}$ ao $\mathrm{Mg}^{2+}$. 

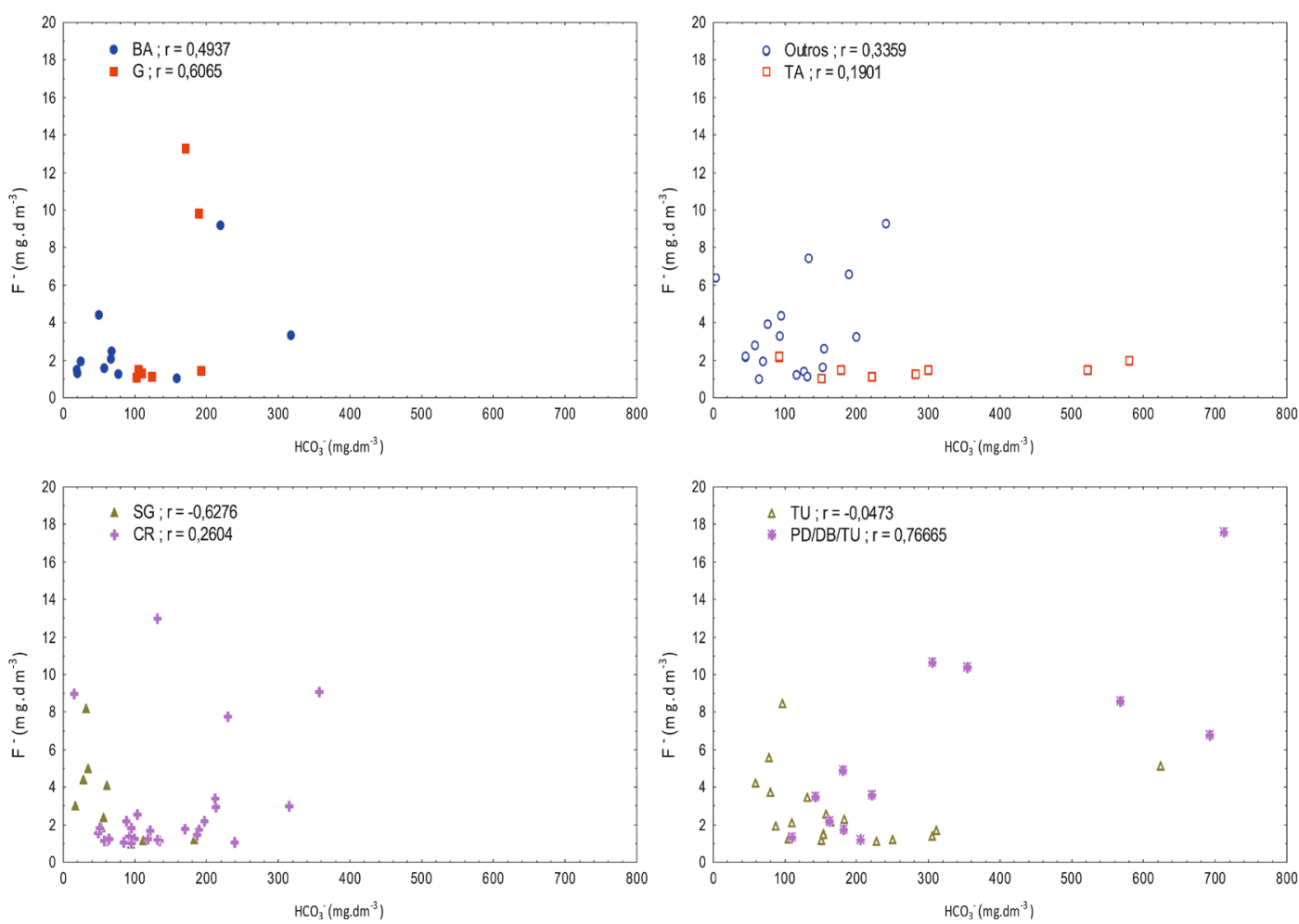

FIGURA 4 - Diagrama de [F- $\mathrm{X}^{-}\left[\mathrm{HCO}_{3}^{-}\right]$por aquífero explorado (BA=Bauru; G=Guarani; $\mathrm{SG}=$ Serra Geral; $\mathrm{CR}=$ Cristalino; $\mathrm{TA}=$ Taubaté; Outros= Diabásio, poços mistos; $\mathrm{PD}=$ Aquitarde Passa Dois; $\mathrm{TU}=$ Tubarão).
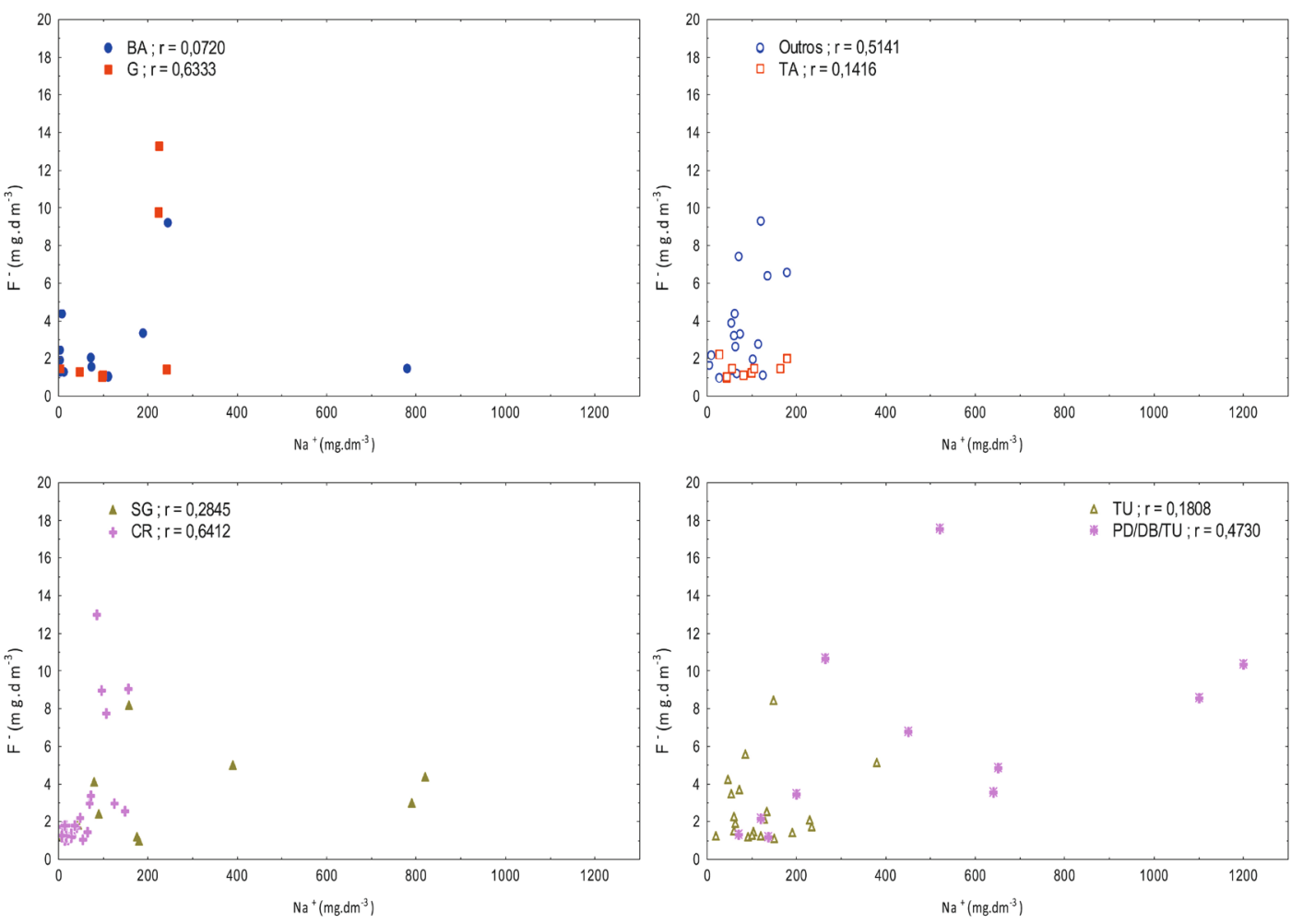

FIGURA 5 - Diagrama $\left[\mathrm{F}^{-}\right] \mathrm{X}\left[\mathrm{Na}^{+}\right]$por aquífero explorado (BA=Bauru; G=Guarani; SG=Serra Geral; $\mathrm{CR}=$ Cristalino; $\mathrm{TA}=$ Taubaté; Outros= Diabásio, poços mistos; $\mathrm{PD}=$ Aquitarde Passa Dois; TU=Tubarão). 

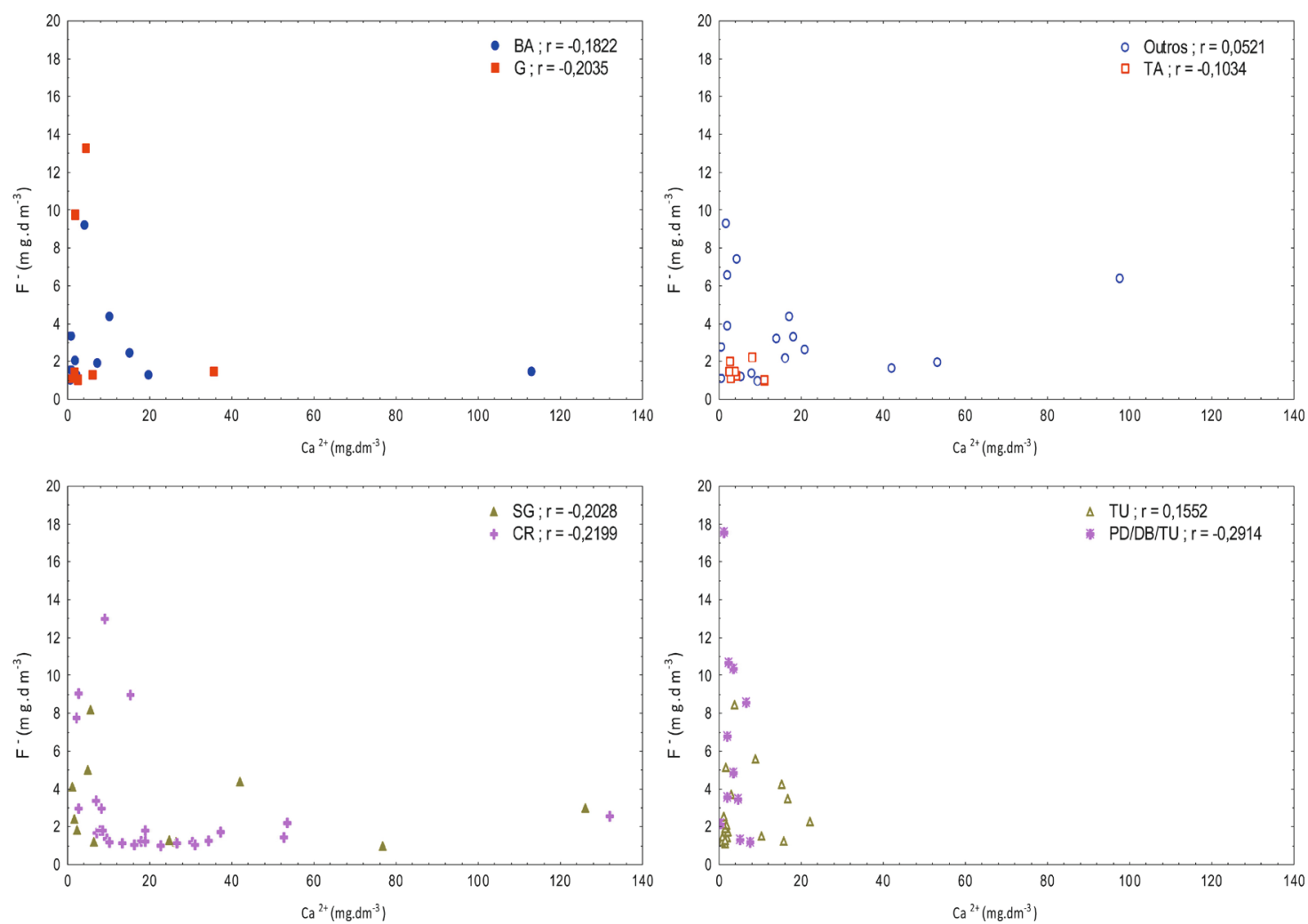

FIGURA 6 - Diagrama de $\left[\mathrm{F}^{-}\right] \mathrm{X}\left[\mathrm{Ca}^{2+}\right]$ por aquífero explorado (BA=Bauru; $\mathrm{G}=\mathrm{Guarani}$; $\mathrm{SG}=$ Serra $\mathrm{Geral}$; $\mathrm{CR}=$ Cristalino; $\mathrm{TA}=$ Taubaté; Outros= Diabásio, poços mistos; $\mathrm{PD}=$ Aquitarde Passa Dois; TU=Tubarão).

Os dados de condutividade elétrica (CE) variam de 65 a $13.500 \mu \mathrm{S} \mathrm{cm}^{-1}$, com mediana de $419 \mathrm{e}$ média de $959 \mu \mathrm{S} \mathrm{cm}^{-1}$. Os valores médios para cada aquífero são de: 143,60 $\mu \mathrm{S} \mathrm{cm}^{-1}$ (Bauru), 376,72 $\mu \mathrm{S} \mathrm{cm}{ }^{-1}$ (Cristalino), 486,78 $\mu \mathrm{S} \mathrm{cm}^{-1}$ (Cristalino/ Tubarão), 586,45 $\mu \mathrm{S} \mathrm{cm}^{-1}$ (Tubarão), 537,44 $\mu \mathrm{S}$ $\mathrm{cm}^{-1}$ (Taubaté), 637,80 $\mu \mathrm{S} \mathrm{cm}$ ch $^{-1}$ (Guarani), 937,11 $\mu \mathrm{S} \mathrm{cm}^{-1}$ (Serra Geral). O Aquitarde Passa Dois apresenta valor médio mais elevado de 2.026,91 $\mu \mathrm{S} \mathrm{cm}{ }^{-1}$.

Alguns valores não foram considerados na obtenção destas médias, por constituírem discrepâncias em relação ao conjunto de dados por aquífero como, por exemplo, os poços de: a) Teodoro Sampaio e Barretos (Aquífero Bauru) que devem sofrer influência da Formação Serra Geral; b) São Vicente (Aquífero Cristalino) que sofrem influência da água do mar em profundidade; e, c) Piratininga no Aquitarde Passa Dois.

Constatou-se elevada correlação entre os teores de $\mathrm{F}^{-}$e a condutividade elétrica nas águas do Aquífero Guarani $(\mathrm{r}=0,94)$ e do Aquífero Bauru $(\mathrm{r}=0,89)$, ao passo que no Aquitarde Passa Dois $(\mathrm{r}=0,66)$ e Aquífero Serra Geral $(\mathrm{r}=0,49)$ ocorre de forma moderada (Figura 7).
Estas anomalias de salinidade, expressas em termos de condutividade elétrica $\left(>1000 \mu \mathrm{S} \mathrm{cm}^{-1}\right)$, devem-se às elevadas concentrações de sulfatos, cloretos, bicarbonatos, sódio e cálcio, e aumentam com a profundidade. Podem indicar maior tempo de residência ou contato das águas com as rochas ou circulação restrita das águas em porções dos aquíferos.

Além disso, as águas salinas apresentam elevada força iônica que favorecem maior liberação de F-, conforme constatado por FRAGA (1992), SILVA (1993), SAXENA \& AHMED (2001), VIDAL (2002), VIERO et al. (2009) e EZAKI (2011).

Ao analisar os índices de saturação de fluorita em relação aos teores de $\mathrm{F}^{-}$nas águas (Figura $8)$ constata-se subsaturação neste mineral (IS $<0$ ) para a maioria das amostras, a qual reflete a lenta cinética de precipitação se comparada com sua dissolução (EDMUNDS \& SMEDLEY 2005).

Por outro lado, observam-se várias amostras saturadas em calcita (IS >0) na figura 9, com precipitação de carbonato, que pode interferir na disponibilidade de flúor na água subterrânea, uma vez que limita a quantidade de $\mathrm{Ca}^{2+}$ dissolvido para a formação de fluorita. 

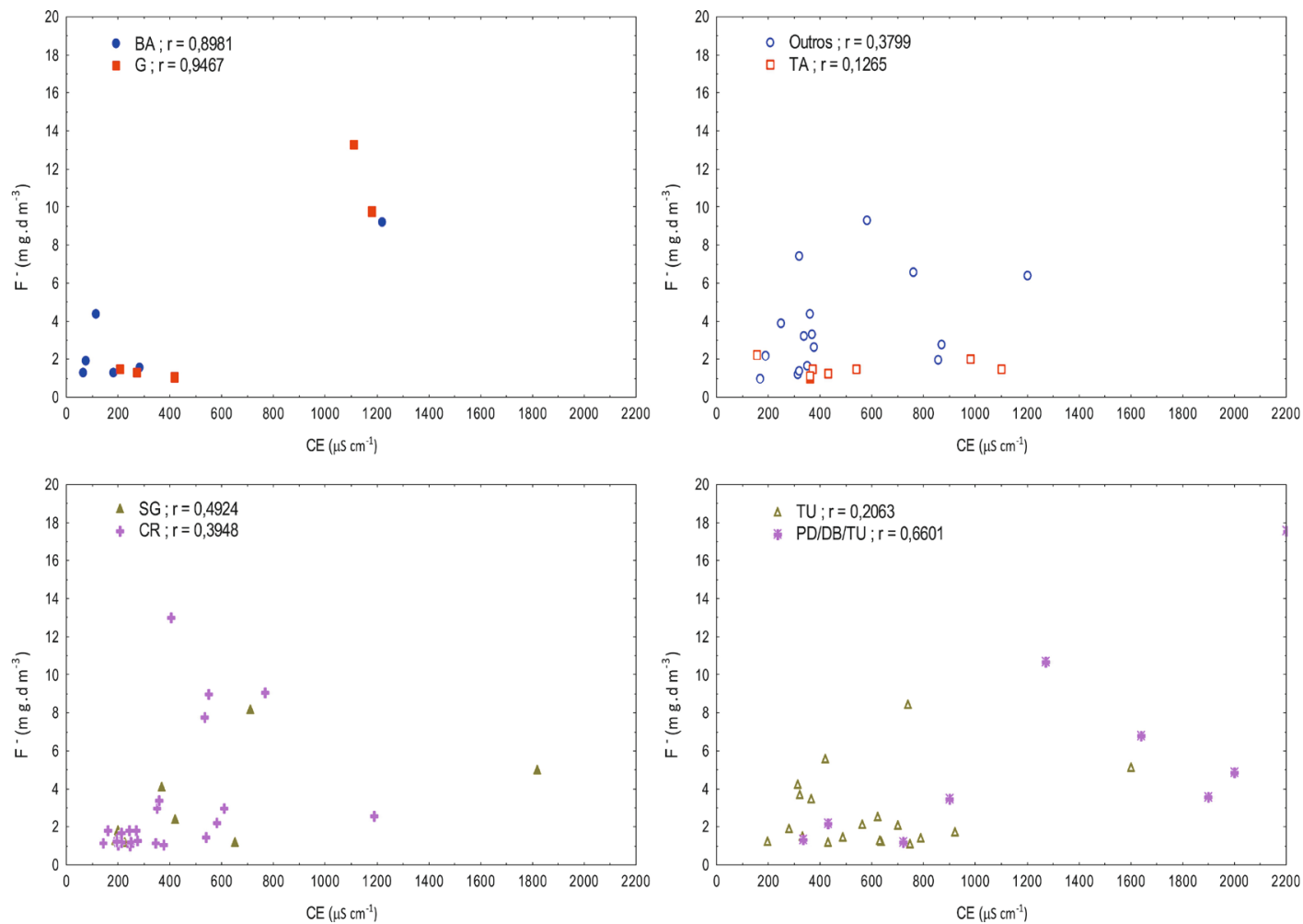

FIGURA 7 - Diagrama de [F-] em função da condutividade elétrica por aquífero explorado (BA=Bauru; $\mathrm{G}=$ Guarani; $\mathrm{SG}=$ Serra Geral; $\mathrm{CR}=$ Cristalino; $\mathrm{TA}=$ Taubaté; Outros= Diabásio, poços mistos; $\mathrm{PD}=$ Aquitarde Passa Dois; TU=Tubarão).
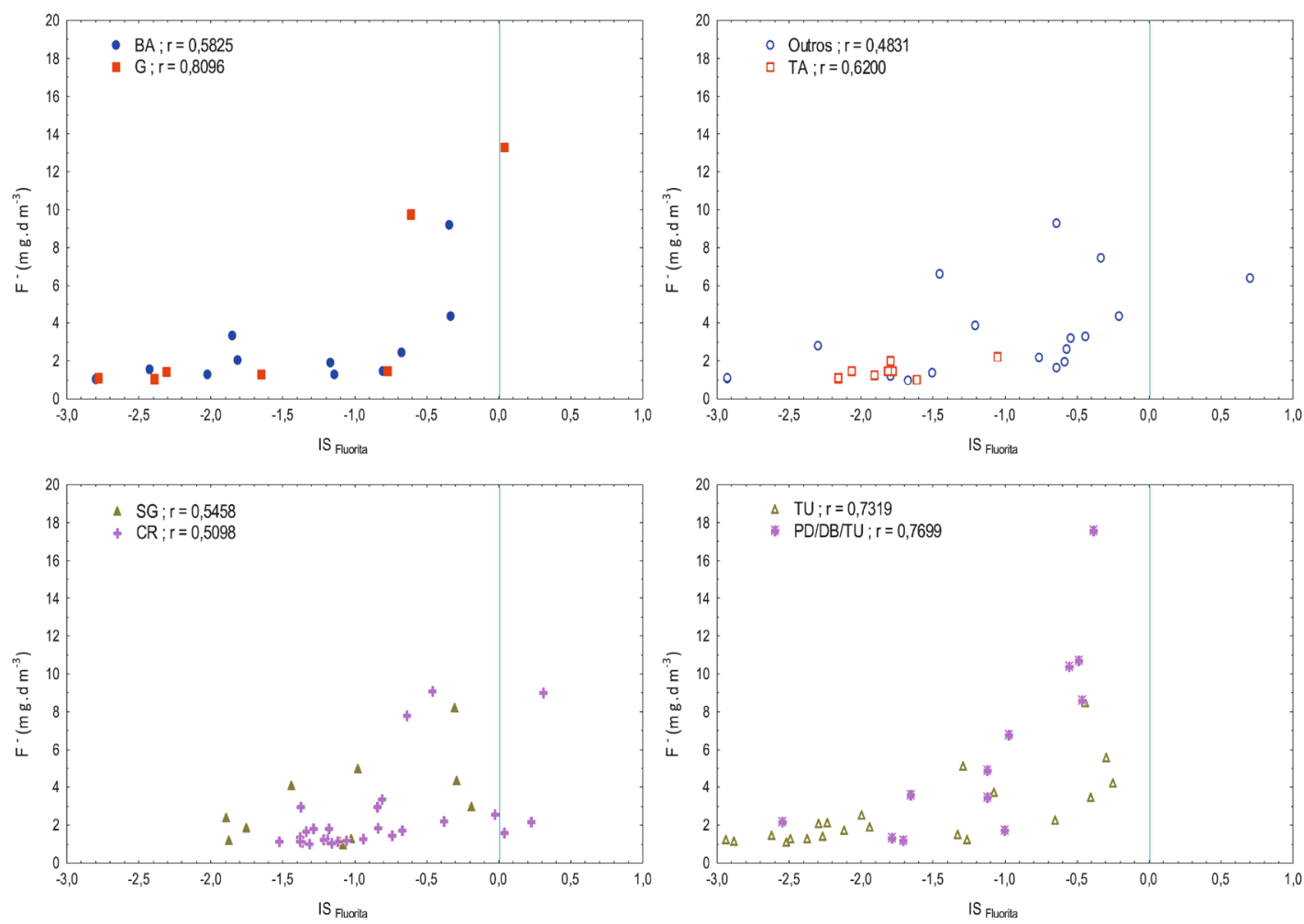

FIGURA 8 - Diagrama de Índice de saturação em fluorita em relação a [F-]. (BA=Bauru; G=Guarani; SG=Serra Geral; $\mathrm{CR}=$ Cristalino; $\mathrm{TA}=$ Taubaté; Outros= Diabásio, poços mistos; $\mathrm{PD}=$ Aquitarde Passa Dois; TU=Tubarão). 

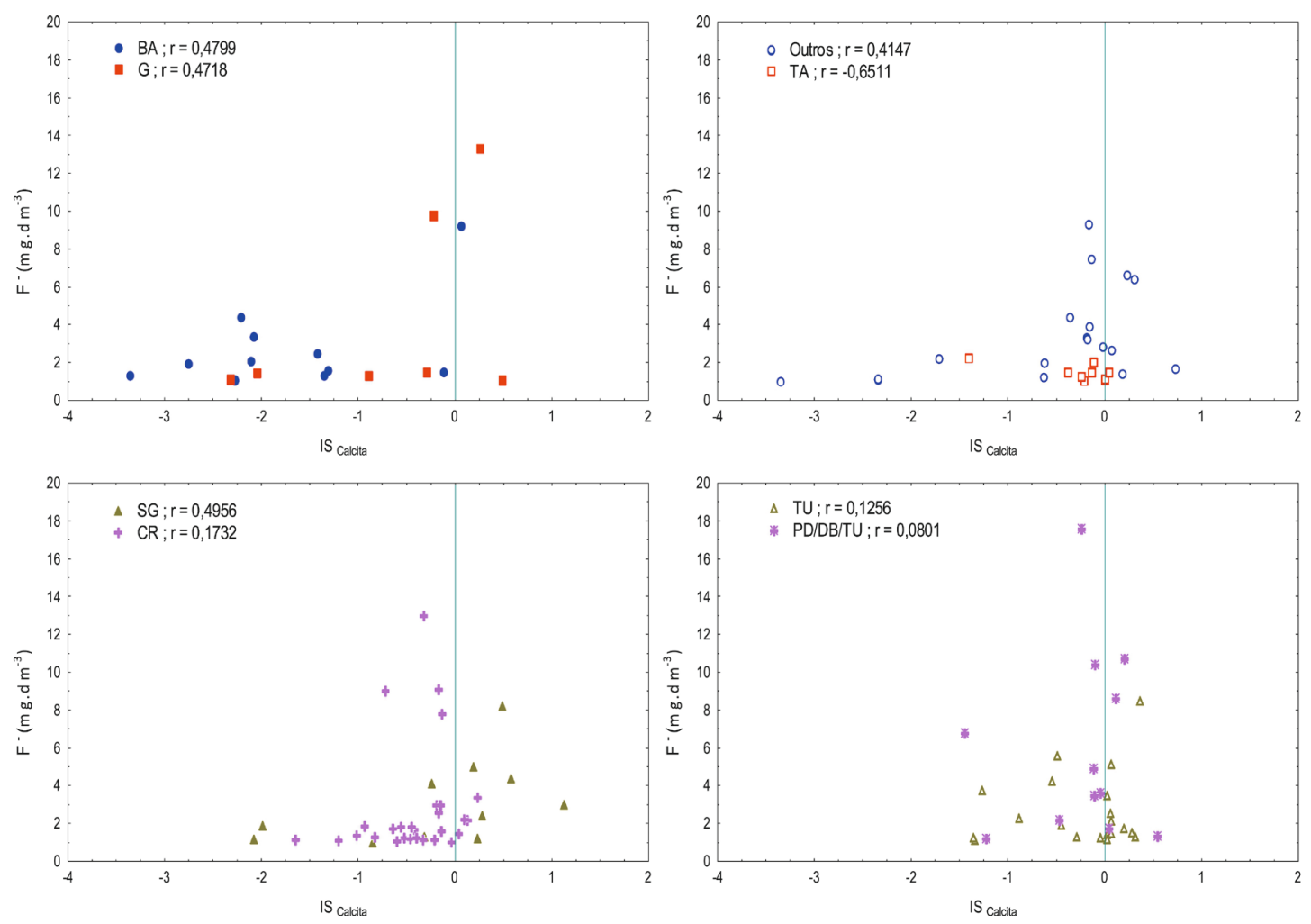

FIGURA 9 - Diagrama de Índice de saturação em calcita em relação a [F- $](B A=B a u r u ; G=$ Guarani; $\mathrm{SG}=\mathrm{Serra}$ Geral; $\mathrm{CR}=$ Cristalino; TA=Taubaté; Outros=Diabásio, poços mistos; $\mathrm{PD}=$ Aquitarde Passa Dois; TU=Tubarão).

Assim, a presença de $\mathrm{F}^{-}$na água é controlada pela solubilidade mineral. Quando $\mathrm{Ca}^{2+}$ é abundante nas águas subterrâneas, a concentração de $\mathrm{F}^{-}$é limitada pela saturação de fluorita. Porém, nos casos onde o teor de $\mathrm{Ca}^{2+}$ é baixo, seja por remoção, troca iônica ou precipitação, a concentração de $\mathrm{F}^{-}$pode aumentar chegando a atingir valores muito altos.

Estudando a alteração de granitos do Aquífero Cristalino em Salto (SP), EZAKI et al. (2016) constataram supersaturação em fluorita no final dos experimentos, sendo o $\mathrm{Ca}^{2+}$ proveniente de alteração de plagioclásio. A liberação progressiva de $\mathrm{F}^{-}$neste estágio final indicou que o $\mathrm{F}^{-}$provinha de contínuo processo de dissolução de biotita. No Aquífero Tubarão, sobrejacente ao Cristalino, a subsaturação em fluorita deve-se às baixas concentrações de flúor das rochas sedimentares, além da remoção de $\mathrm{Ca}^{2+}$ da solução por troca iônica com $\mathrm{Na}^{+}$em argilominerais. Desta forma, a origem do $\mathrm{F}^{-}$estaria associada à alteração de micas e argilominerais.

\section{CONCLUSÃO}

As anomalias de fluoretos ( $\left.\mathrm{F}^{-}\right)$nos aquíferos do estado de São Paulo ocorrem de forma pontual em poços destinados ao abastecimento público ou particular, e estão registradas no cadastro estadual do DAEE (SIDAS) ou em estudos e relatórios técnico-científicos. No entanto, é muito provável que o universo de ocorrências seja maior do que o obtido no levantamento de dados ora apresentado, uma vez que a atividade de perfuração de poços é contínua e progressiva.

Dentre os principais aquíferos do estado, o Guarani é o mais estudado no que se refere à geoquímica do flúor por ser o mais produtivo e explorado. Porém, em relação à frequência e teores em $\mathrm{F}^{-}$também são significativas as ocorrências nos aquíferos Cristalino (Pré-Cambriano), Tubarão e Serra Geral e no Aquitarde Passa Dois.

A origem de $\mathrm{F}^{-}$nos aquíferos pode ser atribuída, em parte, ao enriquecimento de processos hidrotermais pretéritos sobre as formações geológi- 
cas, os quais estão associados a eventos tectônicos de grande extensão e ocasionados pela quebra do supercontinente Gondwana e derrames vulcânicos na Bacia do Paraná. Esses processos teriam formado diversas mineralizações nas rochas pré-cambrianas e basaltos, devido à circulação de soluções magmáticas residuais ricas em flúor, e pela remobilização do flúor contido nas rochas sedimentares percoladas.

A liberação atual e o enriquecimento em $\mathrm{F}$ são atribuídos à interação rocha (mineral)-água sob condições hidroquímicas com $\mathrm{pH}$ neutro a alcalino (7 - 9), em águas tipicamente $\mathrm{Na}-\mathrm{HCO} 3$, pobres em $\mathrm{Ca}^{2+}$ e sob influência da salinidade e da força iônica das soluções.

Os minerais das rochas vulcânicas ou de composição granítica que podem fornecer F- para as águas dos aquíferos fissurais são, principalmente, biotita e anfibólio, onde o $\mathrm{F}^{-}$substitui $\mathrm{OH}^{-}$da estrutura mineral; e, ocasionalmente, fluorita que ocorre tanto em veios de depósitos hidrotermais ou como minerais secundários em fraturas; e apatita. Em aquíferos sedimentares o $\mathrm{F}^{-}$se concentra, principalmente, em argilominerais (illita, muscovita, esmectita, vermiculita, caulinita, entre outros), também substituindo $\mathrm{OH}^{-}$.

Alguns estudos das décadas de 1980 e 1990 já levantavam a hipótese de que a composição química diferenciada das águas dos aquíferos Guarani e Serra Geral estaria associada a alinhamentos tectônicos, de direções NW, NS e EW - respectivamente, correspondentes às drenagens Tietê, $\mathrm{Pa}$ ranapanema e Guapiara -, por onde os fluidos hidrotermais mesozoicos teriam percolado.

No Aquífero Guarani há três hipóteses para a presença de anomalias de $\mathrm{F}^{-}$nas porções confinadas e profundas: 1) contribuição dos diques básicos associados a eventos magmáticos tardios e derrames correspondentes à Formação Serra Geral para o enriquecimento das rochas sedimentares e o semi-confinamento do Guarani; 2) solubilização de precipitados químicos ("crostas salinizadas" de $\mathrm{SO}_{4}{ }^{2-} \mathrm{e} \mathrm{Cl}^{-}$) ricos em flúor formados em clima árido; e, 3) fontes de $\mathrm{F}^{-}$provenientes de rochas pré-Guarani, ou seja, das formações Corumbataí/ Teresina/Irati.

Quanto à ocorrência de $\mathrm{F}^{-}$no Aquífero Serra Geral, as principais hipóteses levantadas estão associadas à: 1) ascensão das águas profundas provenientes do Aquífero Guarani confinado; 2) mineralização da água em fraturas horizontais em profundidade e/ou em zonas vesículo-amigdaloidais que condicionam seu armazenamento; e, 3) alteração de minerais secundários ricos em flúor que pre- enchem fraturas subverticais sob condições geoquímicas características, anteriormente mencionadas.

No Aquífero Tubarão a heterogeneidade litológica influencia a circulação das águas subterrâneas, propiciando maior tempo de interação água-minerais, devido a circulação restrita e existência de porções confinadas, o que pode elevar a salinidade destas águas. Esta condição de escoamento lento e de estagnação de fluxo é mais acentuada no Aquitarde Passa Dois e, desse modo, explica as elevadas condutividades elétricas de suas águas.

Assim, os elevados teores de $\mathrm{F}^{-}$podem estar associados às características intrínsecas de cada unidade litológica e à presença de minerais ricos em flúor. Existe, ainda, a hipótese de estas rochas estarem intensamente recortadas por intrusões magmáticas responsáveis pela circulação de fluidos e, consequentemente, pela mobilização de $\mathrm{F}^{-}$ nos sedimentos.

Por último, nos aquíferos Bauru e Taubaté constatou-se que a ocorrência de $\mathrm{F}^{-}$está associada às condições hidrogeoquímicas similares aos demais, mas ainda há carência e necessidade de estudos sobre sua origem.

\section{AGRADECIMENTOS}

Os autores agradecem à Diretora de Procedimentos de Outorgas do DAEE-Departamento de Águas e Energia Elétrica do Estado de São Paulo, que permitiu a consulta ao banco de dados físicos do SIDAS; ao IPT-Instituto de Pesquisas Tecnológicas pela autorização à consulta do Relatório Técnico $n^{\circ} 24.123$; ao LEBAC-UNESP pelo fornecimento de dados do Projeto "Águas subterrâneas no Estado de São Paulo. Diretrizes de Utilização e Proteção, 2013"; e aos revisores e editores da Revista do IG que muito contribuíram com sugestões e correções deste texto.

\section{REFERÊNCIAS BIBLIOGRÁFICAS}

ABDELRAHMAN, A.M.; WATANABE, K.; TAKEUCHI, S.; MIZUNO, T. 2009. The origin of fluoride-rich groundwater in Mizunami area, Japan - Mineralogy and geochemistry implications. Engineering Geology, 108: 76-85.

ALCHERA, J.R.; SEIXAS, M.E.P.; MORAES, E.B.; SILVA, S.J.A. 1987. Alumina ativada para a desfluoretação de águas. Revista DAE, 47(148): 59-70. 
ALMANN, R.; KORITNIG, S. 1969. Fluorine. In: K.H. Wedepohl (Ed.) Handbook of Geochemistry. Vol II/1. Berlin, SpringerVerlag, p. 9-B - 9-O.

AMPABIRE, W.B.; BOYLE, E.R.; MICHEL, F.A. 1997. Geochemistry, genesis and health implications of fluoriferous groundwaters in the upper regions of Ghana. Environmental Geology, 33(1): 13-24.

BANKS, D.; REIMANN, C.; SKARPHAGEN, H. 1998. The comparative hydrochemistry of two granitic island aquifers: The Isles of Scilly, UK and the Hvaler Islands, Norway. Science of the Total Environment, 209(2-3): 169-183.

BARISON, M.R. 2003. Estudo hidrogeoquímico da porção meridional do Sistema Aquífero Bauru no Estado de São Paulo. Instituto de Geociências e Ciências Exatas, Universidade Estadual Paulista, Rio Claro, Tese de Doutorado, $153 \mathrm{p}$.

BARISON, M.R.; CHANG, H.K. 2004. Parâmetros hidrogeoquímicos regionais do Sistema Aquífero Bauru no Estado de São Paulo. In: ABAS, CONGR. BRAS. ÁGUAS SUBTERRÂNEAS, 13, Cuiabá. Livro de Resumos, 22 p.

BISTRICHI, C.A.; CARNEIRO, C.D.R.; DANTAS, A.S.L.; PONÇANO, W.L.; CAMPANHA, G.C.; NAGATA, N.; ALMEIDA, M.A.; STEIN, D.P.; MELO, M.S.; CREMONINI, O.D. 1981. Mapa Geológico do Estado de São Paulo. IPT, São Paulo, Vol. II, Escala 1:500.000.

BITTENCOURT, A.V.L. 1996. Sobre o controle do quimismo de águas termais da Bacia do Paraná. Boletim Paranaense de Geociências, 44: 117-129.

BONOTTO, D.M. 2006. Hydro(radio)chemical relationships in the giant Guarani aquifer, Brazil. Journal of Hydrology, 323: 353-386.

BONOTTO, D.M. 2012. A comparative study of aquifer systems occurring at the Paraná sedimentary basin, Brazil: major hydrochemical trends. Environmental Earth Sciences, 67: 2285-2300.

BOYLE, D.R. 1992. Effects of base exchange softening on fluoride uptake in groundwaters of the Moncton Sub-Basin, New Brunswick, Canada. In: Kharaka \& Maestt (Eds.) WaterRock Interaction. Rotterdam, Balkema, p. 771-774.

CAMPOS, H.C.N.S. 1987. Contribuição ao estudo hidrogeoquímico do Grupo Bauru no Estado de São Paulo. Instituto de Geociências, Universidade de São Paulo, São Paulo, Dissertação de Mestrado, 58 p.

CAMPOS, H.C.N.S. 1993. Caracterização e cartografia das províncias hidrogeoquímicas do Estado de São Paulo. Instituto de Geociências, Universidade de São Paulo, São Paulo, Tese de Doutorado, $177 \mathrm{p}$.

CAMPOS, H.C.N.S. 2004. Águas subterrâneas na Bacia do Paraná. Geosul, 19(37): 47-65.

CANGUSSU, M.C.T.; NARVAI, P.C.; FERNANDEZ, R.C.; DJEHIZIAN, V. 2002. A fluorose dentária no Brasil: uma revisão crítica. $\mathrm{Ca}$ dernos de Saúde Pública, 18(1): 7-15.

CETESB - COMPAHIA DE TECNOLOGIA DE SANEAMENTO AMBIENTAL. 2004. Relatório de qualidade das águas subterrâneas do Estado de São Paulo 2001-2003. São Paulo: CETESB, 137p. (Série Relatórios/CETESB). Disponível em http://aguassubterraneas.cetesb.sp.gov.br/publicacoes-e-relatorios.

CETESB - COMPAHIA DE TECNOLOGIA DE SANEAMENTO AMBIENTAL. 2007. Relatório de qualidade das águas subterrâneas do Estado de São Paulo 2004-2006. São Paulo: CETESB, 199p. (Série Relatórios/Secretaria do Meio Ambiente). Disponível em http:// aguassubterraneas.cetesb.sp.gov.br/publicacoes-e-relatorios.

CETESB - COMPAHIA AMBIENTAL DO ESTADO DE SÃO PAULO. 2010. Qualidade das águas subterrâneas do Estado de São Paulo 2007-2009. São Paulo: CETESB, 258 p. (Série Relatórios/CETESB). Disponível em http://aguassubterraneas.cetesb.sp.gov. $\mathrm{br} /$ publicacoes-e-relatorios. Acessado em mar. 2016.

CETESB - COMPAHIA AMBIENTAL DO ESTADO DE SÃO PAULO. 2013. Qualidade das águas subterrâneas do Estado de São Paulo 2010-2012. São Paulo: CETESB, 
242 p. (Série Relatórios). Disponível em http://aguassubterraneas.cetesb.sp.gov.br/ publicacoes-e-relatorios.

CETESB - COMPAHIA AMBIENTAL DO ESTADO DE SÃO PAULO. 2016. Qualidade das águas subterrâneas do Estado de São Paulo 2013-2015. Série Relatórios. São Paulo, CETESB, 308 p. Disponível em: http:// aguassubterraneas.cetesb.sp.gov.br/publicacoes-e-relatorios.

CHAE, G.T.; YUN, S.T; KWON, M.J.; KIM, Y.S.; MAYER, B. 2006. Batch dissolution of granite and biotite in water: Implication for fluorine geochemistry in groundwater. Geochemical Journal, 40(1): 95-102.

CHAE, G.T.; YUN, S.T.; MAYER, B.; KIM, K.H.; KIM, S.Y.; KWON, J.K.; KIM, K.; KOH, Y. 2007. Fluorine geochemistry in bedrock groundwater of South Korea. Science of the Total Environment, 385: 272-283.

DAEE - DEPARTAMENTO DE ÁGUAS E ENERGIA ELÉTRICA. 1974. Estudo de águas subterrâneas - Região Administrativa 6 - Ribeirão Preto. São Paulo: DAEE, 4 v.

DAEE - DEPARTAMENTO DE ÁGUAS E ENERGIA ELÉTRICA. 1975. Estudo de Águas Subterrâneas - Região Administrativa 1 - Grande São Paulo. São Paulo: DAEE, 3 v.

DAEE - DEPARTAMENTO DE ÁGUAS E ENERGIA ELÉTRICA. 1976. Estudo de Águas Subterrâneas - Regiões Administrativas 7, 8, 9 - Bauru, São José do Rio Preto, Araçatuba. São Paulo: DAEE, v. 1 e 2.

DAEE - DEPARTAMENTO DE ÁGUAS E ENERGIA ELÉTRICA. 1977. Estudo de Águas Subterrâneas - Região Administrativa 3 - São José dos Campos. São Paulo: DAEE, v. 1 e 3 .

DAEE - DEPARTAMENTO DE ÁGUAS E ENERGIA ELÉTRICA. 1979a. Estudo de águas subterrâneas, Região Administrativa 2 - Santos. São Paulo: DAEE, 2 v.

DAEE - DEPARTAMENTO DE ÁGUAS E ENERGIA ELÉTRICA. 1979b. Estudo de Águas Subterrâneas - Regiões Administrativas 10 e 11 - Presidente Prudente e Marilia. São Paulo: DAEE, v.1 e 2.
DAEE - DEPARTAMENTO DE ÁGUAS E ENERGIA ELÉTRICA. 1981. Estudo de Águas Subterrâneas. Região Administrativa 5. Campinas. São Paulo, DAEE, 2 v.

DAEE - DEPARTAMENTO DE ÁGUAS E ENERGIA ELÉTRICA. 1982. Estudo de Águas Subterrâneas. Região Administrativa 4. Sorocaba. São Paulo, DAEE, 2 v.

DAEE/IG/IPT/CPRM - DEPARTAMENTO DE ÁGUAS E ENERGIA ELÉTRICA/ INSTITUTO GEOLÓGICO/ INSTITUTO DE PESQUISAS TECNOLÓGICAS/ SERVIÇO GEOLÓGICO DO BRASIL. 2005. Mapa de Águas Subterrâneas do Estado de São Paulo, escala 1:1.000.000. Nota explicativa. DAEE/ IG/IPT/CPRM/, São Paulo, 3 v. (mapa e CDROM).

DAEE/UNESP - DEPARTAMENTO DE ÁGUAS E ENERGIA ELÉTRICA/ UNIVERSIDADE ESTADUAL PAULISTA. 2013. Águas subterrâneas no Estado de São Paulo. Diretrizes de Utilização e Proteção. São Paulo, DAEE/LEBAC - Instituto Geociências e Ciências Exatas da UNESP, Laboratório de Estudo de Bacias, $44 \mathrm{p}$.

DINIZ, H.N. 1990. Estudo hidrogeológico do Subgrupo Itararé no Médio Rio Tietê, Município de Tietê, SP. Instituto de Geociências, Universidade de São Paulo, São Paulo, Dissertação de Mestrado, 118 p.

DINIZ, H.N.; MAGACHO, M.R.; AZEVEDO, A.A.B.; MATTOS, F.; CANAVER, L.S. 2006. Concentração de fluoretos nas águas dos poços profundos da cidade de Lorena e prevalência de fluorose dentária. In: ABAS, CONGRESSO BRASILEIRO DE ÁGUAS SUBTERRÂNEAS, 4, Curitiba, $20 \mathrm{p}$.

DIOGO, A.; BERTACHINI, A.C.; CAMPOS, H.C.N.S.; SILVA, R.B.G. 1981. Estudo preliminar das características hidráulicas e hidroquímicas do Grupo Tubarão no Estado de São Paulo. In: SBG, SIMPÓSIO REGIONAL DE GEOLOGIA, 3, Curitiba, Atas, v.1, p. 359-368.

EDGAR, A.D.; ARIMA, M. 1985. Fluorine and chlorine contents of phlogopites crystallized from ultrapotassic rock compositions in high pressure experiments: implications 
for halogen reservoirs in source regions. American Mineralogist, 70: 529-536.

EDMUNDS, W.M.; SMEDLEY, P.L. 2005. Fluoride in natural waters. In: Essentials of medical geology: the impacts of natural environment on public health. Amsterdam, Elsevier, p. 301-309.

EDMUNDS, W.M; SMEDLEY, P.L. 2013. Chapter 12: Fluoride in natural waters. In: O. Selinus, B. Alloway, J. A. Centeno, R. B. Finkelman, R. Fuge, U. Lindho and P. L. Smedley (Eds.) Essentials of Medical Geology. Impacts of the natural environment on Public Health. New York, Elsevier Academic Press, British Geological Survey.

EZAKI, S. 2011. Hidrogeoquímica dos Aquíferos Tubarão e Cristalino na Região de Salto (SP). Instituto de Geociências, Universidade de São Paulo, São Paulo, Tese de Doutorado, $180 \mathrm{p}$.

EZAKI, S.; HYPOLITO, R.; PÉREZAGUILAR, A. 2016. Experimental fluorine liberation from Precambrian granites and Carboniferous-Permian sedimentary rocks associated with crystalline and sedimentary aquifers, Paraná Basin, southeastern Brazil. Geochemical Journal, 50(5): 379-392.

FLORÊNCIO, R.V.S. 2000. As argilas do Subgrupo Itararé: potencialidades como matérias primas cerâmicas e como inertizadoras de resíduos industriais. Instituto de Geociências, Universidade de São Paulo, São Paulo, Tese de Doutorado, 184 p.

FRAGA, C.G. 1992. Origem de Fluoreto em águas subterrâneas dos sistemas aquíferos Botucatu e Serra Geral da Bacia do Paraná. Instituto de Geociências, Universidade de São Paulo, São Paulo, Tese de Doutorado, 178 p.

FRANK, H.T.; GOMES, M.E.B.; FORMOSO, M.L.L.; GARCIA, G.G. 2008. Contaminação de flúor dos aquíferos da Bacia do Paraná derivada da desgaseificação de intrusivas da Formação Serra Geral: nova hipótese. In: $A B A S$, ENCONTRO NACIONAL DE PERFURADORES DE POÇOS, 15 / I SIMPÓSIO DE HIDROGEOLOGIA DO SUL-SUDESTE, Natal, Anais, CD-ROM.
FRAZÃO, P.; PERES, M.A.; CURY, J.A. 2011. Qualidade da água para consumo humano e concentração de fluoreto. Revista de Saúde Pública, 45(5): 964-973.

GALEMBECK, T.M.B 1997. O Complexo Múltiplo, Centro e Plurisserial Itu-SP. Instituto de Geociências e Ciências Exatas, UNESP, Rio Claro, Tese de Doutorado, 374 p.

GARCEZ, L.L.; SANT'AGOSTINHO, L.M.; MOTTA, J.F.M. 2003. A presença de flúor nos siltitos da Formação Corumbataí e o impacto ambiental causado por sua liberação durante o processo produtivo de revestimentos cerâmicos na região de Santa Gertrudes SP. Instituto de Geociências, Universidade de São Paulo, São Paulo, Monografia de Trabalho de Conclusão de Curso, 54 p.

GARICI, S.J.; DAVIES, T.C. 1993. The occurrence and geochemistry of fluoride in some natural waters of Kenya. Journal of Hydrology, 143(3-4): 395-412.

GASCOYNE, M. 2004. Hydrogeochemistry, groundwater ages and sources of salts in a granitic batholith on the Canadian Shield, southeastern Manitoba. Applied Geochemistry, 19: 519-560.

GASTMANS, D.; VEROSLAVSKY, G.; CHANG, H.K.; CAETANO-CHANG, M.R.; PRESSINOTTI, M.M.N. 2012. Modelo hidrogeológico conceptual del Sistema Acuífero Guarani (SAG): uma herramienta para la gestión. Boletín Geológico y Minero, 123 (3): 249-265.

GENXU, W.; GUODONG, C. 2001. Fluoride distribution in water and governing factors of environment in arid north-west China. Journal of Arid Environments, 49: 601-604.

GIAMPÁ, C.E.Q.; BRUNO, C.R.M.; SOUZA, J.C. 1981. Água subterrânea das formações Bauru e Serra Geral no Estado de São Paulo. Constatações práticas. Revista Águas Subterrâneas, 4: 17-24.

GIAMPÁ, C.E.Q.; FRANCO FILHO, R.W.B. 1982. Modo de ocorrência dos fluoretos nas águas subterrâneas da Formação Serra Geral, constatação em Santa Albertina - São Paulo. In: ABAS, CONGRESSO BRASILEIRO 
DE ÁGUA SUBTERRÂNEAS, 2, Salvador, Anais, p. 299-304

GOFFERMANN, M.; VIERO, A.P.; SILVA, E.B. 2015. Caracterização hidrogeológica e hidroquímica das águas subterrâneas da região de São Gabriel, RS. Pesquisas em Geociências, 42(3): 239-261.

GUO, L.; WANG, Y.; MA, T.; MA, R. 2007. Geochemical processes controlling the elevated fluoride concentrations in groundwaters of the Taiyuan Basin, Northern China. Journal of Geochemical Exploration, 93: 1-12.

GUPTA, A.K.; AYOOB, S. 2016. Fluoride in Drinking Water. Status, Issues, and Solutions. CRC Press, Boca Raton, 188 p.

HEM, J.D.H. 1968. Graphical methods for studies of aqueous aluminium hydroxide, fluoride and sulfate complexes. U.S. Geological Survey Water Supply - Paper 1827-B, 33 p.

HEM, J.D.H. 1985. Study and Interpretation of the Chemical Characteristics of Natural Water.3rd Ed. U.S. Geological Survey WaterSupply, Paper 2254. USGS - Department of the Interior, United States Government Printing Office.

HYPOLITO, R.; EZAKI, S.; PÉREZ-AGUILAR, A. 2010. Fluoreto nas águas subterrâneas dos aquíferos Tubarão e Cristalino, região de Salto-Indaiatuba (SP). Revista Escola de Minas, 63(4): 715-726.

KERN, M.L; VIEIRO, A.P.; MACHADO, G. 2007. The fluoride in the groundwater of Guarani Aquifer System: the origin associated with black shales of Paraná Basin. Environmental Geology, 55(6): 1219-1233.

KIANG, C.H.; STRADIOTO, M.R.; PAULA E SILVA, F.P. 2016. Tipos hidroquímicos do Sistema Aquífero Bauru no Estado de São Paulo. Revista Águas Subterrâneas, 30(2): 224-245.

KIM, K.; JEONG, GI Y. 2005. Factors influencing natural occurrence of fluoride-rich groundwaters: a case study in the southeastern part of the Korean Peninsula. Chemosphere, 58: 1399-1408.
KIMMELMANN, A.A.; SILVA, R.B.F.; REBOUÇAS, A.C.; SANTIAGO, M.M.F. 1986. Hidrologia isotópica e química do Aquífero Botucatu-Bacia do Paraná - Brasil. In: ABAS, CONGRESSO BRASILEIRO DE ÁGUAS SUBTERRÂNEAS, 4, Brasília, Anais, p. 1-25.

KIMMELMANN E SILVA, A.A.; REBOUÇAS, A.C.; SANTIAGO, M.M.F; SILVA, R.B.G. 1989a. Isotopic study of the Botucatu Aquifer System in the brazilian portion of the Paraná Basin. In: IAEA, Reginal Seminar for Latin America, Isotope Hydrology Investigations in Latin America, Vienna, Proceedings.

KIMMELMANN E SILVA, A.A.; REBOUÇAS, A.C.; SANTIAGO, M.M.F. 1989b. 14C analysis of groundwater from the Botucatu Aquifer system in Brazil. Radiocarbon, 31: 926-933.

KUHN, R. 1968. Geochemistry of German Potash Deposits. Geological Society of America Special Papers, 88: 427-504.

KUNDU, N.; PANIGRAHI, M.K.; TRIPATHY, S.; MUNSHI, S.; POWELL, M.A.; HART, B.R. 2001. Geochemical appraisal of fluoride contamination of groundwater in the Nayagarh District of Orissa, India Environmental Geology, 41: 451-460.

LICHT, A.O.B. 2001. A geoquímica multielementar na gestão ambiental - identificação e caracterização de províncias geoquímicas naturais, alterações antrópicas da paisagem, áreas favoráveis à prospecção mineral e regiões de risco para a saúde no Estado do Paraná, Brasil. Universidade Federal do Paraná, Curitiba, Tese de Doutorado, 236 p.

MANZANO, M.Y; GUIMARAENS, M. 2012. Hidroquímica del Sistema Acuífero Guaraní e implicaciones para la gestión. Boletín Geológico y Minero, 123(3): 281-295.

MARIMON, M.P.C. 2006. O Flúor nas Águas Subterrâneas da Formação Santa Maria, na Região de Santa Cruz do Sul e Venâncio Aires, RS, Brasil. Instituto de Geociências da Universidade Federal do Rio Grande do Sul, Porto Alegre, Tese de Doutorado, 165 p.

MARIMON, M.P.C.; KNOLLER, K.; ROISENBERG, A. 2009. Anomalous 
fluoride concentration in groundwater - is it natural or pollution? A stable isotope approach. Isotopes in Environmental and Health Studies, 43(2): 165-175.

MARIMON, M.P.C.; ROISENBERG, A.; SUHOGUSOFF, A.V.; VIERO, A.P. 2013. Hydrogeochemistry and statistical analysis applied to understand fluoride provenance in the Guarani Aquifer System, Southern Brazil. Environmental Geochemistry and Health, 35: 391-403.

MENG, S.X.; MAYNARD, J.B. 2001. Use of statistical analysis to formulate conceptual models of geochemical behavior: water chemical data from the Botucatu aquifer in São Paulo State, Brazil. Journal of Hydrology, 250: 78-97.

NANNI, A.S. 2008. O flúor em águas do Sistema Aquífero Serra Geral no Rio Grande do Sul: origem e condicionamento geológico. Instituto de Geociências, Universidade do Rio Grande do Sul, Porto Alegre, Tese de Doutorado, $127 \mathrm{p}$.

NANNI, A.S.; ROISENBERG, A.; FACHEL, J.M.G.; MESQUITA, G.; DANIELI, C. 2008. Fluoride characterization by principal component analysis in the hydrochemical facies of Serra Geral Aquifer System in Southern Brazil. Anais da Academia Brasileira de Ciências, 80(4): 693-701.

NARVAI, P.C. 2000. Cárie dental e flúor: Uma relação do séc. XX. Ciência e Saúde Coletiva, ABRASCO, Rio de Janeiro, 5: 183-189.

NARVAI, P.C. 2001. Vigilância sanitária da fluoretação das águas de abastecimento público no Município de São Paulo, Brasil, no período de 1990-1999. Faculdade de Saúde Púbica, Universidade de São Paulo, São Paulo, Tese de Livre Docência, 166 p.

OZSVATH, D.L. 2006. Fluoride concentrations in crystalline bedrock aquifer Marathon County, Wisconsin. Environmental Geology, 50: 132-138.

PACHECO, D.F. 2009. Estudo hidrogeoquímico do flúor em aquífero da região da Barra Funda, São Paulo. Instituto de Geociências da Universidade de São Paulo, São Paulo, Monografia de Trabalho de Formatura, 53 p.
PARKHURST, D.L.; APPELO, C.A.J. 1999. User's Guide to PHREEQC (Version 2): a Computer Program for Speciation, Bath-reaction, One-dimensional Transport, and Inverse Geochemical Calculations. US Geology Survey Water Resource Investigation Report.

PERRONI, J.C.A.; SILVA, R.B.G.; HIRATA, R.C.; DOZZI, L.F.S. 1985. Ocorrências de fluoretos nos aquíferos da Bacia do Paraná do Estado de São Paulo. In: SBG, SIMPÓSIO REGIONAL DE GEOLOGIA, 5, São Paulo, Anais, vol. 2, p. 503-514.

PERRONI, J.C.A.; DOZZI, L.F.S.; FRASCÁ, M.H.B.O.; HIRATA, R.; SILVA, R.B.G. 1986. Estudo de teores anômalos de fluoretos em águas dos Aquíferos Botucatu e Serra Geral no Estado de São Paulo. Primeira etapa do trabalho: Análise dos dados disponíveis. IPT, São Paulo. Relatório No 24.123, 2 v., 128 p.

PERROTA, M.M.; SALVADOR, E.D.; LOPES, R.C.; D'AGOSTINHO, L.Z.; PERRUFO, N.; GOMES, S.D.; SACHS, L.L.B.; MEIRA, V.T.; GARCIA, M.G.M; LACERDA FILHO, J.V. 2005. Mapa Geológico do Estado de São Paulo, escala 1:750.000. Programa Levantamentos Geológicos Básicos do Brasil, CPRM, São Paulo.

PETRI, S.; PIRES, F.A. 1992. O Subgrupo Itararé (Permocarbonífero) na região do Médio Tietê, Estado de São Paulo. Revista Brasileira de Geociências, 22(3): 301-310.

PINHEIRO, C.E.; CARVALHO, A.C.; VONO, B.G.; ZARAMELLA, A. 1965. Estudo Preliminar sobre o teor de flúor das águas da Região de Pereiras (SP). Revista do Instituto de Medicina Tropical de São Paulo, 1: 228-232.

PINO, D.S. 2009. Estudos de isótopos de estrôncio, oxigênio e hidrogênio em um caso de contaminação de flúor no Município de São Paulo. Instituto de Geociências, Universidade de São Paulo, São Paulo, Monografia de Trabalho de Formatura, 117 p.

RAMIRES, I.; BUZALAF, M.A.R. 2007. A fluoretação da água de abastecimento público e seus benefícios no controle da cárie dentária - cinquenta anos no Brasil. Ciência \& Saúde Coletiva, 12(4): 1057-1065. 
RIBEIRO, R.G. 1992. Contribuição ao estudo do fluoreto nas águas subterrâneas da Bacia do Médio-Tietê (Região de Piracicaba) - Caracterização e Metodologias propostas para sua extração. Instituto de Geociências, Universidade de São Paulo, São Paulo, Dissertação de Mestrado, $151 \mathrm{p}$.

ROCHA, G.; FERNANDES, A.J.; MANCUSO, M.A.; CAMPOS, J.E.; TAKAHASHI, A.T.; ODA, G.H.; PERROTTA, M.M.; SALVADOR, E.D.; ALBUQUERQUE FILHO, J.L; GIMENEZ FILHO, A.; AZEVEDO, S.G.; DENSER, M.; PIZZATTO, L.G.; PAULON, N. 2006. Mapa de Águas Subterrâneas do Estado de São Paulo. In: ABAS, CONGRESSO BRASILEIRO DE ÁGUAS SUBTERRÂNEAS, 14, Curitiba, Livro de Resumos, 20 p.

ROISENBERG, C.; VIERO, P.V.; ROISENBERG, A.; SCHWARTBACH, M.S.R.; MORANTE, I.C. 2003. Caracterização geoquímica gênese dos principais íons das águas subterrâneas de Porto Alegre, RS. Revista Brasileira de Recursos Hídricos, 8(4): 137-1347.

SALLUN, A.E.M.; DINIZ, H.N. 2016. Anomalia natural de bário, flúor e enxofre em rochas sedimentares da Formação Tremembé, Bacia de Taubaté (SP, Brasil). Geociências, 35(1): 31-46.

SALVETTI, R.A.P. 2005. Sistemas Deposicionais e Paleogeografia do Subgrupo Itararé (Neopaleozóico da Bacia do Paraná), na Região entre Itu e Indaiatuba, SP. Instituto de Geociências, Universidade de São Paulo, São Paulo, Dissertação de Mestrado, 100 p.

SANTIAGO, M.R. 2010. Análise das ocorrências anômalas de fluoreto em águas subterrâneas. Centro de Ciências Tecnológicas, Universidade Federal de Santa Maria, Santa Maria, Dissertação de Mestrado, 102 p.

SANTOS, P.R. 1996. Condicionamento geológico da sedimentação glacial: o Neopaleozóico da Bacia do Paraná e o Terciário da Antártida. Instituto de Geociências, Universidade de São Paulo, São Paulo, Tese de Livre Docência, $111 \mathrm{p}$.

SÃO PAULO. SECRETARIA DA SAÚDE DO ESTADO DE SÃO PAULO. 1995. Resolução
SS-250, de 15/08/1995. Diário Oficial do Estado de São Paulo, 16 ago.1995.

SAVI, C.N. 1980. Gênese e controle das mineralizações de fluorita da região de Criciúma-SC. Instituto de Geociências da Universidade de Brasília, Brasília, Dissertação de Mestrado, $112 \mathrm{p}$.

SAXENA, V.K.; AHMED, S. 2001. Dissolution of fluoride in groundwater: a water-rock interaction study. Environmental Geology, 40: 1084-1087.

SAXENA, V.K., AHMED, S. 2003. Inferring the chemical parameters for the dissolution of fluoride in groundwater. Environmental Geology, 43: 731-736.

SILVA, R.B.G. 1983. Estudo hidroquímico e isotópico das águas subterrâneas do Aquífero Botucatu no Estado de São Paulo. Instituto de Geociências, Universidade de São Paulo, São Paulo, Tese de Doutorado, 133 p.

SILVA, R.B.G.; DIOGO, A. 1982. Características hidroquímicas do Aquífero Botucatu no Estado de São Paulo. In: ABAS, CONGRESSO BRASILEIRO DE ÁGUAS SUBTERRÂNEAS, 2, Salvador, Anais, p. 411-420.

SILVÉRIO DA SILVA, J.L.; HIRATA, R.C.A.; FLORES, E.L.M.; DRESSLER, V.L. 2002. Novas hipóteses sobre a origem do flúor no Sistema Aquífero Guarani na Depressão Central Gaúcha, Brasil. In: ABAS, CONGRESSO BRASILEIRO DE ÁGUAS SUBTERRÂNEAS, 12, Florianópolis, Anais, CD-ROM, $21 \mathrm{p}$.

SPILLER, L.E. 2005. Estruturas armazenadoras e qualidade das águas subterrâneas do Aquífero Serra Geral em São Paulo. In: ABAS, ENCONTRO NACIONAL DE PERFURADORES DE POÇOS, 14 / SIMPÓSIO DE HIDROGEOLOGIA DO SUDESTE, 2, São Paulo, 18 p.

SRACEK, O.; HIRATA, R. 2002. Geochemical and stable isotopic evolution of the Guarani Aquifer System in the State of São Paulo, Brazil. Hydrogeology Journal, 10: 643-655.

STRÜBEL, G. 1965. Quantitative Untersuchungen über die hydrothermale Loslichkeit von 
FluBspat $\left.\mathrm{CaF}_{2}\right)$. Neues Jahrbuch für Mineralogie-Monatshefte, 3: 83-95.

SZIKSZAY, M.; TEISSEDRE, J.M.; BARNER, U.; MATSUI, E. 1981.Geochemical and isotopic characteristics of spring and groundwater in the state of São Paulo, Brazil. Journal of Hydrology, 54(1): 23-32.

UCHOA, H.W.; SALIBA, N.A. 1970. Prevalência de fluorose dental na cidade de Pereira Barreto. Boletim do Serviço Odontologia Sanitária, 6 (3): 11-6.

USEPA - UNITED STATES ENVIRONEMNTAL PROTECTION AGENCY. 2016. Regional Screening Levels (RSLs) - Generic Tables (May 2016) - Resident Soil Table. Technical Background Document. EPA US Environmental Protection Agency. Disponível em https://www.epa.gov/risk/ regional-screening-levels-rsls-users-guidemay-2016. Acessado em 20 jun. 2016.

VIDAL, A.C. 1997. Caracterização hidrogeoquímica dos compartimentos estruturais da Bacia de Taubaté. Instituto de Geociências, UNICAMP, Campinas, Dissertação de Mestrado, $128 \mathrm{p}$.
VIDAL, A.C. 2002. Estudo hidrogeológico do Aquífero Tubarão na área de afloramento da porção central do Estado de São Paulo. Instituto de Geociências e Ciências Exatas, UNESP, Rio Claro, Tese de Doutorado, 109 p.

VIDAL, A.C.; KIANG, C.H. 2002. Caracterização hidroquímica dos aquíferos da Bacia de Taubaté. Revista Brasileira de Geociências, 32(2): 26-276.

VIERO, A.P.; ROISENBERG, C.; ROISENBERG, A.; VIGO, A. 2009. The origin of fluoride in the granitic aquifer of Porto Alegre, Southern Brazil. Environmental Geology, 56: 17071719.

WHO - WORLD HEATH ORGANIZATION. 2006. Fluoride in Drinking-water. Guidelines for Drinking-water Quality. Geneva, World Health Organization.

ZALÁN, P.V; WOLF, S.; CONCEIÇÃO, J.C.J.; ASTOLFI, M.A.M.; VIEIRA, I.S.; APPI, V.T.; ZANOTTO, O.A.; MARQUES, A. 1991. Tectonics and sedimentation of the Paraná Basin. In: Ulbrich, H., Rocha Campos, A.C. (Eds.) Gondwana Seven. Proceedings, São Paulo, p. 83-117.

\section{Endereço dos autores:}

Sibele Ezaki e Annabel Pérez-Aguilar - Instituto Geológico, Rua Joaquim Távora, 822, CEP 04015-011, São Paulo, SP, Brasil.E-mail: sibezaki@gmail.com; annabel.perez.aguilar@gmail.com

Raphael Hypolito - Instituto de Geociências, Universidade de São Paulo, CEPAS, Laboratório de Hidrogeoquímica III. Rua do Lago, 562, CEP 05508-080, Cidade Universitária, São Paulo, SP, Brasil. E-mail:rhypo@usp.br

Mirian Chieko Shinzato - Instituto de Ciências Ambientais, Químicas e Farmacêuticas da Universidade Federal de São Paulo, Rua São Nicolau, 210, CEP09913-030, Diadema, SP, Brasil.E-mail: mirianshinzato@, hotmail.com

Artigo submetido em 27 de julho de 2016, aceito em 20 de novembro de 2016. 
APÊNDICE 1 - Relação de poços tubulares com concentrações de $\mathrm{F}^{-}$superiores a $1,0 \mathrm{mg} \mathrm{dm}^{-3}$ no Estado de São Paulo.

\begin{tabular}{|c|c|c|c|c|c|c|c|c|c|c|}
\hline$N^{o}$ & $\begin{array}{l}\text { Identificação } \\
\text { no estudo }\end{array}$ & $N^{o} D A E E$ & Municipio & Coord E & Coord N & Aquifero & $\begin{array}{l}\text { Prof. } \\
\text { (m) }\end{array}$ & $\begin{array}{c}\text { Data da } \\
\text { Coleta }\end{array}$ & $\begin{array}{c}F^{-} \\
\left(m g d m^{-3}\right)\end{array}$ & Fonte \\
\hline 1 & & $172 / 006$ & Águas da Prata & $-46,71$ & $-21,95$ & $\mathrm{CR}$ & & $24 / 04 / 2002$ & 1,59 & 24 \\
\hline 2 & 1065 & & Americana & $-47,33$ & $-22,75$ & $\mathrm{TU}^{*}$ & & & 1,28 & 17 \\
\hline 3 & BA0226P & & Américo Campos & $-49,72$ & $-20,30$ & $\mathrm{BA}$ & & set $/ 12$ & 1,57 & 16 \\
\hline 4 & $152 \mathrm{P}$ & & Amparo & $-46,73$ & $-22,29$ & $\mathrm{CR}$ & 121 & out $/ 10$ & 13,00 & 16 \\
\hline 5 & BO-159 & & Andradina & $-51,37$ & $-20,89$ & BA & & & 3,35 & 23 \\
\hline 6 & 1292 & $336 / 002$ & Angatuba & $-48,31$ & $-23,56$ & $\mathrm{PD} / \mathrm{DB}$ & 203 & $14 / 01 / 1981$ & 1,35 & 10,12 \\
\hline $7 *$ & 15 & $273 / 003$ & Anhembi & $-48,17$ & $-22,76$ & $\mathrm{PD}$ & 300 & $10 / 03 / 1981$ & 10,40 & 24 \\
\hline 8 & & $030 / 017$ & Aparecida Deste & $-50,90$ & $-20,47$ & $\mathrm{BA}$ & & $07 / 10 / 2003$ & 1,10 & 23 \\
\hline 9 & BO-140 & & Apiai & $-48,93$ & $-24,45$ & $\mathrm{CR}$ & & & 1,75 & 24 \\
\hline 10 & & 090/010 & Araçatuba & $-50,47$ & $-21,14$ & $\mathrm{BA}^{* *}$ & & $06 / 09 / 2000$ & 2,20 & 6 \\
\hline 11 & 70 & $339 / 008$ & Araçoiaba da Serra & $-47,62$ & $-23,51$ & $\mathrm{TU}$ & 154 & $14 / 01 / 1981$ & 1,34 & 5 \\
\hline 12 & 49 & $220 / 022$ & Araras & $-47,24$ & $-22,38$ & CEN/TU & 133 & $04 / 02 / 1980$ & 2,70 & 5 \\
\hline 13 & 44 & $219 / 015$ & Araras & $-47,37$ & $-22,42$ & TU/DB** & 264 & $04 / 02 / 1980$ & 1,08 & 10,12 \\
\hline 14 & 725 & $163 / 007$ & Arealva & $-48,90$ & $-21,94$ & SG & 364 & $21 / 02 / 1979$ & 3,00 & 23 \\
\hline 15 & 63 & & Atibaia & $-46,57$ & $-23,05$ & $\mathrm{CR}$ & & 29/07/2009 & 1,26 & 10,11 \\
\hline 16 & 138 & $058 / 021$ & Barretos & $-48,54$ & $-20,56$ & $\mathrm{BA}$ & 720 & 01/06/1977 & 1,50 & 24 \\
\hline 17 & & $058 / 013$ & Barretos & $-48,56$ & $-20,57$ & $\mathrm{BA}$ & & $01 / 04 / 2000$ & 1,50 & 12 \\
\hline 18 & 1310 & $342 / 921$ & Barueri & $-46,86$ & $-23,52$ & $\mathrm{CR}$ & 250 & $08 / 05 / 1975$ & 2,10 & 23 \\
\hline 19 & BO-170 & & Birigui & $-50,36$ & $-21,30$ & $\mathrm{BA}$ & 120 & & 1,06 & 16 \\
\hline 20 & PC234P & & Biritiba Mirin & $-46,04$ & $-23,57$ & $\mathrm{CR}$ & $140 ?$ & $a b r / 10$ & 1,10 & 10 \\
\hline $21 *$ & 25 & $297 / 006$ & Bofete & $-48,30$ & $-23,20$ & PD & 450 & $10 / 03 / 1981$ & 17,60 & 12 \\
\hline 22 & 142 & $138 / 005$ & Borborema & $-49,08$ & $-21,62$ & SG & 180 & $\mathrm{jul} / 81$ & 4,11 & 12 \\
\hline 23 & 338 & 091/011 & Brejo Alegre/ Glicério & $-50,18$ & $-21,17$ & SG & 210 & 09/03/1979 & 5,00 & 12 \\
\hline 24 & 1220 & $307 / 059$ & Caçapava & $-45,71$ & $-23,11$ & TA & 150 & $12 / 08 / 1976$ & 1,00 & 17 \\
\hline 25 & 1221 & $307 / 063$ & Caçapava & $-45,72$ & $-23,17$ & TA & 150 & $14 / 09 / 1979$ & 1,36 & 13 \\
\hline 26 & cp20 & & Caçapava & $-45,69$ & $-23,10$ & TA & 220 & $27 / 03 / 1996$ & 1,02 & 5,17 \\
\hline 27 & 23 & & Cajobi & $-49,80$ & $-20,84$ & BA & 126 & $01 / 03 / 2001$ & 1,14 & 11 \\
\hline 28 & 84 & $277 / 060$ & Campinas & $-47,12$ & $-22,84$ & $\mathrm{CR} / \mathrm{TU}$ & 141 & $22 / 01 / 1981$ & 3,90 & 16 \\
\hline 29 & & $302 / 278$ & Campo Limpo & $-46,78$ & $-23,21$ & $\mathrm{CR}$ & & & 2,50 & 22 \\
\hline 30 & 25 & & Capela do alto & $-47,75$ & $-23,46$ & $\mathrm{TU}$ & 390 & out $/ 10$ & 1,42 & 12 \\
\hline 31 & 1675 & & Capivari & $-47,50$ & $-23,02$ & TU & 301 & $10 / 09 / 2009$ & 1,54 & 6,17 \\
\hline 32 & 1144 & $298 / 002$ & Cerquilho & $-47,75$ & $-23,14$ & $\mathrm{TU}$ & 125 & $27 / 06 / 1977$ & 3,20 & 16 \\
\hline 33 & 29 & $298 / 017$ & Cesário Lange & $-47,95$ & $-23,27$ & $\mathrm{TU}$ & 200 & $15 / 01 / 1981$ & 1,42 & 10,12 \\
\hline 34 & $27 \mathrm{P}$ & & Cesário Lange & $-47,96$ & $-23,22$ & $\mathrm{TU}$ & 280 & out $/ 10$ & 1,73 & 17 \\
\hline 35 & 1149 & $298 / 018$ & Cesário Lange & $-47,95$ & $-23,23$ & $\mathrm{TU}$ & 250 & $12 / 05 / 1980$ & 1,12 & 10,12 \\
\hline 36 & c16 & & Cesário Lange & $-47,96$ & $-23,23$ & $\mathrm{TU}^{*}$ & & & 2,34 & 6 \\
\hline 37 & 22 & $021 / 004$ & Colombia & $-48,68$ & $-20,17$ & SG & 153 & $06 / 04 / 1978$ & 2,40 & 10 \\
\hline 38 & 16 & $274 / 005$ & Conchas & $-47,99$ & $-22,99$ & $\mathrm{PD} / \mathrm{TU}$ & 317 & $15 / 01 / 1981$ & 8,60 & 10 \\
\hline 39 & 198 & $192 / 009$ & Corumbataí & $-47,59$ & $-22,20$ & PD & 396 & $\operatorname{mar} / 84$ & 10,70 & 10,12 \\
\hline 40 & 197 & $192 / 008$ & Corumbataí & $-47,58$ & $-22,21$ & $\mathrm{PD} / \mathrm{DB}$ & 118 & fev/83 & 1,21 & 16 \\
\hline
\end{tabular}

* Poços PETROBRÁS; ** Aquífero inferido; Aquíferos: BA-Bauru, CR-Cristalino, DB-Diabásio, G-Guarani; PD-Aquitarde Passa Dois, SG-Serra Geral; TA-Taubaté; TU-Tubarão; ND-Não definido.

Fontes: 1) DAEE 1975; 2) DAEE 1976; 3) DAEE 1979a; 4) DAEE 1979b; 5) DAEE 1981; 6) DAEE 1982; 7) SILVA \& DIOGO 1982; 8) SILVA 1983; 9) KIMMELMAN et al. 1986; 10) PERRONI et al. 1986; 11) ALCHERA et al. 1987; 12) CAMPOS 1993; 13) CETESB 2004; 14) CETESB 2007; 15) CETESB 2010; 16) CETESB 2013; 17) VIDAL 1997; 18) HIRATA et al. 2002; 19) PACHECO 2009; 20) EZAKI 2011; 21) BONOTTO 2012; 22) IG 2013; 23) DAEE/UNESP 2013; 24) DAEE - SIDAS 


\begin{tabular}{|c|c|c|c|c|c|c|c|c|c|c|}
\hline$N^{o}$ & $\begin{array}{l}\text { Identificação } \\
\text { no estudo }\end{array}$ & $N^{o} D A E E$ & Município & Coord E & Coord N & Aquifero & $\begin{array}{l}\text { Prof. } \\
(m)\end{array}$ & $\begin{array}{c}\text { Data da } \\
\text { Coleta }\end{array}$ & $\begin{array}{c}F^{-} \\
\left(m g d m^{-3}\right)\end{array}$ & Fonte \\
\hline 41 & 1003 & $249 / 011$ & Cosmópolis & $-47,22$ & $-22,66$ & $\mathrm{TU}$ & 158 & 08/08/1980 & 5,60 & 17 \\
\hline 42 & PC171P & & Cotia & $-46,89$ & $-23,61$ & $\mathrm{CR}$ & & $\mathrm{abr} / 10$ & 1,31 & 12 \\
\hline 43 & $\mathrm{Ch} 02$ & & Cruzeiro & $-45,02$ & $-22,61$ & TA & 135 & jul/96 & 1,50 & 14 \\
\hline 44 & 1340 & $363 / 010$ & Cubatão & $-46,39$ & $-23,85$ & $\mathrm{CR}$ & 1850 & $21 / 09 / 1978$ & 2,20 & 24 \\
\hline 45 & 36 & & Elias Fausto & $-47,31$ & $-23,07$ & $\mathrm{TU}$ & 171 & $\mathrm{mar} / 04$ & 1,27 & 2 \\
\hline 46 & & 095/075 & Elisiário & $-49,03$ & $-21,18$ & BA & & $09 / 11 / 2004$ & 1,10 & 16 \\
\hline 47 & 22-X-D-1-2 & 095/016 & Elisiário/Catanduva & $-49,09$ & $-21,18$ & ND & & ago/75 & 1,32 & 15 \\
\hline 48 & PC163P & & Embu - Poço & $-46,86$ & $-23,64$ & $\mathrm{CR}$ & $262 ?$ & $\mathrm{abr} / 10$ & 1,18 & 4 \\
\hline 49 & 37 & & Estrela do Norte & $-51,67$ & $-22,48$ & $\mathrm{BA}$ & $162 ?$ & $01 / 06 / 2009$ & 1,28 & 2 \\
\hline 50 & 2620014 & $262 / 014$ & Florinea & $-50,76$ & $-22,90$ & SG & 150 & $24 / 10 / 1978$ & 1,33 & 12 \\
\hline 51 & 22-X-C-IV-2 & $132 / 003$ & Gabriel Monteiro & $-50,58$ & $-21,52$ & BA & 150 & $\mathrm{mai} / 75$ & 1,24 & 10 \\
\hline 52 & 615 & $132 / 021$ & Gabriel Monteiro & $-50,58$ & $-21,53$ & BA & 180 & $12 / 0 / 1977$ & 1,10 & 13 \\
\hline 53 & 66 & $071 / 016$ & Gastão Vidigal & $-50,19$ & $-20,80$ & SG & 225 & $\mathrm{jul} / 76$ & 4,40 & 12 \\
\hline 54 & 49 & & General Salgado & $-50,36$ & $-20,56$ & BA & 169 & $01 / 09 / 2001$ & 1,06 & 12 \\
\hline 55 & 128 & $057 / 015$ & Guaraci & $-48,93$ & $-20,50$ & $\mathrm{BA} / \mathrm{SG}^{*}$ & 150 & $18 / 02 / 1986$ & 2,80 & 5 \\
\hline 56 & 95 & $050 / 002$ & Guzolândia & $-50,67$ & $-20,65$ & $\mathrm{BA} / \mathrm{SG}$ & 214 & $26 / 05 / 1975$ & 1,64 & 23 \\
\hline 57 & 64 & $249 / 036$ & Holambra & $-47,09$ & $-22,64$ & $\mathrm{CR} / \mathrm{TU}$ & 232 & 08/08/1980 & 6,40 & 2 \\
\hline 58 & BO-158 & & Icém & $-49,21$ & $-20,34$ & BA & & & 2,08 & 2 \\
\hline 59 & 22-E-II-4 & $037 / 001$ & Icém & $-49,20$ & $-20,34$ & SG & & & 5,10 & 5 \\
\hline 60 & 22-C-II-3 & $028 / 012$ & $\begin{array}{l}\text { Ilha Solteira/ } \\
\text { Pereira Barreto }\end{array}$ & $-51,35$ & $-20,47$ & SG & & & 1,19 & 20 \\
\hline 61 & 112 & $301 / 081$ & Indaiatuba & $-47,21$ & $-23,11$ & $\mathrm{CR}$ & & $20 / 02 / 1981$ & 1,30 & 22 \\
\hline 62 & 3523 & & Indaiatuba & $-47,13$ & $-23,05$ & $\mathrm{CR}$ & 220 & 09/09/2009 & 1,41 & 24 \\
\hline 63 & 3668 & & Indaiatuba & $-47,23$ & $-21,13$ & $\mathrm{CR}$ & 250 & $26 / 04 / 2010$ & 1,72 & 24 \\
\hline 64 & 4303 & $301 / 173$ & Indaiatuba & $-47,16$ & $-23,13$ & $\mathrm{CR}$ & 117 & $01 / 02 / 2008$ & 1,87 & 24 \\
\hline 65 & 3854 & $301 / 337$ & Indaiatuba & $-47,20$ & $-23,09$ & $\mathrm{CR} / \mathrm{TU}$ & 282 & $27 / 11 / 2006$ & 1,09 & 24 \\
\hline 66 & 3503 & & Indaiatuba & $-47,15$ & $-23,05$ & $\mathrm{CR} / \mathrm{TU}$ & 252 & $29 / 08 / 1980$ & 1,00 & 20 \\
\hline 67 & 3895 & $301 / 275$ & Indaiatuba & $-47,20$ & $-23,08$ & $\mathrm{CR} / \mathrm{TU}$ & 189 & $05 / 12 / 2005$ & 1,30 & 20 \\
\hline 68 & 3513 & $300 / 077$ & Indaiatuba & $-47,28$ & $-23,12$ & $\mathrm{TU}$ & 150 & $15 / 5 / 08$ & 3,74 & 24 \\
\hline 69 & 4108 & $300 / 078$ & Indaiatuba & $-47,28$ & $-23,13$ & $\mathrm{TU}$ & 150 & $15 / 5 / 08$ & 1,27 & 2 \\
\hline 70 & 3497 & & Indaiatuba & $-47,24$ & $-23,13$ & $\mathrm{TU}$ & 112 & 01/08/1977 & 4,00 & 17 \\
\hline 71 & $22-\mathrm{V}-1 \mathrm{~V}-3$ & 003/007 & Indiaporã & $-50,38$ & $-20,00$ & SG & 134 & nov/75 & 1,20 & 16 \\
\hline 72 & bac1 & & Iperó & $-47,65$ & $-23,38$ & $\mathrm{TU}^{*}$ & & & 1,45 & 12 \\
\hline 73 & PC056P & & Itapira & $-46,74$ & $-22,39$ & $\mathrm{CR}$ & $113 ?$ & $\operatorname{mar} / 11$ & 1,20 & 10,12 \\
\hline 74 & 1361 & $393 / 001$ & Itapirapuã Paulista & $-49,17$ & $-24,58$ & $\mathrm{CR}$ & 151 & $06 / 12 / 1976$ & 1,02 & 10 \\
\hline 75 & 632 & $140 / 005$ & Itápolis & $-48,69$ & $-21,51$ & $\mathrm{BA} / \mathrm{SG}$ & 101 & $16 / 10 / 1977$ & 2,20 & 16 \\
\hline 76 & 41 & $046 / 004$ & Itapura & $-51,51$ & $-20,65$ & SG & 160 & $\operatorname{mar} / 82$ & 2,50 & 12 \\
\hline 77 & TU249P & & Itararé & $-49,47$ & $-23,97$ & $\mathrm{TU}$ & $288 ?$ & out/11 & 2,50 & 13 \\
\hline 78 & 570 & $118 / 024$ & Jaboticabal & $-48,32$ & $-21,25$ & $\mathrm{SG} / \mathrm{G}$ & 456 & $24 / 05 / 1976$ & 1,00 & 12 \\
\hline 79 & 62 & & Jarinu & $-46,68$ & $-23,21$ & $\mathrm{CR}$ & 200 & $01 / 09 / 2003$ & 1,26 & 10 \\
\hline 80 & 1167 & $303 / 001$ & Jarinu & $-46,73$ & $-23,10$ & $\mathrm{CR}$ & 160 & $27 / 04 / 1980$ & 2,22 & 12 \\
\hline
\end{tabular}

* Poços PETROBRÁS; ** Aquífero inferido; Aquíferos: BA-Bauru, CR-Cristalino, DB-Diabásio, G-Guarani; PD-Aquitarde Passa Dois, SG-Serra Geral; TA-Taubaté; TU-Tubarão; ND-Não definido.

Fontes: 1) DAEE 1975; 2) DAEE 1976; 3) DAEE 1979a; 4) DAEE 1979b; 5) DAEE 1981; 6) DAEE 1982; 7) SILVA \& DIOGO 1982; 8) SILVA 1983; 9) KIMMELMAN et al. 1986; 10) PERRONI et al. 1986; 11) ALCHERA et al. 1987; 12) CAMPOS 1993; 13) CETESB 2004; 14) CETESB 2007; 15) CETESB 2010; 16) CETESB 2013; 17) VIDAL 1997; 18) HIRATA et al. 2002; 19) PACHECO 2009; 20) EZAKI 2011; 21) BONOTTO 2012; 22) IG 2013; 23) DAEE/UNESP 2013; 24) DAEE - SIDAS 


\begin{tabular}{|c|c|c|c|c|c|c|c|c|c|c|}
\hline$N^{o}$ & $\begin{array}{l}\text { Identificação } \\
\text { no estudo }\end{array}$ & $N^{o} D A E E$ & Municipio & Coord E & Coord N & Aquifero & $\begin{array}{l}\text { Prof. } \\
\text { (m) }\end{array}$ & $\begin{array}{c}\text { Data da } \\
\text { Coleta }\end{array}$ & $\begin{array}{c}F^{-} \\
\left(m g d m^{-3}\right)\end{array}$ & Fonte \\
\hline 81 & 223 & $214 / 028$ & Jaú & $-48,54$ & $-22,27$ & SG & 180 & $\mathrm{mai} / 82$ & 1,86 & 24 \\
\hline 82 & 1223 & $309 / 003$ & Lagoinha & $-45,21$ & $-23,18$ & CR & 203 & 06/09/1979 & 1,16 & 17 \\
\hline 83 & 28 & $193 / 002$ & Leme & $-47,40$ & $-22,22$ & $\mathrm{PD} / \mathrm{DB}$ & 200 & $26 / 01 / 1980$ & 7,10 & 5 \\
\hline 84 & 29 & $193 / 016$ & Leme & $-47,38$ & $-22,17$ & $\mathrm{PD} / \mathrm{DB}$ & 351 & $26 / 01 / 1980$ & 3,50 & 5 \\
\hline 85 & 137 & & Leme & $-47,20$ & $-22,17$ & $\mathrm{TU}$ & & $15 / 09 / 2009$ & 5,09 & 23 \\
\hline 86 & TU153P & & Limeira & $-47,37$ & $-22,55$ & $\mathrm{TU}$ & $488 ?$ & out $/ 11$ & 1,00 & 16 \\
\hline $87^{*}$ & 59 & $135 / 005$ & Lins & $-49,76$ & $-21,69$ & G & 3459 & $28 / 10 / 1981$ & 1,02 & 9 \\
\hline 88 & 135/28 (3-SP) & & Lins & $-49,77$ & $-21,67$ & G & 1042 & $12 / 12 / 1984$ & 2,04 & 23 \\
\hline 89 & BO-99 & & Lins & $-49,75$ & $-21,68$ & $\mathrm{SG} / \mathrm{G}$ & 817 & & 1,11 & 17,23 \\
\hline 90 & 115 & & Lorena & $-45,11$ & $-22,73$ & $\mathrm{TA}$ & 182 & $27 / 08 / 2009$ & 1,26 & 23 \\
\hline 91 & 116 & & Lorena & $-45,10$ & $-22,73$ & TA & & $27 / 08 / 2009$ & 1,14 & 17 \\
\hline 92 & 105 & & Lorena & $-45,13$ & $-22,74$ & $\mathrm{TA}$ & 350 & 03/07/1996 & 1,50 & 23 \\
\hline 93 & BO-176 & & Macaubal & $-49,97$ & $-20,80$ & BA & & & 2,47 & 16 \\
\hline 94 & PC257P & & Miracatu & $-47,16$ & $-24,01$ & $\mathrm{CR}$ & $130 ?$ & out $/ 12$ & 1,19 & 16 \\
\hline 95 & PC173P & & Mogi das Cruzes & $-46,24$ & $-23,54$ & $\mathrm{CR}$ & & out $/ 10$ & 1,02 & 10 \\
\hline 96 & 285 & $276 / 065$ & Mombuca & $-47,55$ & $-22,94$ & $\mathrm{TU}$ & 300 & jun/78 & 1,28 & 24 \\
\hline 97 & & 097/114 & Monte Alto & $-48,55$ & $-21,21$ & $\mathrm{BA}$ & & $03 / 02 / 2004$ & 1,05 & 14 \\
\hline 98 & 74 & & Monte Mor & $-47,30$ & $-22,95$ & $\mathrm{TU}$ & 350 & set/06 & 1,00 & 2 \\
\hline 99 & 22-D-IV-2 & $052 / 008$ & Nhandeara & $-50,04$ & $-20,70$ & $\mathrm{BA}$ & 250 & set $/ 75$ & 1,52 & 12 \\
\hline 100 & 727 & $164 / 013$ & Nova Europa & $-48,57$ & $-21,78$ & G & 305 & $22 / 02 / 1985$ & 1,10 & 13 \\
\hline 101 & 78 & & Nova Granada & $-49,34$ & $-20,43$ & $\mathrm{BA}$ & 84 & $01 / 03 / 2001$ & 1,24 & 8 \\
\hline 102 & 44 & $115 / 001$ & Novo Horizonte & $-49,23$ & $-21,47$ & G & 600 & $27 / 10 / 1981$ & 1,09 & 23 \\
\hline 103 & BO-103 & & Novo Horizonte & $-49,23$ & $-21,47$ & G & 550 & & 1,13 & 23 \\
\hline 104 & BO-32 & & Orindiuva & $-49,35$ & $-20,17$ & SG & 305 & & 1,00 & 1,12 \\
\hline 105 & 2024 & $342 / 1024$ & Osasco & $-46,77$ & $-23,55$ & $\mathrm{CR}$ & 300 & 08/05/1976 & 1,40 & 21 \\
\hline $106^{*}$ & 2060002 & $206 / 002$ & Paraguacu Paulista & $-50,61$ & $-22,42$ & G & 3663 & $27 / 10 / 1978$ & 2,00 & 24 \\
\hline 107 & 72 & & Paraguaçu Paulista & $-50,63$ & $-22,36$ & BA & 72 & & 1,00 & 12 \\
\hline 108 & & $007 / 001$ & Paulo de Faria & $-49,43$ & $-20,00$ & $\mathrm{BA} / \mathrm{SG}$ & & $20 / 09 / 2002$ & 4,92 & 10,11 \\
\hline 109 & 921 & $213 / 032$ & Pederneiras & $-48,77$ & $-22,35$ & G & 298 & $12 / 02 / 1980$ & 1,50 & 10,12 \\
\hline 110 & & $298 / 013$ & Pereiras & $-47,98$ & $-23,07$ & $\mathrm{PD} / \mathrm{TU}$ & 282 & nov $/ 80$ & 6,80 & 17 \\
\hline 111 & 1145 & $298 / 012$ & Pereiras & $-47,98$ & $-23,08$ & $\mathrm{TU}$ & 225 & $15 / 01 / 1981$ & 5,14 & 17 \\
\hline 112 & Pi11 & & Pindamonhangaba & $-45,46$ & $-22,93$ & TA & 360 & 06/08/1996 & 2,00 & 24 \\
\hline 113 & Pi14 & & Pindamonhangaba & $-45,50$ & $-22,97$ & TA & 140 & 06/08/1996 & 1,50 & 12 \\
\hline 114 & & $096 / 150$ & Pindorama & $-48,90$ & $-21,14$ & $\mathrm{BA}$ & & $31 / 05 / 2001$ & 1,00 & 5 \\
\hline 115 & 1029 & $256 / 025$ & Piquete & $-45,20$ & $-22,61$ & $\mathrm{CR}$ & 105 & 08/09/1976 & 1,20 & 16 \\
\hline $116^{*}$ & 55 & $246 / 010$ & Piracicaba & $-47,78$ & $-22,67$ & $\mathrm{PD}$ & & $06 / 02 / 1980$ & 3,60 & 23 \\
\hline 117 & 58 & $247 / 021$ & Piracicaba & $-47,73$ & $-22,68$ & $\mathrm{PD} / \mathrm{TU}$ & 266 & $06 / 02 / 1980$ & 4,90 & 10 \\
\hline 118 & $267 \mathrm{P}$ & & Pirassununga & $-47,45$ & $-22,01$ & $\mathrm{TU}$ & 150 & $\operatorname{mar} / 10$ & 1,94 & 4 \\
\hline 119 & 94 & & Pirassununga & $-47,43$ & $-21,97$ & $\mathrm{TU}$ & & $25 / 08 / 2009$ & 8,48 & 12 \\
\hline 120 & 211 & $212 / 158$ & Piratininga & $-49,13$ & $-22,41$ & $\mathrm{PD} / \mathrm{TU}$ & 991 & out $/ 79$ & 1,76 & 21 \\
\hline 121 & 1500006 & $150 / 006$ & Presidente Epitácio & $-52,10$ & $-21,81$ & BA & 176 & $11 / 05 / 1978$ & 1,32 & $\begin{array}{l}4,7,8, \\
18,21\end{array}$ \\
\hline 122 & 675 & $150 / 005$ & Presidente Epitácio & $-52,15$ & $-21,76$ & $\mathrm{BA}$ & & $11 / 05 / 1978$ & 1,92 & 6,12 \\
\hline 123 & 80 & & Presidente Epitácio & $-52,09$ & $-21,77$ & $\mathrm{SG} / \mathrm{G}$ & 3953 & & 6,60 & 4,11 \\
\hline
\end{tabular}

* Poços PETROBRÁS; ** Aquífero inferido; Aquíferos: BA-Bauru, CR-Cristalino, DB-Diabásio, G-Guarani; PD-Aquitarde Passa Dois, SG-Serra Geral; TA-Taubaté; TU-Tubarão; ND-Não definido.

Fontes: 1) DAEE 1975; 2) DAEE 1976; 3) DAEE 1979a; 4) DAEE 1979b; 5) DAEE 1981; 6) DAEE 1982; 7) SILVA \& DIOGO 1982; 8) SILVA 1983; 9) KIMMELMAN et al. 1986; 10) PERRONI et al. 1986; 11) ALCHERA et al. 1987; 12) CAMPOS 1993; 13) CETESB 2004; 14) CETESB 2007; 15) CETESB 2010; 16) CETESB 2013; 17) VIDAL 1997; 18) HIRATA et al. 2002; 19) PACHECO 2009; 20) EZAKI 2011; 21) BONOTTO 2012; 22) IG 2013; 23) DAEE/UNESP 2013; 24) DAEE - SIDAS 


\begin{tabular}{|c|c|c|c|c|c|c|c|c|c|c|}
\hline$N^{o}$ & $\begin{array}{l}\text { Identificação } \\
\text { no estudo }\end{array}$ & $N^{o} D A E E$ & Municipio & Coord E & Coord N & Aquifero & $\begin{array}{l}\text { Prof. } \\
\text { (m) }\end{array}$ & $\begin{array}{c}\text { Data da } \\
\text { Coleta }\end{array}$ & $\begin{array}{c}F^{-} \\
\left(m g d m^{-3}\right)\end{array}$ & Fonte \\
\hline 124 & 87 & $177 / 082$ & Presidente Prudente & $-51,42$ & $-22,12$ & G & 1800 & $18 / 01 / 1982$ & 13,30 & 24 \\
\hline 125 & 44 & $317 / 007$ & Quadra & $-48,09$ & $-23,30$ & $\mathrm{TU}$ & 210 & 08/03/1980 & 1,24 & 12 \\
\hline 126 & & $158 / 007$ & Queiroz & $-50,25$ & $-21,79$ & $\mathrm{BA}$ & 144 & & 4,40 & 5 \\
\hline 127 & 3831 & $299 / 030$ & Rafard & $-47,60$ & $-23,05$ & $\mathrm{TU}$ & 193 & $03 / 03 / 2000$ & 1,00 & 5 \\
\hline 128 & 791 & $177 / 082$ & Regente Feijó & $-51,32$ & $-22,16$ & G & 120 & $27 / 08 / 1980$ & 9,80 & 5 \\
\hline 129 & 42 & $218 / 012$ & Rio Claro & $-47,60$ & $-22,47$ & DB & 128 & 08/02/1980 & 1,40 & 17 \\
\hline 130 & 56 & $247 / 007$ & Rio Claro & $-47,59$ & $-22,53$ & $\mathrm{PD} / \mathrm{DB}$ & 225 & $07 / 02 / 1980$ & 6,60 & 2 \\
\hline 131 & 39 & $218 / 004$ & Rio Claro & $-47,58$ & $-22,45$ & $\mathrm{PD} / \mathrm{DB}$ & 201 & $08 / 02 / 1980$ & 2,20 & 24 \\
\hline 132 & $\mathrm{rp} 1$ & & Rio das Pedras & $-47,61$ & $-22,85$ & $\mathrm{PD} / \mathrm{TU}^{*}$ & & & 4,78 & 17 \\
\hline 133 & 22-W-III-4 & 006/003 & Riolândia & $-49,68$ & $-19,97$ & SG & 300 & set $/ 75$ & 8,20 & 6 \\
\hline 134 & & 006/004 & Riolândia & $-49,63$ & $-19,99$ & SG & & $28 / 09 / 2009$ & 10,20 & 20 \\
\hline 135 & 1063 & & Saltinho & $-47,68$ & $-22,85$ & $\mathrm{TU}$ & 450 & & 2,10 & 20 \\
\hline 136 & 33 & $300 / 035$ & Salto & $-47,28$ & $-23,20$ & $\mathrm{CR}$ & & $18 / 02 / 1981$ & 1,23 & 22 \\
\hline 137 & 518 & $300 / 152$ & Salto & $-47,26$ & $-23,20$ & $\mathrm{CR}$ & 175 & $1 / 4 / 08$ & 1,86 & 22 \\
\hline 138 & 1933 & & Salto & $-47,34$ & $-23,19$ & $\mathrm{CR}$ & 300 & $14 / 8 / 07$ & 1,82 & 20 \\
\hline 139 & 3821 & & Salto & $-47,27$ & $-23,22$ & $\mathrm{CR}$ & 270 & $27 / 04 / 2010$ & 1,26 & 24 \\
\hline 140 & 4444 & & Salto & $-47,33$ & $-23,20$ & $\mathrm{CR}$ & 198 & $31 / 03 / 2008$ & 2,58 & 24 \\
\hline 141 & & & Salto & $-47,27$ & $-23,18$ & $\mathrm{CR}$ & 450 & $2 / 4 / 08$ & 1,08 & 24 \\
\hline 142 & 1939 & & Salto & $-47,28$ & $-23,20$ & $\mathrm{CR}$ & 142 & $06 / 11 / 2001$ & 1,42 & 24 \\
\hline 143 & 3902 & $300 / 150$ & Salto & $-47,28$ & $-23,20$ & $\mathrm{CR}$ & 150 & $06 / 11 / 2001$ & 1,64 & 24 \\
\hline 144 & 4122 & $300 / 024$ & Salto & $-47,27$ & $-23,20$ & $\mathrm{CR}$ & 150 & $06 / 11 / 2001$ & 1,64 & 24 \\
\hline 145 & 4120 & $300 / 022$ & Salto & $-47,28$ & $-23,20$ & $\mathrm{CR}$ & 120 & $06 / 11 / 2001$ & 1,40 & 24 \\
\hline 146 & 2266 & & Salto & $-47,28$ & & $\mathrm{CR}$ & 150 & $06 / 11 / 2001$ & 1,12 & 24 \\
\hline 147 & 4117 & $300 / 019$ & Salto & $-47,28$ & $-23,21$ & $\mathrm{CR}$ & 130 & $15 / 05 / 1996$ & 1,85 & 20 \\
\hline 148 & 4118 & $300 / 020$ & Salto & $-47,28$ & $-23,21$ & $\mathrm{CR}$ & 152 & $14 / 05 / 1996$ & 1,83 & 20 \\
\hline 149 & 1024 & & Salto & $-47,27$ & $-23,21$ & $\mathrm{CR}$ & 250 & $31 / 10 / 2007$ & 1,95 & 20 \\
\hline 150 & 1938 & & Salto & $-47,34$ & $-23,19$ & $\mathrm{CR} / \mathrm{TU}$ & & $3 / 4 / 08$ & 1,95 & 20 \\
\hline 151 & 2011 & & Salto & $-47,27$ & $-23,17$ & $\mathrm{CR} / \mathrm{TU}$ & 160 & $3 / 5 / 07$ & 2,63 & 20 \\
\hline 152 & 2014 & $300 / 169$ & Salto & $-47,27$ & $-23,17$ & $\mathrm{CR} / \mathrm{TU}$ & 182 & $1 / 4 / 08$ & 3,31 & 22 \\
\hline 153 & 3660 & & Salto & $-47,28$ & $-23,18$ & $\mathrm{CR} / \mathrm{TU}$ & 180 & $21 / 11 / 08$ & 3,23 & 20 \\
\hline 154 & 3663 & & Salto & $-47,29$ & $-23,18$ & $\mathrm{CR} / \mathrm{TU}$ & 170 & $21 / 11 / 08$ & 4,38 & 22 \\
\hline 155 & 3665 & & Salto & $-47,30$ & $-23,17$ & $\mathrm{CR} / \mathrm{TU}$ & 282 & $27 / 04 / 2010$ & 7,45 & 20 \\
\hline 156 & 4132 & & Salto & $-47,26$ & $-23,16$ & $\mathrm{CR} / \mathrm{TU}$ & 276 & $21 / 11 / 08$ & 1,22 & 20 \\
\hline 157 & 948 & $300 / 128$ & Salto & $-47,27$ & $-23,17$ & $\mathrm{TU}$ & 200 & $03 / 05 / 2007$ & 3,49 & 20 \\
\hline 158 & 949 & $300 / 129$ & Salto & $-47,27$ & $-23,17$ & $\mathrm{TU}$ & 216 & $31 / 3 / 08$ & 4,25 & 24 \\
\hline 159 & 1930 & & Salto & $-47,34$ & $-23,18$ & $\mathrm{TU}$ & 80 & $2 / 4 / 08$ & 3,45 & 12 \\
\hline 160 & 1935 & & Salto & $-47,34$ & $-23,19$ & $\mathrm{TU}$ & 120 & $2 / 4 / 08$ & 2,67 & 24 \\
\hline 161 & 2251 & $300 / 179$ & Salto & $-47,28$ & $-23,16$ & $\mathrm{TU}$ & 175 & $29 / 08 / 2007$ & 1,42 & 23 \\
\hline 162 & 17 & 013/014 & Santa Albertina & $-50,73$ & $-20,05$ & SG & 200 & $10 / 09 / 1978$ & 4,40 & 23 \\
\hline 163 & & $012 / 020$ & Santa Fe do Sul & $-50,92$ & $-20,20$ & SG & & 03/08/2006 & 1,20 & 5 \\
\hline 164 & 55 & & Santa Gertrudes & $-47,53$ & $-22,46$ & $\mathrm{TU}$ & & $21 / 07 / 2009$ & 2,55 & 5 \\
\hline 165 & 54 & & Santa Gertrudes & $-47,54$ & $-22,44$ & $\mathrm{TU}$ & & $21 / 07 / 2009$ & 1,19 & 23 \\
\hline 166 & 56 & & Santa Gertrudes & $-47,54$ & $-22,46$ & $\mathrm{TU}$ & & $21 / 07 / 2009$ & 1,49 & 23 \\
\hline
\end{tabular}

* Poços PETROBRÁS; ** Aquífero inferido; Aquíferos: BA-Bauru, CR-Cristalino, DB-Diabásio, G-Guarani; PD-Aquitarde Passa Dois, SG-Serra Geral; TA-Taubaté; TU-Tubarão; ND-Não definido.

Fontes: 1) DAEE 1975; 2) DAEE 1976; 3) DAEE 1979a; 4) DAEE 1979b; 5) DAEE 1981; 6) DAEE 1982; 7) SILVA \& DIOGO 1982; 8) SILVA 1983; 9) KIMMELMAN et al. 1986; 10) PERRONI et al. 1986; 11) ALCHERA et al. 1987; 12) CAMPOS 1993; 13) CETESB 2004; 14) CETESB 2007; 15) CETESB 2010; 16) CETESB 2013; 17) VIDAL 1997; 18) HIRATA et al. 2002; 19) PACHECO 2009; 20) EZAKI 2011; 21) BONOTTO 2012; 22) IG 2013; 23) DAEE/UNESP 2013; 24) DAEE - SIDAS 


\begin{tabular}{|c|c|c|c|c|c|c|c|c|c|c|}
\hline$N^{o}$ & $\begin{array}{l}\text { Identificação } \\
\text { no estudo }\end{array}$ & $N^{o} D A E E$ & Municipio & Coord $E$ & Coord N & Aquifero & $\begin{array}{l}\text { Prof. } \\
\text { (m) }\end{array}$ & $\begin{array}{c}\text { Data da } \\
\text { Coleta }\end{array}$ & $\begin{array}{c}F^{-} \\
\left(m g d m^{-3}\right)\end{array}$ & Fonte \\
\hline 167 & 53 & & Santa Gertrudes & $-47,54$ & $-22,45$ & TU & & $21 / 07 / 2009$ & 2,15 & 23 \\
\hline 168 & PC278P & & Santo Antonio da Posse & $-47,01$ & $-22,60$ & $\mathrm{CR}$ & $300 ?$ & out $/ 12$ & 9,00 & 16 \\
\hline 169 & & $153 / 004$ & Santo Expedito & $-51,39$ & $-21,85$ & BA & 196 & jun/76 & 4,40 & 4,11 \\
\hline 170 & & $363 / 046$ & Santos & $-46,34$ & $-23,96$ & $\mathrm{CR}$ & 60 & $22 / 09 / 1978$ & 1,48 & 3 \\
\hline 171 & & $363 / 047$ & Santos & $-46,36$ & $-23,95$ & $\mathrm{CR}$ & 202 & $23 / 11 / 1978$ & 1,28 & 3 \\
\hline 172 & 1436 & $343 / 1436$ & São Caetano do Sul & $-46,57$ & $-23,61$ & $\mathrm{CR}$ & & & 1,20 & 1 \\
\hline 173 & 101 & & São Caetano do Sul & $-46,56$ & $-23,63$ & $\mathrm{CR}$ & & $27 / 08 / 2009$ & 2,98 & 23 \\
\hline 174 & 102 & & São Caetano do Sul & $-46,56$ & $-23,63$ & $\mathrm{CR}$ & & $27 / 08 / 2009$ & 3,42 & 23 \\
\hline 175 & & $074 / 010$ & São José do Rio Preto & $-49,37$ & $-20,77$ & $\mathrm{BA} / \mathrm{G}$ & & $25 / 06 / 1998$ & 1,02 & 24 \\
\hline 176 & 1224 & $343 / 1224$ & São Paulo & $-46,62$ & $-23,53$ & $\mathrm{CR}$ & & & 1,00 & 1 \\
\hline 177 & PC0057 & $343 / 057$ & São Paulo & $-46,69$ & $-23,51$ & $\mathrm{CR}$ & 150 & & 10,00 & 19 \\
\hline 178 & PC0066 & $343 / 066$ & São Paulo & $-46,67$ & $-23,53$ & $\mathrm{CR}$ & 250 & & 5,80 & 19 \\
\hline 179 & PC0150 & $343 / 150$ & São Paulo & $-46,67$ & $-23,52$ & $\mathrm{CR}$ & 405 & & 7,80 & 19 \\
\hline 180 & PC0219 & $343 / 219$ & São Paulo & $-46,68$ & $-23,52$ & $\mathrm{CR}$ & 260 & & 6,60 & 19 \\
\hline 181 & PC0338 & $343 / 338$ & São Paulo & $-46,67$ & $-23,53$ & $\mathrm{CR}$ & 230 & & 4,20 & 19 \\
\hline 182 & PC0675 & $343 / 675$ & São Paulo & $-46,66$ & $-23,52$ & $\mathrm{CR}$ & 100 & & 3,00 & 19 \\
\hline 183 & PC1124 & $343 / 1124$ & São Paulo & $-46,69$ & $-23,52$ & $\mathrm{CR}$ & 390 & & 9,10 & 19 \\
\hline 184 & PC1184 & $343 / 1184$ & São Paulo & $-46,67$ & $-23,52$ & $\mathrm{CR}$ & 330 & & 5,30 & 19 \\
\hline 185 & 2541 & $343 / 2541$ & São Paulo & $-46,66$ & $-23,52$ & $\mathrm{CR} / \mathrm{SP}$ & & & 10,80 & 1 \\
\hline 186 & PC1338 & $343 / 1338$ & São Paulo & $-46,67$ & $-23,52$ & $\mathrm{CR} / \mathrm{SP}$ & 360 & & 9,30 & 19 \\
\hline 187 & 234 & $343 / 234$ & São Paulo & $-46,61$ & $-23,52$ & ND & & & 1,60 & 1 \\
\hline 188 & 2659 & $343 / 2659$ & São Paulo & $-46,70$ & $-23,50$ & ND & & & 2,60 & 1 \\
\hline 189 & 183 & & São Paulo & $-46,76$ & $-23,87$ & $\mathrm{CR}$ & 150 & out/06 & 1,18 & 14 \\
\hline 190 & 162 & & São Paulo & $-46,62$ & $-23,52$ & $\mathrm{CR}$ & $328 ?$ & $\mathrm{abr} / 06$ & 3,20 & 14 \\
\hline 191 & 3195 & $343 / 3195$ & São Paulo - Aricanduva & $-46,52$ & $-23,56$ & ND & & & 1,40 & 1 \\
\hline 192 & 3051 & $343 / 3051$ & São Paulo - Ipiranga & $-46,60$ & $-23,57$ & ND & & & 1,90 & 1 \\
\hline 193 & 3046 & $343 / 3046$ & São Paulo - Jaguaré & $-46,75$ & $-23,54$ & ND & & & 4,40 & 1 \\
\hline 194 & 250 & $343 / 250$ & São Paulo - Lapa & $-46,71$ & $-23,52$ & ND & & & 2,00 & 1 \\
\hline 195 & 3045 & $343 / 3045$ & São Paulo - Moóca & $-46,60$ & $-23,55$ & ND & & & 1,40 & 1 \\
\hline 196 & 3197 & $343 / 3197$ & São Paulo - Santo Amaro & $-46,69$ & $-23,68$ & ND & & & 1,20 & 1 \\
\hline 197 & & $363 / 035$ & São Vicente & $-46,38$ & $-23,97$ & $\mathrm{CR}$ & 100 & $23 / 09 / 1978$ & 1,60 & 3 \\
\hline 198 & 181 & & Sertãozinho & $-48,01$ & $-21,15$ & G & & $10 / 09 / 2009$ & 1,31 & 23 \\
\hline 199 & 631 & $140 / 004$ & Tabatinga & $-48,59$ & $-21,72$ & SG & 120 & $27 / 05 / 1976$ & 1,32 & 10,12 \\
\hline 200 & BO-134 & & Taguai & $-49,41$ & $-23,45$ & $\mathrm{TU}$ & & & 2,30 & 23 \\
\hline 201 & 111 & & Taubaté & $-45,54$ & $-23,07$ & TA & & $26 / 08 / 2009$ & 2,22 & 23 \\
\hline 202 & 1205 & $307 / 001$ & Taubaté & $-45,60$ & $-23,04$ & $\mathrm{TA}$ & 500 & $20 / 01 / 1977$ & 2,50 & 12 \\
\hline 203 & t05 & & Taubaté & $-45,60$ & $-23,05$ & TA & 400 & 01/08/1996 & 3,00 & 17 \\
\hline 204 & & $200 / 006$ & Teodoro Sampaio & $-52,24$ & $-22,31$ & BA & 199 & out $/ 78$ & 9,20 & $\begin{array}{c}4,10 \\
11\end{array}$ \\
\hline 205 & 1090 & $279 / 002$ & Tuiuti & $-46,73$ & $-22,85$ & $\mathrm{CR}$ & 150 & $19 / 04 / 1980$ & 1,84 & 12 \\
\hline 206 & 1092 & $279 / 003$ & Tuiuti & $-46,65$ & $-22,83$ & $\mathrm{CR}$ & 141 & $28 / 04 / 1980$ & 2,08 & 12 \\
\hline 207 & & $108 / 011$ & Valparaiso & $-50,96$ & $-21,32$ & G & & $14 / 05 / 1999$ & 1,63 & 24 \\
\hline 208 & BO-165 & & Valparaíso & $-50,88$ & $-21,23$ & G & 1120 & & 1,43 & 23 \\
\hline
\end{tabular}

* Poços PETROBRÁS; ** Aquífero inferido; Aquíferos: BA-Bauru, CR-Cristalino, DB-Diabásio, G-Guarani; PD-Aquitarde Passa Dois, SG-Serra Geral; TA-Taubaté; TU-Tubarão; ND-Não definido.

Fontes: 1) DAEE 1975; 2) DAEE 1976; 3) DAEE 1979a; 4) DAEE 1979b; 5) DAEE 1981; 6) DAEE 1982; 7) SILVA \& DIOGO 1982; 8) SILVA 1983; 9) KIMMELMAN et al. 1986; 10) PERRONI et al. 1986; 11) ALCHERA et al. 1987; 12) CAMPOS 1993; 13) CETESB 2004; 14) CETESB 2007; 15) CETESB 2010; 16) CETESB 2013; 17) VIDAL 1997; 18) HIRATA et al. 2002; 19) PACHECO 2009; 20) EZAKI 2011; 21) BONOTTO 2012; 22) IG 2013; 23) DAEE/UNESP 2013; 24) DAEE - SIDAS 
APÊNDICE 2 - Compilação de dados analíticos de composição química das águas subterrâneas ricas em F-e classificação hidroquímica.

\begin{tabular}{|c|c|c|c|c|c|c|c|c|c|c|c|c|c|c|c|}
\hline$N^{o}$ & $p H$ & $\begin{array}{c}C E \\
\left(\mu \mathrm{cm}^{-1}\right)\end{array}$ & $\mathrm{Na}^{+}$ & $\mathrm{Ca}^{2+}$ & $K^{+}$ & $\mathrm{Mg}^{2+}$ & $\mathrm{HCO}_{3}^{-}$ & $\mathrm{CO}_{3} 2^{-}$ & $\mathrm{Cl}^{-}$ & $\mathrm{SO}_{4} 2^{-}$ & $F^{-}$ & $\mathrm{SiO}_{2}$ & $\begin{array}{c}\text { IS } \\
\text { Fluorita }\end{array}$ & $\begin{array}{c}\text { IS } \\
\text { Calcita }\end{array}$ & $\begin{array}{l}\text { Classificação } \\
\text { de Piper }\end{array}$ \\
\hline 2 & 9,70 & 630 & 100,00 & 1,50 & 2,10 & 1,00 & 206,00 & & 7,50 & 35,00 & 1,28 & 15,80 & $-2,49$ & 0,32 & $\mathrm{Na}-\mathrm{HCO} 3$ \\
\hline 3 & 8,00 & 282 & 73,40 & 0,75 & 0,20 & 0,13 & 57,00 & 69,00 & 0,51 & 12,31 & 1,57 & & $-2,43$ & $-1,31$ & $\mathrm{Na}-\mathrm{CO} 3-\mathrm{HCO} 3$ \\
\hline 4 & 8,10 & 404 & 85,80 & 8,95 & 2,06 & 0,85 & 131,00 & & 15,00 & 19,00 & 13,00 & & 0,47 & $-0,32$ & $\mathrm{Na}-\mathrm{HCO} 3$ \\
\hline 5 & & & 189,00 & 0,76 & 0,60 & 0,00 & 318,00 & 34,50 & 25,40 & 33,10 & 3,35 & & $-1,85$ & $-2,08$ & $\mathrm{Na}-\mathrm{HCO} 3$ \\
\hline 6 & 9,20 & 334 & 70,00 & 5,10 & 1,10 & 2,60 & 110,00 & 34,00 & 2,50 & 4,00 & 1,35 & 21,60 & $-1,79$ & 0,54 & $\mathrm{Na}-\mathrm{HCO} 3-\mathrm{CO} 3$ \\
\hline $7 *$ & 8,60 & 5700 & 1200,00 & 3,50 & 3,00 & 1,20 & 354,00 & 32,00 & 1250,00 & 422,00 & 10,40 & 10,00 & $-0,56$ & $-0,10$ & $\mathrm{Na}-\mathrm{Cl}$ \\
\hline 9 & & & 9,21 & 37,20 & 0,87 & 11,70 & 189,00 & 0,00 & 2,21 & 7,11 & 1,75 & & $-0,67$ & $-0,64$ & $\mathrm{Ca}-\mathrm{Mg}-\mathrm{HCO} 3$ \\
\hline 14 & 9,35 & 3850 & 790,00 & 126,00 & 1,90 & 0,00 & 17,00 & 28,00 & 144,00 & 1650,00 & 3,00 & 20,90 & $-0,19$ & 1,13 & $\mathrm{Na}-\mathrm{SO} 4$ \\
\hline 15 & 7,68 & 209 & 30,00 & 17,80 & 0,41 & 1,05 & 99,20 & & 6,60 & 5,95 & 1,26 & 13,30 & $-1,22$ & $-0,53$ & $\mathrm{Na}-\mathrm{Ca}-\mathrm{HCO} 3$ \\
\hline 17 & 8,44 & 4000 & 780,00 & 113,00 & 4,20 & 1,00 & 19,00 & 2,00 & 410,00 & 1450,00 & 1,50 & 23,00 & $-0,81$ & $-0,12$ & $\mathrm{Na}-\mathrm{SO} 4-\mathrm{Cl}$ \\
\hline 19 & & & 111,00 & 0,74 & 0,37 & 0,00 & 158,00 & 32,45 & 18,60 & 20,70 & 1,06 & & $-2,80$ & $-2,28$ & $\mathrm{Na}-\mathrm{HCO} 3-\mathrm{CO} 3$ \\
\hline 20 & 7,10 & 200 & 20,70 & 16,30 & 2,96 & 2,79 & 84,20 & & 4,84 & 9,67 & 1,10 & & $-1,36$ & $-1,20$ & $\mathrm{Na}-\mathrm{Ca}-\mathrm{HCO} 3$ \\
\hline $21^{*}$ & 8,50 & 2200 & 520,00 & 1,20 & 1,50 & 0,30 & 712,00 & 38,00 & 210,00 & 5,00 & 17,60 & 17,00 & $-0,38$ & $-0,24$ & $\mathrm{Na}-\mathrm{HCO} 3-\mathrm{Cl}$ \\
\hline 22 & 8,90 & 367 & 80,00 & 1,20 & 0,50 & 0,00 & 61,00 & 82,00 & 5,70 & 13,00 & 4,11 & 57,00 & $-1,44$ & $-0,24$ & $\mathrm{Na}-\mathrm{CO} 3-\mathrm{HCO} 3$ \\
\hline 23 & 9,50 & 1820 & 390,00 & 4,90 & 0,80 & 1,00 & 35,00 & 35,00 & 70,00 & 680,00 & 5,00 & 31,00 & $-0,98$ & 0,19 & $\mathrm{Na}-\mathrm{SO} 4$ \\
\hline 26 & 8,03 & 360 & 43,00 & 11,00 & 1,90 & 0,63 & 151,20 & & 9,00 & 1,00 & 1,02 & 35,10 & $-1,61$ & $-0,21$ & $\mathrm{Na}-\mathrm{Ca}-\mathrm{HCO} 3$ \\
\hline 28 & 9,00 & 250 & 54,00 & 2,00 & 0,40 & 0,20 & 76,00 & 20,00 & 3,00 & 5,00 & 3,90 & 18,60 & $-1,21$ & $-0,16$ & $\mathrm{Na}-\mathrm{HCO} 3-\mathrm{CO} 3$ \\
\hline 31 & 8,60 & 332 & 60,60 & 10,40 & 0,30 & 1,01 & 154,00 & & 3,51 & 36,10 & 1,54 & 9,56 & $-1,33$ & 0,28 & $\mathrm{Na}-\mathrm{HCO} 3-\mathrm{SO} 4$ \\
\hline 33 & 8,80 & 790 & 190,00 & 1,90 & 0,70 & 0,20 & 305,00 & 41,00 & 12,40 & 56,00 & 1,42 & 14,90 & $-2,27$ & 0,02 & $\mathrm{Na}-\mathrm{HCO} 3$ \\
\hline 34 & 9,00 & 920 & 234,00 & 2,12 & 0,84 & 0,42 & 311,00 & 43,00 & 16,40 & 133,00 & 1,73 & & $-2,12$ & 0,19 & Na-HCO3-SO4 \\
\hline 35 & 7,50 & 748 & 150,00 & 1,40 & 0,80 & 0,30 & 228,00 & 59,00 & 6,50 & 30,00 & 1,12 & 13,50 & $-2,52$ & $-1,34$ & $\mathrm{Na}-\mathrm{HCO} 3-\mathrm{CO} 3$ \\
\hline 37 & 9,65 & 421 & 90,00 & 1,60 & 1,90 & 0,50 & 56,00 & 85,00 & 4,00 & 49,00 & 2,40 & 95,00 & $-1,90$ & 0,28 & $\mathrm{Na}-\mathrm{CO} 3-\mathrm{SO} 4-\mathrm{HCO} 3$ \\
\hline 38 & 8,40 & 5200 & 1100,00 & 6,60 & 3,40 & 0,30 & 568,00 & 10,00 & 780,00 & 638,00 & 8,60 & 12,20 & $-0,47$ & 0,11 & $\mathrm{Na}-\mathrm{Cl}-\mathrm{SO} 4$ \\
\hline 39 & 8,95 & 1270 & 264,00 & 2,30 & 1,30 & 1,00 & 305,00 & 50,00 & 83,00 & 81,00 & 10,70 & 15,90 & $-0,49$ & 0,20 & $\mathrm{Na}-\mathrm{HCO} 3-\mathrm{Cl}$ \\
\hline 40 & 7,00 & 722 & 136,00 & 7,50 & 0,60 & 1,60 & 205,00 & 27,00 & 60,40 & 11,00 & 1,21 & 16,10 & $-1,71$ & $-1,22$ & $\mathrm{Na}-\mathrm{HCO} 3-\mathrm{Cl}$ \\
\hline 41 & 8,20 & 420 & 85,00 & 8,80 & 0,20 & 0,30 & 78,00 & 0,00 & 12,00 & 81,00 & 5,60 & 16,00 & $-0,30$ & $-0,49$ & $\mathrm{Na}-\mathrm{SO} 4-\mathrm{HCO} 3$ \\
\hline 43 & 8,30 & 370 & 55,80 & 3,52 & 0,77 & 0,27 & 178,30 & & 7,25 & 0,50 & 1,50 & 27,41 & $-1,78$ & $-0,38$ & $\mathrm{Na}-\mathrm{HCO} 3$ \\
\hline 44 & 6,80 & & 1740,00 & 1050,00 & 22,00 & 225,00 & 197,00 & & 5280,00 & 220,00 & 2,20 & & 0,22 & 0,13 & $\mathrm{Na}-\mathrm{Ca}-\mathrm{Cl}$ \\
\hline 48 & 7,70 & 346 & 27,20 & 26,50 & 2,23 & 2,12 & 134,00 & & 3,78 & 8,00 & 1,18 & & $-1,12$ & $-0,22$ & $\mathrm{Ca}-\mathrm{Na}-\mathrm{HCO} 3$ \\
\hline 49 & 6,90 & 181 & 11,70 & 19,60 & 2,36 & 3,49 & 77,00 & 0,00 & 5,60 & 1,10 & 1,28 & & $-1,14$ & $-1,35$ & $\mathrm{Ca}-\mathrm{Na}-\mathrm{HCO} 3$ \\
\hline 55 & 9,68 & 868 & 114,00 & 0,56 & 0,68 & 5,88 & 58,00 & 116,00 & 4,00 & 14,40 & 2,80 & 1,00 & $-2,30$ & $-0,02$ & $\mathrm{Na}-\mathrm{CO} 3$ \\
\hline 56 & 8,40 & 350 & 4,10 & 42,00 & 8,00 & 0,50 & 153,00 & 4,00 & 2,00 & & 1,64 & 75,00 & $-0,64$ & 0,73 & $\mathrm{Ca}-\mathrm{HCO} 3$ \\
\hline 57 & 8,80 & 1200 & 135,00 & 97,50 & 0,50 & 0,10 & 4,00 & 8,00 & 143,00 & 301,00 & 6,40 & 23,00 & 0,70 & 0,31 & $\mathrm{Na}-\mathrm{Ca}-\mathrm{SO} 4-\mathrm{Cl}$ \\
\hline 58 & & & 72,50 & 1,76 & 0,34 & 0,33 & 66,80 & 32,85 & 5,70 & 35,00 & 2,08 & & $-1,81$ & $-2,11$ & $\mathrm{Na}-\mathrm{CO} 3-\mathrm{HCO} 3-\mathrm{SO} 4$ \\
\hline 60 & 5,90 & 225 & 9,60 & 26,40 & 1,90 & 6,30 & 111,00 & 0,00 & 0,70 & 0,00 & 1,19 & 45,00 & $-1,10$ & $-2,08$ & $\mathrm{Ca}-\mathrm{Mg}-\mathrm{HCO} 3$ \\
\hline 62 & 7,49 & 198 & 28,90 & 9,44 & 0,10 & 1,91 & 91,40 & & 5,42 & 11,40 & 1,41 & 17,80 & $-1,38$ & $-1,01$ & $\mathrm{Na}-\mathrm{Ca}-\mathrm{HCO} 3$ \\
\hline 63 & 8,10 & 212 & 40,80 & 7,11 & 0,55 & 0,40 & 121,00 & & 1,21 & 9,35 & 1,72 & 8,96 & $-1,34$ & $-0,42$ & $\mathrm{Na}-\mathrm{HCO} 3$ \\
\hline 68 & 7,84 & 322 & 71,93 & 3,00 & 0,86 & 0,29 & 79,72 & & 23,90 & 44,60 & 3,74 & 3,38 & $-1,08$ & $-1,27$ & $\mathrm{Na}-\mathrm{HCO} 3-\mathrm{SO} 4-\mathrm{Cl}$ \\
\hline 69 & 6,87 & 196 & 20,10 & 15,80 & 2,14 & 4,49 & 104,63 & & 2,59 & 10,50 & 1,27 & 29,90 & $-1,26$ & $-1,36$ & $\mathrm{Na}-\mathrm{Ca}-\mathrm{HCO} 3$ \\
\hline 71 & 8,70 & 650 & 176,00 & 6,40 & 0,50 & 1,70 & 183,00 & 24,00 & 4,00 & 134,00 & 1,20 & 51,00 & $-1,88$ & 0,23 & Na-HCO3-SO4 \\
\hline 74 & 8,10 & 246 & 13,60 & 22,70 & 2,30 & 6,60 & 95,00 & & 4,00 & 16,00 & 1,02 & 43,00 & $-1,31$ & $-0,04$ & $\mathrm{Ca}-\mathrm{Na}-\mathrm{Mg}-\mathrm{HCO} 3$ \\
\hline 75 & 6,87 & 190 & 8,30 & 16,10 & 6,90 & 4,70 & 45,00 & & 10,00 & 2,00 & 2,20 & 27,90 & $-0,76$ & $-1,71$ & $\mathrm{Ca}-\mathrm{Mg}-\mathrm{Na}-\mathrm{HCO} 3$ \\
\hline 78 & 5,30 & 170 & 27,00 & 9,30 & 2,30 & 0,50 & 64,00 & & 5,50 & 9,00 & 1,00 & 55,50 & $-1,68$ & $-3,35$ & $\mathrm{Na}-\mathrm{Ca}-\mathrm{HCO} 3$ \\
\hline 80 & 8,00 & 582 & 47,50 & 53,40 & 1,40 & 2,20 & 88,00 & & 10,00 & 157,00 & 2,22 & 28,00 & $-0,38$ & 0,09 & $\mathrm{Ca}-\mathrm{Na}-\mathrm{SO} 4-\mathrm{HCO} 3$ \\
\hline 81 & 7,00 & 201 & 43,50 & 2,30 & 0,20 & 1,20 & 53,00 & 34,00 & 4,40 & 5,00 & 1,86 & 28,00 & $-1,75$ & $-1,99$ & $\mathrm{Na}-\mathrm{CO} 3-\mathrm{HCO} 3$ \\
\hline 82 & 8,20 & 143 & 15,00 & 13,20 & 1,50 & 0,20 & 61,00 & & 2,50 & 5,00 & 1,16 & 29,00 & $-1,38$ & $-0,33$ & $\mathrm{Ca}-\mathrm{Na}-\mathrm{HCO} 3$ \\
\hline 84 & 8,60 & 900 & 200,00 & 4,60 & 0,90 & 0,50 & 142,00 & 26,00 & 67,50 & 210,00 & 3,50 & 17,50 & $-1,13$ & $-0,11$ & $\mathrm{Na}-\mathrm{SO} 4-\mathrm{HCO} 3-\mathrm{Cl}$ \\
\hline 89 & & & 124,00 & 0,51 & 0,30 & 0,00 & 130,82 & 75,01 & 5,30 & 12,90 & 1,11 & & $-2,93$ & $-2,34$ & $\mathrm{Na}-\mathrm{CO} 3-\mathrm{HCO} 3$ \\
\hline 90 & 8,19 & 432 & 98,90 & 4,11 & 1,08 & 0,09 & 282,00 & 4,75 & 2,05 & 0,46 & 1,26 & 8,05 & $-1,91$ & $-0,24$ & $\mathrm{Na}-\mathrm{HCO} 3$ \\
\hline 91 & 8,71 & 362 & 80,90 & 2,83 & 1,71 & 0,08 & 221,00 & 7,38 & 1,78 & 1,30 & 1,14 & 7,15 & $-2,16$ & 0,00 & $\mathrm{Na}-\mathrm{HCO} 3$ \\
\hline 92 & 8,53 & 540 & 105,35 & 3,77 & 0,70 & 0,10 & 300,00 & & 8,67 & 0,50 & 1,50 & 18,56 & $-1,82$ & 0,05 & $\mathrm{Na}-\mathrm{HCO} 3$ \\
\hline 93 & & & 3,31 & 15,00 & 3,83 & 3,50 & 67,00 & 0,00 & 0,39 & 0,10 & 2,47 & & $-0,67$ & $-1,42$ & $\mathrm{Ca}-\mathrm{Mg}-\mathrm{HCO} 3$ \\
\hline 94 & 7,06 & 212 & 28,20 & 10,10 & 3,61 & 3,43 & 57,00 & & 14,70 & 29,00 & 1,19 & & $-1,52$ & $-1,65$ & $\mathrm{Na}-\mathrm{Ca}-\mathrm{HCO} 3-\mathrm{SO} 4-\mathrm{Cl}$ \\
\hline 96 & 8,70 & 630 & 100,00 & 1,50 & 2,10 & 1,00 & 206,00 & 23,00 & 7,50 & 35,00 & 1,28 & 15,80 & $-2,38$ & $-0,29$ & $\mathrm{Na}-\mathrm{HCO} 3$ \\
\hline 102 & 9,50 & 418 & 98,00 & 2,45 & 0,70 & 1,02 & 102,00 & 69,00 & 11,20 & 15,00 & 1,09 & 27,00 & $-2,39$ & 0,49 & $\mathrm{Na}-\mathrm{CO} 3-\mathrm{HCO} 3$ \\
\hline 103 & & & 99,00 & 0,66 & 0,33 & 0,00 & 123,93 & 46,88 & 10,00 & 11,60 & 1,13 & & $-2,78$ & $-2,32$ & $\mathrm{Na}-\mathrm{HCO} 3-\mathrm{CO} 3$ \\
\hline
\end{tabular}

OBS: concentrações iônicas em $\mathrm{mg} \mathrm{dm}{ }^{-3}$. 


\begin{tabular}{|c|c|c|c|c|c|c|c|c|c|c|c|c|c|c|c|}
\hline$N^{o}$ & $p H$ & $\begin{array}{c}C E \\
\left(\mu S \mathrm{~cm}^{-1}\right)\end{array}$ & $\mathrm{Na}^{+}$ & $\mathrm{Ca}^{2+}$ & $K^{+}$ & $\mathrm{Mg}^{2+}$ & $\mathrm{HCO}_{3}^{-}$ & $\mathrm{CO}_{3}{ }^{-}$ & $\mathrm{Cl}^{-}$ & $\mathrm{SO}_{4} 2^{-}$ & $F^{-}$ & $\mathrm{SiO}_{2}$ & $\begin{array}{c}\text { IS } \\
\text { Fluorita }\end{array}$ & $\begin{array}{c}I S \\
\text { Calcita }\end{array}$ & $\begin{array}{c}\text { Classificação } \\
\text { de Piper }\end{array}$ \\
\hline 104 & & & 180,00 & 76,70 & 0,00 & 0,25 & 94,20 & 0,00 & 17,30 & 502,00 & 1,00 & & $-1,08$ & $-0,85$ & $\mathrm{Na}-\mathrm{Ca}-\mathrm{SO} 4$ \\
\hline 109 & 7,60 & 208 & 2,70 & 35,50 & 5,40 & 3,40 & 105,00 & & 0,50 & 5,00 & 1,50 & 28,00 & $-0,77$ & $-0,29$ & $\mathrm{Ca}-\mathrm{HCO} 3$ \\
\hline 110 & 7,00 & 1640 & 450,00 & 1,90 & 1,60 & & 692,00 & 84,00 & 80,20 & 76,00 & 6,80 & 12,60 & $-0,97$ & $-1,44$ & $\mathrm{Na}-\mathrm{HCO} 3$ \\
\hline 111 & 8,70 & 1600 & 380,00 & 1,70 & 0,90 & 0,30 & 624,00 & 49,00 & 58,00 & 49,00 & 5,14 & 13,20 & $-1,29$ & 0,07 & $\mathrm{Na}-\mathrm{HCO} 3$ \\
\hline 112 & 8,29 & 980 & 178,40 & 2,62 & 2,61 & 0,52 & 579,80 & & 6,07 & 0,50 & 2,00 & 18,05 & $-1,79$ & $-0,12$ & $\mathrm{Na}-\mathrm{HCO} 3$ \\
\hline 113 & 8,34 & 1100 & 163,10 & 2,43 & 2,76 & 0,56 & 521,60 & & 6,52 & 0,50 & 1,50 & 13,70 & $-2,06$ & $-0,14$ & $\mathrm{Na}-\mathrm{HCO} 3$ \\
\hline 115 & 7,27 & 250 & 18,40 & 30,40 & 4,50 & 3,90 & 131,00 & 26,00 & 1,50 & 1,00 & 1,20 & 38,00 & $-1,06$ & $-0,46$ & $\mathrm{Ca}-\mathrm{Na}-\mathrm{HCO} 3-\mathrm{CO} 3$ \\
\hline $116^{*}$ & 9,00 & 1900 & 640,00 & 1,90 & 1,00 & 0,60 & 221,00 & 52,00 & 481,00 & 320,00 & 3,60 & 12,30 & $-1,66$ & $-0,05$ & $\mathrm{Na}-\mathrm{Cl}-\mathrm{SO} 4$ \\
\hline 117 & 8,80 & 2000 & 650,00 & 3,50 & 1,40 & 0,60 & 181,00 & 24,00 & 482,00 & 440,00 & 4,90 & 12,90 & $-1,12$ & $-0,11$ & $\mathrm{Na}-\mathrm{Cl}-\mathrm{SO} 4$ \\
\hline 118 & 8,70 & 281 & 63,10 & 1,53 & 0,05 & 0,16 & 87,00 & 30,00 & 5,34 & 17,30 & 1,94 & & $-1,94$ & $-0,45$ & $\mathrm{Na}-\mathrm{HCO} 3-\mathrm{CO} 3$ \\
\hline 119 & 9,66 & 740 & 148,00 & 3,83 & 0,00 & 0,01 & 96,80 & & 42,90 & 182,00 & 8,48 & 7,54 & $-0,44$ & 0,36 & $\mathrm{Na}-\mathrm{SO} 4-\mathrm{HCO} 3$ \\
\hline 120 & 7,90 & 13500 & 3400,00 & 122,00 & 16,00 & 72,00 & 182,00 & 0,00 & 820,00 & 5320,00 & 1,76 & 18,00 & $-1,00$ & 0,04 & $\mathrm{Na}-\mathrm{SO} 4$ \\
\hline 121 & 6,40 & 65 & 3,60 & 2,10 & 5,50 & 2,20 & 20,00 & & 6,00 & 1,00 & 1,32 & 41,00 & $-2,02$ & $-3,36$ & $\mathrm{Mg}-\mathrm{Na}-\mathrm{K}-\mathrm{HCO} 3-\mathrm{Cl}$ \\
\hline 122 & 6,40 & 75 & 3,00 & 7,20 & 3,40 & 1,10 & 24,00 & & 3,50 & 2,00 & 1,92 & 51,00 & $-1,17$ & $-2,75$ & $\mathrm{Ca}-\mathrm{HCO} 3$ \\
\hline 123 & 8,70 & 760 & 178,00 & 1,99 & 1,39 & 0,05 & 189,00 & 33,00 & 56,00 & 81,70 & 6,60 & 36,10 & $-1,45$ & 0,23 & $\mathrm{Na}-\mathrm{HCO} 3-\mathrm{SO} 4-\mathrm{Cl}$ \\
\hline 124 & 8,95 & 1110 & 225,00 & 4,49 & 2,20 & 0,24 & 170,00 & 22,00 & 133,00 & 92,00 & 13,30 & 32,00 & 0,04 & 0,26 & $\mathrm{Na}-\mathrm{Cl}-\mathrm{HCO} 3$ \\
\hline 125 & 9,40 & 637 & 120,00 & 0,60 & 1,40 & 0,40 & 250,00 & 59,00 & 1,50 & 3,00 & 1,24 & 13,90 & $-2,94$ & $-0,05$ & $\mathrm{Na}-\mathrm{HCO} 3-\mathrm{CO} 3$ \\
\hline 128 & 8,70 & 1180 & 224,00 & 1,80 & 1,70 & 0,60 & 189,00 & 51,00 & 120,00 & 69,00 & 9,80 & 40,00 & $-0,61$ & $-0,22$ & $\mathrm{Na}-\mathrm{Cl}-\mathrm{HCO} 3$ \\
\hline 129 & 8,50 & 320 & 55,00 & 7,90 & 0,50 & 0,80 & 126,00 & 32,00 & 1,50 & 3,00 & 1,40 & 46,00 & $-1,51$ & 0,18 & $\mathrm{Na}-\mathrm{HCO} 3-\mathrm{CO} 3$ \\
\hline 131 & 9,10 & 430 & 120,00 & 0,40 & 0,30 & 0,10 & 162,00 & 74,00 & 3,00 & 35,00 & 2,20 & 17,60 & $-2,55$ & $-0,47$ & $\mathrm{Na}-\mathrm{HCO} 3-\mathrm{CO} 3$ \\
\hline 134 & 9,45 & 710 & 158,00 & 5,60 & 1,00 & 0,50 & 32,00 & 48,00 & 16,50 & 188,00 & 8,20 & 39,00 & $-0,31$ & 0,49 & $\mathrm{Na}-\mathrm{SO} 4-\mathrm{CO} 3$ \\
\hline 135 & 9,30 & 700 & 230,00 & 1,80 & 2,20 & 0,20 & 109,66 & & 6,78 & 35,00 & 2,10 & 17,50 & $-2,30$ & & $\mathrm{Na}-\mathrm{HCO} 3$ \\
\hline 137 & 7,25 & 244 & 16,80 & 18,80 & 2,46 & 1,41 & 94,67 & & 1,00 & 2,50 & 1,86 & 28,70 & $-0,84$ & $-0,93$ & $\mathrm{Ca}-\mathrm{Na}-\mathrm{HCO} 3$ \\
\hline 138 & 7,90 & 271 & 35,83 & 7,82 & 1,09 & 7,92 & 169,40 & & 2,01 & 10,69 & 1,82 & & $-1,28$ & $-0,45$ & $\mathrm{Na}-\mathrm{Mg}-\mathrm{HCO} 3$ \\
\hline 139 & 7,70 & 195 & 16,10 & 18,80 & 0,54 & 3,58 & 118,00 & & 0,69 & 1,67 & 1,26 & 19,80 & $-1,19$ & $-0,40$ & $\mathrm{Ca}-\mathrm{Na}-\mathrm{HCO} 3$ \\
\hline 140 & 7,41 & 1188 & 148,00 & 132,00 & 0,53 & 4,52 & 103,00 & & 95,30 & 469,00 & 2,58 & 6,01 & $-0,03$ & $-0,17$ & $\mathrm{Ca}-\mathrm{Na}-\mathrm{SO} 4$ \\
\hline 141 & 7,02 & 375 & 54,30 & 31,00 & 1,62 & 2,62 & 239,16 & & 3,95 & 2,50 & 1,08 & 22,40 & $-1,16$ & $-0,60$ & $\mathrm{Na}-\mathrm{Ca}-\mathrm{HCO} 3$ \\
\hline 150 & 7,45 & 856 & 102,00 & 53,10 & 1,57 & 11,30 & 69,75 & & 70,00 & 288,00 & 1,95 & 23,00 & $-0,59$ & $-0,62$ & $\mathrm{Na}-\mathrm{Ca}-\mathrm{SO} 4-\mathrm{Cl}$ \\
\hline 151 & 8,08 & 377 & 62,77 & 20,83 & 0,68 & 1,09 & 154,46 & & 13,88 & 48,50 & 2,63 & & $-0,57$ & 0,07 & $\mathrm{Na}-\mathrm{Ca}-\mathrm{HCO} 3-\mathrm{SO} 4$ \\
\hline 152 & 8,11 & 367 & 74,16 & 18,00 & 0,49 & 1,02 & 93,07 & & 15,90 & 68,40 & 3,31 & 25,30 & $-0,44$ & $-0,19$ & $\mathrm{Na}-\mathrm{Ca}-\mathrm{HCO} 3-\mathrm{SO} 4$ \\
\hline 153 & 7,87 & 337 & 59,93 & 13,89 & 0,24 & 1,20 & 199,30 & & 2,77 & 16,60 & 3,23 & 27,50 & $-0,55$ & $-0,18$ & $\mathrm{Na}-\mathrm{HCO} 3$ \\
\hline 154 & 7,94 & 361 & 61,64 & 17,07 & 0,24 & 1,21 & 94,67 & & 9,00 & 63,50 & 4,38 & 23,80 & $-0,21$ & $-0,36$ & Na-Ca-HCO3-SO4 \\
\hline 155 & 8,60 & 320 & 69,90 & 4,25 & 0,18 & 0,07 & 133,00 & 2,62 & 5,14 & 22,80 & 7,45 & 5,88 & $-0,33$ & $-0,14$ & $\mathrm{Na}-\mathrm{HCO} 3$ \\
\hline 156 & 8,06 & 313 & 65,49 & 5,31 & 0,88 & 2,26 & 116,34 & & 9,12 & 24,10 & 1,22 & 23,80 & $-1,79$ & $-0,63$ & $\mathrm{Na}-\mathrm{HCO} 3$ \\
\hline 157 & 8,18 & 366 & 54,40 & 16,70 & 0,26 & 0,55 & 131,00 & & 9,44 & 38,90 & 3,49 & 9,35 & $-0,40$ & 0,02 & $\mathrm{Na}-\mathrm{Ca}-\mathrm{HCO} 3-\mathrm{SO} 4$ \\
\hline 158 & 7,98 & 314 & 46,20 & 15,20 & 0,40 & 0,54 & 59,46 & & 9,13 & 40,40 & 4,25 & 26,40 & $-0,25$ & $-0,54$ & $\mathrm{Na}-\mathrm{Ca}-\mathrm{HCO} 3-\mathrm{SO} 4$ \\
\hline 162 & 9,05 & 3820 & 820,00 & 42,00 & 2,50 & 1,20 & 28,00 & 30,00 & 334,00 & 1300,00 & 4,40 & 55,00 & $-0,29$ & 0,58 & $\mathrm{Na}-\mathrm{SO} 4-\mathrm{Cl}$ \\
\hline 164 & 9,43 & 622 & 134,00 & 1,19 & 0,00 & 0,07 & 157,00 & 28,60 & 11,00 & 104,00 & 2,55 & 6,83 & $-2,00$ & 0,06 & $\mathrm{Na}-\mathrm{HCO} 3-\mathrm{SO} 4$ \\
\hline 165 & 9,67 & 430 & 91,20 & 0,72 & 0,00 & 0,01 & 151,00 & 36,90 & 2,39 & 35,40 & 1,19 & 7,71 & $-2,88$ & 0,03 & $\mathrm{Na}-\mathrm{HCO} 3-\mathrm{CO} 3$ \\
\hline 166 & 9,63 & 487 & 103,00 & 0,85 & 0,00 & 0,01 & 154,00 & 36,00 & 3,35 & 55,30 & 1,49 & 6,83 & $-2,62$ & 0,07 & $\mathrm{Na}-\mathrm{HCO} 3-\mathrm{CO} 3-\mathrm{SO} 4$ \\
\hline 167 & 9,55 & 564 & 127,00 & 1,00 & 9,81 & 0,01 & 164,00 & 27,20 & 15,40 & 85,60 & 2,15 & 6,79 & $-2,23$ & 0,07 & $\mathrm{Na}-\mathrm{HCO} 3-\mathrm{SO} 4$ \\
\hline 168 & 8,50 & 550 & 95,60 & 15,30 & 0,45 & 0,06 & 15,00 & & 38,00 & 148,00 & 9,00 & & 0,31 & $-0,72$ & $\mathrm{Na}-\mathrm{SO} 4-\mathrm{Cl}$ \\
\hline 169 & 6,50 & 115 & 7,10 & 10,10 & 6,80 & 3,50 & 50,00 & 0,00 & 6,00 & 0,00 & 4,40 & 19,30 & $-0,34$ & $-2,21$ & $\mathrm{Ca}-\mathrm{Na}-\mathrm{Mg}-\mathrm{HCO} 3$ \\
\hline 170 & 7,60 & 540 & 65,00 & 52,60 & 5,10 & 17,00 & 186,00 & 0,00 & 150,00 & 19,00 & 1,48 & 16,30 & $-0,74$ & 0,04 & $\mathrm{Na}-\mathrm{Ca}-\mathrm{Cl}-\mathrm{HCO} 3$ \\
\hline 171 & 7,30 & 275 & 7,90 & 34,20 & 0,73 & 3,40 & 64,00 & 0,00 & 13,00 & 32,00 & 1,28 & 11,00 & $-0,94$ & $-0,83$ & $\mathrm{Ca}-\mathrm{HCO} 3-\mathrm{SO} 4$ \\
\hline 173 & 8,05 & 350 & 69,30 & 8,26 & 1,30 & 2,60 & 213,00 & & 3,40 & 6,32 & 2,98 & 8,30 & $-0,84$ & $-0,19$ & $\mathrm{Na}-\mathrm{HCO} 3$ \\
\hline 174 & 8,57 & 357 & 71,80 & 6,93 & 1,39 & 1,94 & 212,00 & 2,79 & 4,44 & 2,43 & 3,42 & 7,50 & $-0,81$ & 0,23 & $\mathrm{Na}-\mathrm{HCO} 3$ \\
\hline 176 & 8,69 & 534 & 106,00 & 2,20 & 1,20 & 0,11 & 229,70 & 9,30 & 19,00 & 27,00 & 7,80 & 17,00 & $-0,64$ & $-0,14$ & $\mathrm{Na}-\mathrm{HCO} 3$ \\
\hline 182 & 8,46 & 610 & 125,00 & 2,70 & 1,20 & 0,05 & 314,40 & 4,80 & 18,00 & 8,80 & 3,00 & 16,00 & $-1,38$ & $-0,15$ & $\mathrm{Na}-\mathrm{HCO} 3$ \\
\hline 183 & 8,40 & 767 & 156,00 & 2,60 & 1,80 & 0,34 & 357,10 & 15,00 & 26,00 & 18,00 & 9,10 & 14,00 & $-0,46$ & $-0,17$ & $\mathrm{Na}-\mathrm{HCO} 3$ \\
\hline 186 & 8,78 & 582 & 120,00 & 1,60 & 1,40 & 0,03 & 240,40 & 16,90 & 10,00 & 28,00 & 9,30 & 17,00 & $-0,64$ & $-0,16$ & $\mathrm{Na}-\mathrm{HCO} 3$ \\
\hline 197 & 7,00 & 9500 & 1260,00 & 1670,00 & 19,20 & 330,00 & 49,00 & 0,00 & 6180,00 & 800,00 & 1,60 & 27,00 & 0,04 & $-0,14$ & $\mathrm{Ca}-\mathrm{Na}-\mathrm{Cl}$ \\
\hline 198 & 7,74 & 273 & 46,70 & 6,06 & 0,90 & 0,36 & 110,00 & & 6,10 & 18,30 & 1,31 & 5,88 & $-1,65$ & $-0,89$ & $\mathrm{Na}-\mathrm{HCO} 3$ \\
\hline 199 & 7,77 & 190 & 6,60 & 24,80 & 3,30 & 4,30 & 93,00 & & 1,20 & & 1,32 & 43,00 & $-1,03$ & $-0,31$ & $\mathrm{Ca}-\mathrm{HCO} 3$ \\
\hline 200 & & & 59,70 & 22,20 & 0,62 & 1,92 & 183,00 & 0,00 & 3,95 & 32,30 & 2,30 & & $-0,65$ & $-0,89$ & $\mathrm{Na}-\mathrm{Ca}-\mathrm{HCO} 3$ \\
\hline 201 & 7,16 & 156 & 27,30 & 7,96 & 6,84 & 1,99 & 91,90 & & 3,37 & 2,32 & 2,22 & 15,40 & $-1,05$ & $-1,41$ & $\mathrm{Na}-\mathrm{Ca}-\mathrm{HCO} 3$ \\
\hline 204 & 8,45 & 1220 & 244,00 & 4,10 & 7,20 & 1,50 & 219,00 & 113,00 & 115,00 & 100,00 & 9,20 & 22,00 & $-0,34$ & 0,06 & $\mathrm{Na}-\mathrm{CO} 3-\mathrm{HCO} 3-\mathrm{Cl}$ \\
\hline 205 & 8,25 & 160 & 14,00 & 8,50 & 1,30 & 2,40 & 51,00 & & 5,10 & 14,00 & 1,84 & 45,00 & $-1,18$ & $-0,56$ & $\mathrm{Na}-\mathrm{Ca}-\mathrm{HCO} 3-\mathrm{SO} 4$ \\
\hline 208 & & & 241,00 & 1,64 & 1,24 & 0,03 & 192,00 & 12,35 & 150,00 & 121,00 & 1,43 & & $-2,31$ & $-2,04$ & $\mathrm{Na}-\mathrm{Cl}-\mathrm{HCO} 3-\mathrm{SO} 4$ \\
\hline
\end{tabular}

OBS: concentrações iônicas em $\mathrm{mg} \mathrm{dm}^{-3}$. 